\title{
Geophysical validation of MIPAS-ENVISAT operational ozone data
}

\author{
U. Cortesi ${ }^{1}$, J. C. Lambert ${ }^{2}$, C. De Clercq ${ }^{2}$, G. Bianchini ${ }^{1}$, T. Blumenstock ${ }^{3}$, A. Bracher ${ }^{4}$, E. Castelli ${ }^{5}$, V. Catoire ${ }^{6}$, \\ K. V. Chance ${ }^{7}$, M. De Mazière ${ }^{2}$, P. Demoulin ${ }^{8}$, S. Godin-Beekmann ${ }^{9}$, N. Jones ${ }^{10}$, K. Jucks ${ }^{7}$, C. Keim ${ }^{3}$, \\ T. Kerzenmacher ${ }^{11}$, H. Kuellmann ${ }^{4}$, J. Kuttippurath ${ }^{4}$, M. Iarlori ${ }^{12}$, G. Y. Liu ${ }^{3}$, Y. Liu ${ }^{13}$, I. S. McDermid ${ }^{14}$, \\ Y. J. Meijer ${ }^{15,}{ }^{*}$, F. Mencaraglia ${ }^{1}$, S. Mikuteit ${ }^{3}$, H. Oelhaf ${ }^{3}$, C. Piccolo ${ }^{16}$, M. Pirre ${ }^{6}$, P. Raspollini ${ }^{1}$, F. Ravegnani ${ }^{5}$, \\ W. J. Reburn ${ }^{17}$, G. Redaelli ${ }^{12}$, J. J. Remedios ${ }^{18}$, H. Sembhi ${ }^{18}$, D. Smale ${ }^{19}$, T. Steck ${ }^{3}$, A. Taddei ${ }^{12}$, C. Varotsos $^{20}$, \\ C. Vigouroux ${ }^{2}$, A. Waterfall ${ }^{17}$, G. Wetzel $^{3}$, and S. Wood $^{19}$ \\ ${ }^{1}$ Istituto di Fisica Applicata "N. Carrara" (IFAC) del Consiglio Nazionale delle Ricerche (CNR), Firenze, Italy \\ ${ }^{2}$ Belgian Institute for Space Aeronomy (BIRA-IASB), Brussels, Belgium \\ ${ }^{3}$ Institut für Meteorologie und Klimaforschung (IMK), Forschungszentrum Karlsruhe GmbH (FZK), Universität Karlsruhe, \\ Karlsruhe, Germany \\ ${ }^{4}$ Institute of Environmental Physics and Remote Sensing, University of Bremen (IUP/IFE), Bremen, Germany \\ ${ }^{5}$ Istituto di Scienze dell'Atmosfera e del Clima (ISAC) del CNR, Bologna, Italy \\ ${ }^{6}$ Laboratoire de Physique et Chimie de l'Environnement (LPCE), CNRS-Université d'Orléans, Orléans, France \\ ${ }^{7}$ Harvard-Smithsonian Center for Astrophysics, Cambridge, MA, USA \\ ${ }^{8}$ Institut d'Astrophysique et de Géophysique, University of Liège, Liège, Belgium \\ ${ }^{9}$ Service d'Aéronomie/IPSL, CNRS-Université Pierre et Marie Curie, Paris, France \\ ${ }^{10}$ University of Wollongong, Wollongong, Australia \\ ${ }^{11}$ University of Toronto, Toronto, Canada \\ ${ }^{12}$ CETEMPS, Universitá di L’Aquila, Dipartimento di Fisica, L’Aquila, Italy \\ ${ }^{13}$ Institute of Atmospheric Physics, CAS, Beijing,China \\ ${ }^{14}$ Jet Propulsion Laboratory, Table Mountain Facility, Wrightwood, CA, USA \\ ${ }^{15}$ National Institute for for Public Health and the Environment, RIVM - LVM, Bilthoven, The Netherlands \\ ${ }^{16}$ University of Oxford, Oxford, UK \\ ${ }^{17}$ CCLRC Rutherford Appleton Laboratory (RAL), UK \\ ${ }^{18}$ University of Leicester, Leicester, UK \\ ${ }^{19}$ National Institute for Water and Air Research Ltd., Lauder, New Zealand \\ ${ }^{20}$ University of Athens, Faculty of Physics, Dept of Applied Physics, Greece \\ *now at: ESA-ESTEC, Noordwijk, The Netherlands
}

Received: 29 March 2007 - Published in Atmos. Chem. Phys. Discuss.: 7 May 2007

Revised: 24 August 2007 - Accepted: 15 September 2007 - Published: 21 September 2007

\begin{abstract}
The Michelson Interferometer for Passive Atmospheric Sounding (MIPAS), on-board the European ENVIronmental SATellite (ENVISAT) launched on 1 March 2002, is a middle infrared Fourier Transform spectrometer measuring the atmospheric emission spectrum in limb sounding geometry. The instrument is capable to retrieve the vertical distribution of temperature and trace gases, aiming at the study of climate and atmospheric chemistry and dynamics, and at applications to data assimilation and weather forecasting.
\end{abstract}

Correspondence to: U. Cortesi

(u.cortesi@ifac.cnr.it)
MIPAS operated in its standard observation mode for approximately two years, from July 2002 to March 2004, with scans performed at nominal spectral resolution of $0.025 \mathrm{~cm}^{-1}$ and covering the altitude range from the mesosphere to the upper troposphere with relatively high vertical resolution (about $3 \mathrm{~km}$ in the stratosphere). Only reduced spectral resolution measurements have been performed subsequently. MIPAS data were re-processed by ESA using updated versions of the Instrument Processing Facility (IPF v4.61 and v4.62) and provided a complete set of level-2 operational products (geolocated vertical profiles of temperature and volume mixing ratio of $\mathrm{H}_{2} \mathrm{O}, \mathrm{O}_{3}, \mathrm{HNO}_{3}, \mathrm{CH}_{4}, \mathrm{~N}_{2} \mathrm{O}$ and $\mathrm{NO}_{2}$ ) with quasi

Published by Copernicus Publications on behalf of the European Geosciences Union. 
continuous and global coverage in the period of MIPAS full spectral resolution mission. In this paper, we report a detailed description of the validation of MIPAS-ENVISAT operational ozone data, that was based on the comparison between MIPAS v4.61 (and, to a lesser extent, v4.62) $\mathrm{O}_{3}$ VMR profiles and a comprehensive set of correlative data, including observations from ozone sondes, ground-based lidar, FTIR and microwave radiometers, remote-sensing and in situ instruments on-board stratospheric aircraft and balloons, concurrent satellite sensors and ozone fields assimilated by the European Center for Medium-range Weather Forecasting.

A coordinated effort was carried out, using common criteria for the selection of individual validation data sets, and similar methods for the comparisons. This enabled merging the individual results from a variety of independent reference measurements of proven quality (i.e. well characterized error budget) into an overall evaluation of MIPAS $\mathrm{O}_{3}$ data quality, having both statistical strength and the widest spatial and temporal coverage. Collocated measurements from ozone sondes and ground-based lidar and microwave radiometers of the Network for the Detection Atmospheric Composition Change (NDACC) were selected to carry out comparisons with time series of MIPAS $\mathrm{O}_{3}$ partial columns and to identify groups of stations and time periods with a uniform pattern of ozone differences, that were subsequently used for a vertically resolved statistical analysis. The results of the comparison are classified according to synoptic and regional systems and to altitude intervals, showing a generally good agreement within the comparison error bars in the upper and middle stratosphere. Significant differences emerge in the lower stratosphere and are only partly explained by the larger contributions of horizontal and vertical smoothing differences and of collocation errors to the total uncertainty. Further results obtained from a purely statistical analysis of the same data set from NDACC ground-based lidar stations, as well as from additional ozone soundings at middle latitudes and from NDACC ground-based FTIR measurements, confirm the validity of MIPAS $\mathrm{O}_{3}$ profiles down to the lower stratosphere, with evidence of larger discrepancies at the lowest altitudes. The validation against $\mathrm{O}_{3}$ VMR profiles using collocated observations performed by other satellite sensors (SAGE II, POAM III, ODIN-SMR, ACE-FTS, HALOE, GOME) and ECMWF assimilated ozone fields leads to consistent results, that are to a great extent compatible with those obtained from the comparison with ground-based measurements. Excellent agreement in the full vertical range of the comparison is shown with respect to collocated ozone data from stratospheric aircraft and balloon instruments, that was mostly obtained in very good spatial and temporal coincidence with MIPAS scans. This might suggest that the larger differences observed in the upper troposphere and lowermost stratosphere with respect to collocated ground-based and satellite $\mathrm{O}_{3}$ data are only partly due to a degradation of MIPAS data quality. They should be rather largely ascribed to the natural variability of these altitude regions and to other components of the comparison errors. By combining the results of this large number of validation data sets we derived a general assessment of MIPAS v4.61 and v4.62 ozone data quality.

A clear indication of the validity of MIPAS $\mathrm{O}_{3}$ vertical profiles is obtained for most of the stratosphere, where the mean relative difference with the individual correlative data sets is always lower than $\pm 10 \%$. Furthermore, these differences always fall within the combined systematic error (from $1 \mathrm{hPa}$ to $50 \mathrm{hPa}$ ) and the standard deviation is fully consistent with the random error of the comparison (from $1 \mathrm{hPa}$ to $\sim 30-40 \mathrm{hPa}$ ). A degradation in the quality of the agreement is generally observed in the lower stratosphere and upper troposphere, with biases up to $25 \%$ at $100 \mathrm{hPa}$ and standard deviation of the global mean differences up to three times larger than the combined random error in the range $50-100 \mathrm{hPa}$. The larger differences observed at the bottom end of MIPAS retrieved profiles can be associated, as already noticed, to the effects of stronger atmospheric gradients in the UTLS that are perceived differently by the various measurement techniques. However, further components that may degrade the results of the comparison at lower altitudes can be identified as potentially including cloud contamination, which is likely not to have been fully filtered using the current settings of the MIPAS cloud detection algorithm, and in the linear approximation of the forward model that was used for the a priori estimate of systematic error components. The latter, when affecting systematic contributions with a random variability over the spatial and temporal scales of global averages, might result in an underestimation of the random error of the comparison and add up to other error sources, such as the possible underestimates of the $\mathrm{p}$ and $\mathrm{T}$ error propagation based on the assumption of a $1 \mathrm{~K}$ and $2 \%$ uncertainties, respectively, on MIPAS temperature and pressure retrievals.

At pressure lower than $1 \mathrm{hPa}$, only a small fraction of the selected validation data set provides correlative ozone data of adequate quality and it is difficult to derive quantitative conclusions about the performance of MIPAS $\mathrm{O}_{3}$ retrieval for the topmost layers.

\section{Introduction}

Ozone is one of the six atmospheric trace gases $\left(\mathrm{H}_{2} \mathrm{O}, \mathrm{O}_{3}\right.$, $\mathrm{HNO}_{3}, \mathrm{CH}_{4}, \mathrm{~N}_{2} \mathrm{O}$ and $\mathrm{NO}_{2}$ ) that, along with temperature, constitute the set of target products of the Michelson Interferometer for Passive Atmospheric Sounding (MIPAS) (Fischer and Oelhaf, 1996) on-board the European ENVIronment SATellite (ENVISAT) and plays a pivotal role in the majority of the research areas covered by the scientific mission of the instrument (Fischer et al., 2000). The need for global and continuous monitoring of ozone total column and vertical distribution is primarily linked to its absorption properties in the ultraviolet, that prevent biologically harmful 
UV radiation from reaching the lower atmosphere and the Earth's surface, and to its impact as a radiatively active gas, that strongly influences the atmospheric heating rates. The former are, in fact, responsible for the protective action of the ozonosphere, that has been severely reduced by ozone depletion at high latitudes and whose recovery can be anticipated only by reliable projections which solve the existing uncertainties on the complex interactions between stratospheric gas-phase and heterogeneous chemistry and dynamics (Solomon, 1999; von der Gathen et al., 1995). The second is evident, first of all, throughout the mutual influence between natural variability and anthropogenic forcing on ozone concentration on one side and the alterations of the temperature profile on the other, that represents one of the most important feedbacks between atmospheric chemistry and climate (Pyle et al., 2005). The ozone levels and their greenhouse effect are especially relevant at the boundary between the Upper Troposphere and the Lower Stratosphere (UTLS region), where they take part in the control of stratospheric-tropospheric exchange, that in turn drives the long-term trends of tropospheric ozone budget and potentially alters the oxidizing capacity and the level of pollution of lower atmospheric layers.

Moreover, several questions related to the chemistry and transport and to the energy budget of the upper atmosphere are still open and demand a more accurate knowledge of the ozone distribution in conditions of local thermodynamic disequilibrium, e.g. the problem of the ozone deficit in the upper stratosphere and lower mesosphere and the investigation of $\mathrm{O}_{3}$ non-LTE (non Local Thermal Equilibrium) emission (Crutzen et al., 1995). New insight into all of these aspects can be gained by exploiting MIPAS ozone and ozone-related species measurement capabilities, which are optimally suited to cover the full altitude range from the lower thermosphere down to the UTLS.

A crucial step towards the exploitation of MIPAS $\mathrm{O}_{3}$ operational products in quantitative studies investigating the above mentioned science issues is, however, a thorough validation process, based on comparison with a comprehensive suite of correlative data sets and capable of deriving an overall assessment of the reliability and quality of MIPAS ozone measurements. This aim has been accomplished - for the set of ozone data obtained by MIPAS during the period from 6 July 2002 to 26 March 2004 (i.e. during the instrument nominal spectral resolution mission, see Sect. 2) - throughout a series of dedicated experiments executed by different teams and providing results that were subsequently combined into a general and consistent picture.

The present paper represents the final outcome of this activity, that involved scientists from the sub-groups of the ENVISAT Atmospheric Chemistry Validation Team (ACVT) contributing to the geophysical validation of MIPAS ozone profiles, i.e. the GBMCD (Ground-Based Measurements and Campaign Database), the ESABC (ENVISAT Stratospheric Aircraft and Balloon Campaigns) and the MASI (Model As- similation and Satellite Intercomparison) sub-groups. The activity started three months after the ENVISAT launch (1 March 2002) with the calibration and validation experiments of the commissioning phase and continued during the 12 months of the main validation phase (1 September 2002 to 1 September 2003) and the first part of the long-term validation programme. Preliminary results of the geophysical validation of MIPAS ozone measurements were presented during the First and the Second ENVISAT Validation Workshop held at ESA's European Space Research INstitute (ESA-ESRIN, Frascati, Italy), in December 2002 and May 2004, respectively. A first attempt was made there to achieve a quantitative evaluation of the quality of MIPAS near real-time (produced within three hours from the measurement time) and off-line (produced with a less stringent constraint for the processing time and using an extended retrieval range) $\mathrm{O}_{3}$ data products, by combining the results of comparisons with ozone sonde, lidar and microwave measurements from individual ground-based stations and networks (Blumenstock et al., 2004), with remote-sensing and in situ observations from balloon and aircraft field campaigns (Cortesi et al., 2004), as well as with profiles from concurrent satellite sensors (Kerridge et al., 2004). As a further and closing step in the process of gradual merging and integration of individual validation results, we finally conducted a coordinated effort, focussing on MIPAS $\mathrm{O}_{3}$ data versions $\mathrm{v} 4.61$ and v4.62, to homogenise criteria and strategies of the comparison with different correlative data sets and to update the pre-launch estimates of precision and accuracy of the selected MIPAS ozone products.

An overview of the latter phase, with presentation of final results and conclusions, is given in the following sections. In Sect. 2, we briefly revisit some basic information about MIPAS operational ozone data, whilst in Sect. 3 we provide general remarks on the choice of the ozone validation data set and strategy. Sections 4, 5 and 6 are devoted to detailed description of the methodology and results of the validation against ground-based, airborne and satellite ozone measurements, respectively. Comparisons between MIPAS and ECMWF (European Center for Medium-range Weather Forecasting) ozone profiles are presented in Sect. 7. A summary of the results from the different categories of correlative measurements is discussed in Sect. 8 and final conclusions about the quality of MIPAS ozone retrieval are presented in Sect. 9.

\section{MIPAS ozone data}

MIPAS is a middle infrared Fourier transform spectrometer operating on-board the ENVISAT platform and acquiring high resolution spectra of atmospheric limb emission in five spectral bands within the frequency range from 685 to $2410 \mathrm{~cm}^{-1}$ (14.6 to $4.15 \mu \mathrm{m}$ ) (Fischer et al., 2007). Launched on the sun-synchronous polar orbit of the satellite with an 
inclination of $98.55^{\circ}$ and at an altitude of about $800 \mathrm{~km}$, MIPAS performed quasi-continuous measurements at nominal spectral resolution $\left(\Delta \sigma=0.025 \mathrm{~cm}^{-1}\right.$, defined as the spacing between independent spectral elements of the unapodized spectrum and corresponding to an interferometer maximum path difference equal to $20 \mathrm{~cm}$ ) during a period of two years. In this standard observation mode, the instrument scanned 17 tangent altitudes for each limb sequence, viewing in the rearward direction along the orbit with a sampling rate of approximately $500 \mathrm{~km}$ along track and with a horizontal resolution across track of about $30 \mathrm{~km}$. The vertical scanning grid ranges between $6 \mathrm{~km}$ and $68 \mathrm{~km}$, with steps of $3 \mathrm{~km}$ from 6 to $42 \mathrm{~km}, 5 \mathrm{~km}$ from 42 to $52 \mathrm{~km}$, and $8 \mathrm{~km}$ from 52 to $68 \mathrm{~km}$. On a daily basis, MIPAS covers the Earth with $5^{\circ}$ latitude by $12.5^{\circ}$ longitude spacing. Complete global coverage is attained approximately every three days by 73 scans per orbit and 14.3 orbits per day scanning the latitudinal range from $87^{\circ} \mathrm{S}$ to $89^{\circ} \mathrm{N}$. MIPAS operation was temporarily halted at the end of March 2004 because of excessive anomalies observed in the interferometric drive unit and resumed in January 2005 in a new operation mode at reduced spectral resolution $\left(0.0625 \mathrm{~cm}^{-1}\right)$ and on a finer vertical grid. The data obtained during the instrument full spectral resolution mission, from 6 July 2002 to 26 March 2004, have been processed by using v4.61 and $\mathrm{v} 4.62$ of ESA level-1b and level-2 (based on an unconstrained non-linear least-square fit procedure) operational algorithms, as described in details in Kleinert et al. (2007) and in Raspollini et al. (2006) respectively, and provide a self-consistent set of quasi-continuous measurements for temperature and the six target species. For the purposes of MIPAS ozone validation, the two versions of ESA operational processor are substantially equivalent; as a baseline for our comparisons we have generally adopted v4.61 data, using v4.62 only for those cases where v4.61 ozone profiles in coincidence with the selected validation measurements were not available. Retrieval of ozone VMR vertical distribution for $\mathrm{v} 4.61 / \mathrm{v} 4.62$ data products was carried out using three microwindows: microwindows [1122.800-1125.800] $\mathrm{cm}^{-1}$ and [1039.375-1040.325] $\mathrm{cm}^{-1}$ (the latter used in the altitude interval $52-68 \mathrm{~km}$ ), in MIPAS band AB (1020-1170 $\left.\mathrm{cm}^{-1}\right)$, associated with the ozone fundamental modes $v_{1}$ and $v_{3}$, and microwindow [763.375$766.375] \mathrm{cm}^{-1}$, in MIPAS band A $\left(685-970 \mathrm{~cm}^{-1}\right)$, close to the center of the $\mathrm{O}_{3} \nu_{2}$ band. The total error budget on the ozone vertical distribution retrieved from individual MIPAS scans can be evaluated by combining the random contribution due to the mapping of the radiometric measurement noise into the retrieved profiles (expressed by the square root of the diagonal elements of the error variance-covariance matrix included in ESA level-2 data products) and the a priori estimates of systematic components (Dudhia et al., 2002) derived from the analysis carried out at University of Oxford (see data available for five different atmospheric scenarios at http://www-atm.physics.ox.ac.uk/group/mipas/err, hereafter indicated as "Oxford University error data set"). In the case of ozone retrievals, the dominating sources of systematic uncertainty come from the propagation of pressure and temperature retrieval error, from spectrocopic errors and from the effects due to atmospheric horizontal gradients, as well as from radiometric gain and calibration errors. Further systematic components, such as those due to interfering species $\left(\mathrm{H}_{2} \mathrm{O}, \mathrm{CO}_{2}, \mathrm{~N}_{2} \mathrm{O}_{5}\right)$ or non-local thermal equilibrium (NLTE) effects contribute less than $1 \%$ to the total error budget. NLTE can have a larger effect above $55 \mathrm{~km}$.

\section{Ozone correlative data sets and validation strategy}

The coordinated effort for the validation of MIPAS operational ozone data $\mathrm{v} 4.61 / \mathrm{v} 4.62$ involved the comparison with collocated measurements of the $\mathrm{O}_{3}$ vertical distribution from a variety of observation platforms and techniques and the combination of the resulting pieces of information into coherent and quantitative statements about the validity of the selected products. We exploited different categories of correlative data, obtained from ground-based stations, from high altitude aircraft and balloon campaigns and from other satellite missions as well as from assimilated $\mathrm{O}_{3}$ fields by ECMWF. We took advantage of the redundancy and complementarity of the reference data sets to strengthen the statistical confidence in our results and to achieve the widest spatial (vertical and geographical) and temporal (diurnal and seasonal) coverage. To this aim, and within the practical limits posed by the large number of validation measurements, special attention was paid to the selection of uniform criteria and methods for individual comparison. With reference to the general guidelines proposed by Fischer et al. (2007) for the validation of MIPAS operational products, we adopted baseline criteria of $300 \mathrm{~km}$ and $3 \mathrm{~h}$ as the ideal for maximum spatial and temporal separation respectively between MIPAS and the correlative ozone profiles. Departure from these criteria was allowed in a number of specific cases and under suitable conditions, up to a maximum of $500 \mathrm{~km}$ and $10 \mathrm{~h}$, in order to increase the statistical value of the comparison. A validation approach relying on the terminology and methodology described in von Clarmann (2006) for the statistical bias and precision determination with matching pairs of $\mathrm{O}_{3}$ VMR measurements was followed (cp., for instance, Sect. 6) and in some cases rigorously applied to evaluate the effects of coincidence errors or horizontal smoothing (cp. Sect. 4.4). Comparisons were mostly performed between profiles of $\mathrm{O}_{3}$ VMR using pressure as vertical coordinate. With the objective to reduce systematic and random comparison errors associated with the MIPAS vertical smoothing error, correlative profiles measured at much higher vertical resolution than that of MIPAS were transformed using the method described in Sect. 4.1.1, which uses both the averaging kernels and the a priori profiles associated with the MIPAS retrievals. This operation was generally performed by using a common routine. Trajectory Hunting Techniques 
Table 1. NDACC and WOUDC ground-based stations contributing to MIPAS $\mathrm{O}_{3}$ validation.

\begin{tabular}{|c|c|c|c|c|c|}
\hline \multicolumn{6}{|l|}{ Ozonesondes } \\
\hline Station & Location & Latitude & Longitude & Institute & Sonde type \\
\hline Alert & Canada & 82.50 & -62.33 & MSC & $\mathrm{ECC}$ \\
\hline Eureka & Canada & 80.05 & -86.42 & MSC & $\mathrm{ECC}$ \\
\hline Ny- Ålesund & Svalbard & 78.91 & 11.88 & AWI & $\mathrm{ECC}$ \\
\hline Thule & Greenland & 76.51 & -68.76 & DMI & $\mathrm{ECC}$ \\
\hline Resolute & Canada & 74.72 & -94.98 & MSC & $\mathrm{ECC}$ \\
\hline Scoresbysund & Greenland & 70.48 & -21.97 & DMI & $\mathrm{ECC}$ \\
\hline Esrange & Sweden & 67.88 & 21.06 & NIES & $\mathrm{ECC}$ \\
\hline Sodankylä & Finland & 67.37 & 26.67 & FMI & $\mathrm{ECC}$ \\
\hline Keflavik & Iceland & 63.97 & -22.60 & INTA & $\mathrm{ECC}$ \\
\hline Orland & Norway & 63.42 & 9.24 & NILU & $\mathrm{ECC}$ \\
\hline Jokioinen & Finland & 60.82 & 23.48 & FMI & $\mathrm{ECC}$ \\
\hline Churchill & Canada & 58.75 & -94.07 & MSC & $\mathrm{ECC}$ \\
\hline Edmonton & Canada & 53.55 & -114.1 & MSC & $\mathrm{ECC}$ \\
\hline Goose Bay & Canada & 53.32 & -60.38 & MSC & $\mathrm{ECC}$ \\
\hline Legionowo & Poland & 52.40 & 20.97 & INWM & $\mathrm{ECC}$ \\
\hline De Bilt & Netherlands & 52.10 & 5.18 & KNMI & $\mathrm{ECC}$ \\
\hline Valentia & Ireland & 51.93 & -10.25 & ME & ECC \\
\hline Uccle & Belgium & 50.80 & 4.35 & KMI & $\mathrm{ECC}$ \\
\hline Praha & Czech Republic & 50.02 & 14.45 & CHMI & $\mathrm{ECC}$ \\
\hline Hohenpeissenberg & Germany & 47.80 & 11.02 & DWD & Brewer-Mast \\
\hline Payerne & Swiss Alps & 46.49 & 6.57 & $\mathrm{MCH}$ & $\mathrm{ECC}$ \\
\hline Tsukuba & Japan & 36.05 & 140.13 & IMA & Carbon-Iodine \\
\hline Paramaribo & Surinam & 5.81 & -55.21 & KNMI & $\mathrm{ECC}$ \\
\hline San Cristobal & Galapagos & -0.92 & -89.60 & CMDL & ECC \\
\hline Nairobi & Kenya & -1.27 & 36.80 & $\mathrm{MCH}$ & $\mathrm{ECC}$ \\
\hline Malindi & Kenya & -2.99 & 40.19 & RPSM & $\mathrm{ECC}$ \\
\hline Natal & Brazil & -5.42 & -35.38 & INPE & $\mathrm{ECC}$ \\
\hline Watukosek & Java & -7.50 & 112.6 & JAXA & ECC \\
\hline Ascension & Island Congo & -7.98 & -14.42 & NASA & ECC \\
\hline Tutuila & Samoa & -14.23 & -170.56 & CMDL & $\mathrm{ECC}$ \\
\hline Fiji & Fiji & -18.13 & 178.42 & CMDL & $\mathrm{ECC}$ \\
\hline Saint-Denis & Reunion & -21.05 & 55.47 & CNRS & $\mathrm{ECC}$ \\
\hline Irene & South Africa & -25.25 & 28.18 & SAWS & ECC \\
\hline Lauder & New Zealand & -45.03 & 169.68 & NIWA & ECC \\
\hline Marambio & Antarctica & -65.28 & -56.72 & INTA & $\mathrm{ECC}$ \\
\hline Dumont d'Urville & Antarctica & -66.67 & 140.01 & CNRS & $\mathrm{ECC}$ \\
\hline Syowa & Antarctica & -69.00 & 39.58 & JMA & Carbon-Iodine \\
\hline Neumayer & Antarctica & -70.65 & -8.25 & AWI & ECC \\
\hline Belgrano & Antarctica & -77.87 & -34.63 & INTA & undefined \\
\hline
\end{tabular}

were applied to calculate lagrangian coincidences, whenever direct matching did not provide sufficient statistics for the comparison (particularly in the case of the comparison with balloon-borne measurements, cp. Sect. 5).

\section{Comparison with WMO/GAW ground-based mea- surements}

4.1 Comparison with NDACC and WOUDC ozone sondes, lidar and microwave networks

\subsubsection{NDACC and WOUDC data}

A comprehensive intercomparison between MIPAS ozone measurements and correlative data obtained from extensive ground-based networks contributing to WMO's (World 
Table 1. Coninuted.

\begin{tabular}{llrrl}
\hline Lidar & & & & \\
\hline Station & Location & Latitude & Longitude & Institute \\
\hline Eureka $^{(*)}$ & Canada & 80.05 & -86.42 & MSC \\
Ny- Ålesund & Svalbard & 78.91 & 11.88 & AWI \\
ALOMAR,Andoya & Norway & 69.28 & 16.02 & NILU \\
Hohenpeissenberg & Germany & 47.80 & 11.02 & DWD \\
Haute Provence & French Alps & 43.94 & 5.71 & CNRS \\
Tsukuba & Japan & 36.05 & 140.13 & NIES \\
Table Mountain & California & 34.23 & -117.41 & JPL \\
Mauna Loa & Hawaii & 19.54 & -155.58 & JPL \\
Lauder & New Zealand & -45.03 & 169.68 & RIVM \\
\hline$(*)$ not included in the analysis of Sect. 4.1 & & & &
\end{tabular}

${ }^{*}$ ) not included in the analysis of Sect. 4.1

Table 1. Continued.

\begin{tabular}{llrrl}
\hline \multicolumn{2}{l}{ Microwave radiometers } & & & \\
\hline Station & Location & Latitude & Longitude & Institute \\
\hline Ny- Ålesund & Svalbard & 78.91 & 11.88 & IFE \\
Kiruna & Sweden & 67.84 & 21.06 & IMK \\
Bremen & Germany & 53.11 & 8.86 & IFE \\
Zugspitze & German Alps & 46.49 & 6.57 & MCH \\
Mauna Loa & Hawaii & 19.54 & -155.58 & UMAS \\
Lauder & New Zealand & -45.03 & 169.68 & UMAS \\
\hline
\end{tabular}

Meteorological Organisation) Global Atmosphere Watch (GAW) programme was carried out at the Belgian Institute for Space Aeronomy (BIRA-IASB). The comparison data set included ozone profiles from 39 ozone sonde stations (O3S), 8 lidar systems (LID) and 7 microwave radiometers (MWR) associated with the Network for Detection of Atmospheric Composition Change (NDACC), formerly the NDSC (Kurylo and Zander, 2001), and/or the World Ozone and Ultraviolet Data Centre (WOUDC). Prior to using data uploaded routinely to the WOUDC archive, their quality was investigated carefully on statistical and climatological grounds. Stations and instruments contributing to the present study are listed in Table 1. Electrochemical concentration cell (ECC) ozone sondes are launched more or less regularly on board small meteorological balloons at a variety of stations from pole to pole. They yield the vertical distribution of ozone VMR from the ground up to burst point, the latter occurring typically around $30 \mathrm{~km}$. Ozone VMR recorded at a typical vertical resolution of $100-150 \mathrm{~m}$ is converted into ozone number density using pressure and temperature data recorded on-board the same balloon. Error on the ozone profile of ozone sonde depends on a large number of parameters. For ECC sonde important parameters are: the manufacturer of the sonde (SPC or EnSci), the percentage of the sensing solution used in the electrochemical cell and the type of correction applied for pump efficiency. Unfortunately, this information is not always given or well identified in the data files. However, as shown during the JOSIE (Jülich Ozone Sonde Intercomparison Experiment) chamber comparison (Smit and Sträter, 2004), if ozone sondes are operated in a specific way, a similar level of precision and accuracy is achievable from the different sonde types. Typical error estimates are:

- systematic error from 3\% (0-20 km) to 5\% (20-35 km);

- precision from $5 \%(0-20 \mathrm{~km})$ to $7 \%(20-35 \mathrm{~km})$.

Differential absorption ozone lidar (DIAL) systems provide the vertical distribution of night-time ozone number density at altitudes between $8-15 \mathrm{~km}$ and $45-50 \mathrm{~km}$. Actual operation depends on the cloud cover and other measurement conditions. The typical integration time of an ozone measurement in the whole stratosphere is $4 \mathrm{~h}$. Typical vertical resolution ranges from $300 \mathrm{~m}$ up to $3 \mathrm{~km}$ depending on the altitude. The accuracy of the lidar ozone profile depends on the duration of the measurement and on the vertical resolution chosen to process the data. Individual errors bars are given in each ozone file. Typical accuracy estimates range from 3 to $7 \%$ 
from 15 to $40 \mathrm{~km}$. At $40-45 \mathrm{~km}$ and above, due to the rapid decrease in signal to noise ratio, the error bars increase and significant bias reaching $10 \%$ may exist (McDermid et al., 1998; Godin et al., 1999).

Millimetre wave radiometers (MWR) operate night and day, providing ozone VMR integrated over typically $2 \mathrm{~h}$ (a few stations provide shorter integration time) from 20-25 to $70 \mathrm{~km}$, with a vertical resolution of 8 to $12 \mathrm{~km}$. Ozone VMR is converted into number density using ECMWF or NCEP meteorological analyses of pressure and temperature. The individual errors bars usually are given in each ozone data file. Typical accuracy ranges from $5 \%$ at $20 \mathrm{~km}$ to $20 \%$ at $70 \mathrm{~km}$ where the information content is smaller leaving a larger weight to a priori constraints (Connor et al., 1995; Tsou, 1995, 2000). Its low vertical resolution poses additional problems for comparisons, for which dedicated methods have been developed (Calisesi et al., 2005).

Taking into account the ground-based error contribution does not change the total error budget dramatically: this contribution is small compared to the contribution of both MIPAS errors and horizontal smoothing differences in presence of large horizontal inhomogeneities in the ozone field.

As the comparisons are based on profiles convoluted with MIPAS averaging kernels, for the ground-based error, according to Calisesi et al. (2005), we have considered the term:

\section{$\mathbf{A K}^{\mathrm{T}} \mathbf{W}^{\mathrm{T}} \mathbf{S}_{\mathbf{G R}} \mathbf{W A K}$}

where AK is MIPAS averaging kernel matrix, $\mathbf{W}$ the interpolation matrix from ground-based grid to MIPAS grid and $\mathbf{S}_{G R}$ the ground-based error covariance.

The study is based on MIPAS off-line processor version 4.61 data and it covers 2003. A moderate relaxation of space and time collocation criteria with respect to the agreed basline was introduced, to find the best trade-off between the opposite requirements of statistical relevance of the results and minimum comparison error associated with the spatial and temporal separation of the measurements:

- $500 \mathrm{~km}$ from ground-based station to tangent point; and

- O3S or LID within $6 \mathrm{~h}$;

- MWR: within $2 \mathrm{~h}$ at Kiruna, Zugspitze, Mauna Loa and Lauder;

- MWR: within 15 min at Payerne, Bremen and NyÅlesund (shorter integration time).

The comparison/ validation strategy consisted of two steps:

(a) Investigation based on ozone partial columns defined by the pressure levels [75-35], [35-15], [15-7], [7-3] and [3-0.8] $\mathrm{hPa}$ and aimed at re-grouping different stations around principal systems with similar patterns of partial column differences and making a phenomenological separation between atmospheric layers dominated by dynamics and layers dominated by photo-chemistry. (b) Based on the classification obtained from the previous step and starting from the time series of ozone partial column, identification of time periods where the agreement has a constant behaviour and derivation of vertically resolved statistics.

\subsubsection{Error budget of ground-based comparisons}

MIPAS and ground-based instruments offer a different perception of atmospheric ozone. Such differences must be considered to interpret comparison results properly. To evaluate the comparison error budget, we took into account, along with the measurement and retrieval error of MIPAS and of the correlative instrument, the contributions associated with the vertical and horizontal smoothing differences and with the spatial separation of the two ozone profiles. Expanding Rodgers' theory and formalism (Rodgers, 1990), we considered, therefore, the following total comparison error covariance $S$.

$$
\begin{aligned}
S= & S_{M}+S_{N}+\left(A_{M, V}-A_{N, V}\right) S_{V}\left(A_{M, V}-A_{N, V}\right)^{T} \\
& +\left(A_{M, H}-A_{N, H}\right) S_{H}\left(A_{M, H}-A_{N, H}\right)^{T}+S_{\triangle \mathrm{O} 3}
\end{aligned}
$$

where:

$\mathrm{S}_{M}=$ MIPAS error (measurement, retrieval and retrieval parameters)

$\mathrm{S}_{N}=$ Correlative instrument error (measurement, retrieval and retrieval parameters)

$\mathrm{A}_{M}=$ MIPAS averaging kernels, vertical ( $\mathrm{V}$ index) and horizontal (H index)

$\mathrm{A}_{N}=$ Correlative instrument averaging kernels, vertical (V) and horizontal (H)

$\mathrm{S}_{V}=$ Atmospheric variability covariance (vertical)

$\mathrm{S}_{H}=$ Atmospheric variability covariance (horizontal)

$\mathrm{S}_{\triangle \mathrm{O} 3}=$ Spatial distance error

The effect of differences in vertical resolution can be estimated by means of the vertical averaging kernels (AK) associated with the MIPAS retrieval of the ozone profile. First, AKs of the low-resolution data are used to map the highresolution profile to the low-resolution perception. The a priori profile used in Optimal Estimation retrievals is also included as it may introduce an additional bias. Second, the smoothing difference error is estimated as the difference between the smoothed and original profiles. For MIPAS comparison with high vertical resolution measurements $(\mathrm{O} 3 \mathrm{~S}$ or lidar):

$\Delta x_{V}=x_{a}^{M}+A_{M}\left(x_{N}-x_{a}^{M}\right)-x_{N}$

where:

$\Delta x_{V}=$ Vertical smoothing error

$x_{N}=$ High resolution profile (O3S or lidar)

$x_{a}^{M}=$ MIPAS ozone profile used to compute the vertical averaging kernels 
and for MIPAS comparison with lower vertical resolution measurements (MWR):

$\Delta x_{V}=x_{a}^{N}+A_{N}\left(x_{M}-x_{a}^{N}\right)-x_{M}$

where:

$x_{M}=$ High resolution profile (MIPAS)

$x_{a}^{N}=$ MWR a priori ozone profile

As the MIPAS processor retrieves only one-dimensional profiles, no AKs are available for the study of horizontal smoothing. The MIPAS uncertainties associated with horizontal smoothing are calculated rather as an estimate of the ozone gradient interfering with the MIPAS line of sight (LOS), that is, the horizontal component of atmospheric noise associated with the MIPAS measurement. We use Eq. (4):

$\Delta x_{H}= \pm \operatorname{abs}\left(\vec{\nabla} X_{\text {MEDIAN }} \cdot \vec{I}_{\text {ENVISAT }}\right) \mid$ MIPAS $\left.\right|_{90 \%}$

where:

$\Delta x_{H}=$ Horizontal smoothing error (or horizontal component of atmospheric noise)

$\vec{\nabla} X_{\text {MEDIAN }}=$ Ozone gradient at the median point of MIPAS LOS

$\vec{I}_{\text {ENVISAT }}=$ ENVISAT direction $($ MIPAS LOS is backward along track)

| MIPAS $\left.\right|_{90 \%}=$ LOS extension of $90 \%$ information air mass .

The ozone gradient is estimated from 4-dimensional ozone fields generated by the Belgian Assimilation System of Chemical Observations from ENVISAT (BASCOE, Errera and Fonteyn, 2001; Fonteyn et al., 2003). BASCOE is a data assimilation system of stratospheric chemistry using the four-dimensional variational (4D-VAR) method. In the course of a run, BASCOE can ingest satellite observations. The resulting "assimilated field" is an estimate of the chemical composition of the stratosphere based both on the set of observations and on the physical laws describing the evolution of the system synthetized into the model. They are defined at 37 hybrid pressure levels from $0.1 \mathrm{hPa}$ down to the surface. The horizontal resolution of BASCOE standard outputs is $3.75^{\circ}$ in latitude by $5^{\circ}$ in longitude. For our study we have used off-line version v3d24 of BASCOE fields.

Finally, to complete the comparison error budget, the ozone partial column difference induced by the spatial/temporal separation of the two ozone profiles can be estimated by:

$$
\Delta \mathrm{O}_{3}=\mathrm{O}_{3}\left(\left|X_{\text {MEDIAN }}^{\text {MIPAS }}\right|\right)-\mathrm{O}_{3}\left(\left|X_{\text {STATION }}\right|\right)
$$

where $\left|X_{\text {MEDIAN }}^{\text {MIPAS }}\right|$ is the estimated geolocation of the median point of MIPAS LOS, $\left|X_{\text {STATION }}\right|$ is the ground-based station geolocation and $\mathrm{O}_{3}(\mathrm{X})$ the ozone partial column at the corresponding location and time estimated using BASCOE assimilated ozone fields. The along orbit distribution - median position and $90 \%$ extension as a function of tangent altitude - of the MIPAS information content was estimated by DeClercq and Lambert (2006) using their two-dimensional radiative transfer model of the MIPAS full limb scanning sequence. It is important to note that BASCOE absolute ozone fields have shown to compare reasonably to HALOE, CRISTA and MLS and, more important here, that relative fields are accurate (Errera and Fonteyn, 2001; Fonteyn et al., 2003).

\subsubsection{Time series of $\mathrm{O}_{3}$ partial column differences: result and discussion}

The first segment of our study concentrated on the analysis of time series of the differences between MIPAS and groundbased ozone partial column data. The analysis included assessments of the different contributions to the total comparison error, as defined in Sect. 4.1.2. Comparison results vary significantly between the lower stratosphere, where dynamics and chemistry interfere, with clear influences of tropospheric dynamics, and the higher stratosphere, where photochemistry dominates. Consequently, a classification based on regularities in the pattern of the $\mathrm{O}_{3}$ partial column differences emerges: in the lower stratosphere $(75-35 \mathrm{hPa})$, results regroup around synoptic and regional systems and the systems linked to stratospheric transport; reaching into the middle stratosphere $(35-15 \mathrm{hPa})$, we move from large synoptic groups to a more zonal behaviour and we can extend the previously described synoptic systems to group more stations; in the middle and upper stratosphere $(15-7 \mathrm{hPa}, 7-3 \mathrm{hPa}, 3-$ $0.8 \mathrm{hPa}$ ), zonal symmetry becomes dominant and comparisons results follow this behaviour. Deviations from zonal symmetry nevertheless exist and must be taken into account. A typical output of the comparison carried out for each of the aforementioned groups of measurement sites is displayed in Fig. 1, presenting the results obtained at Western and Central Europe stations. The plot shows, as black dots, the percentage relative difference in ozone partial column $(73-35 \mathrm{hPa})$ between MIPAS and correlative ozone sonde data at Western and Central Europe stations over 2003, and smoothing and collocation errors (running mean in plain and standard deviation in dashed) estimated by the aforementioned methods. Grey rectangles identify monthly means (central line) and standard deviations of the differences.

In general, the comparison error is dominated by the effect of differences in horizontal smoothing of atmospheric variability. While ground-based instrumentation captures only a portion of the air mass probed by MIPAS, MIPAS smoothes atmospheric inhomogeneities over several hundred kilometres. Red curves in Fig. 1 give the range of atmospheric variability smoothed by the MIPAS measurement, that is, an upper limit of the expected difference between MIPAS and ground-based ozone column data. We can conclude from the plot that differences in horizontal smoothing can account for 
the observed standard deviation of the comparisons in most of the cases, but not for systematic differences as those appearing in Fig. 1 in summer 2003. Horizontal smoothing differences are followed in magnitude by errors associated with geolocation differences. The latter also correlate with the standard deviation of comparisons, but their amplitude is dominated by MIPAS horizontal smoothing effects. Errors associated with vertical smoothing differences are smaller. Their effect could account for a small, constant offset in the comparisons. In most cases, comparison results can be interpreted by considering the different error contributions. However, in some cases, they cannot account fully for the difference noticed between MIPAS and correlative partial column data. MIPAS reports larger partial columns than the ground based-instruments:

1. in the $75-35 \mathrm{hPa}$ layer at stations from northern (see Fig. 1) and southern mid latitudes, equator and tropics;

2. at $35-15 \mathrm{hPa}$ over stations at the equator, in the tropics, and in Antarctica during ozone hole event; and

3. in the $3-0.8 \mathrm{hPa}$ layer at European stations.

At $7-3 \mathrm{hPa}$, MIPAS partial columns underestimate correlative observations in Hawaii. The comparison error budget cannot account for these observed differences. In all other analysed situations, MIPAS partials column data agree well with those reported by the ground-based instrumentation, and the observed differences fit well within the comparison error budget.

4.1.4 Comparison of $\mathrm{O}_{3}$ vertical profiles: results and discussion

The first step of our analysis was instrumental in getting an overall view of the agreement between MIPAS and WMO/GAW ground-based data, and also in determining time periods and groups of stations where comparison results are sufficiently consistent to allow the meaningful derivation of statistical values. As a second step of our analysis, we derived vertically resolved statistics of the comparisons between MIPAS v4.61 ozone profiles and correlative data obtained at NDACC and WOUDC stations. The comparisons have been performed at each individual station listed in Table 1 and summary plots have been computed for stations belonging to the same synoptic system/ zonal region and showing mostly identical comparison results. The groups are the same as above, except that in this case we have separated ozone sondes and lidar results to allow better discrimination of ground-based error contributions.

At Arctic, Northern and Southern middle latitude sites, the results can be separated between 1 October to 31 March and 1 April to 30 September. At tropical and equatorial stations, the weak seasonal variation allows us to draw annual plots. At Antarctic stations results can be separated between "ozone

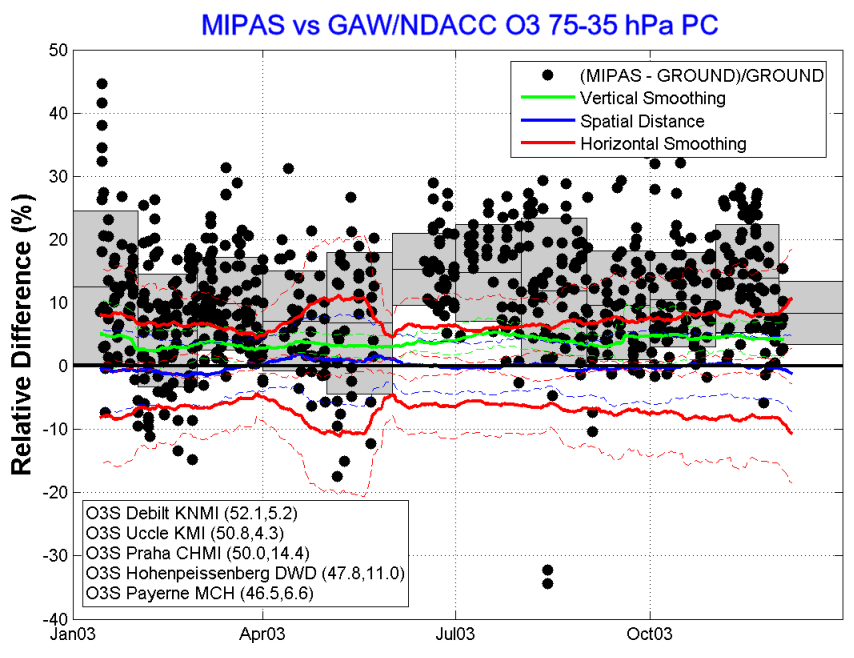

Fig. 1. Time-series of the percentage relative difference in ozone partial column $(75-35 \mathrm{hPa})$ between MIPAS and correlative ozonesonde data at five Western and Central Europe stations for 2003, and estimated smoothing and collocation errors (running mean in plain and $1 \sigma$ standard deviation in dashed). Grey-shaded rectangles identify monthly means (central line) and standard deviations of the differences.

hole" (that is, for 2003, 21 August to 15 October) and "normal ozone" periods (that is, for 2003, 16 October to $20 \mathrm{Au}$ gust).

A few examples of the results obtained for the absolute and relative differences of MIPAS $\mathrm{O}_{3}$ vertical profiles with ozone sonde and lidar data are shown in Figs. $2 \mathrm{a}$ and b, respectively. Each plot of Fig. 2 shows, for each collocated pair of profiles, absolute differences between MIPAS and correlative measurements (light grey lines). To eliminate vertical smoothing differences, high-resolution correlative measurements have been previously convoluted with MIPAS averaging kernels and biased by the first-guess profile, following the method proposed by Rodgers and Connor (2003). Black lines depict statistical values (mean and $1 \sigma$ standard deviation) of the absolute or relative differences between MIPAS and ground-based data. Red lines depict the total systematic error of the comparison. The mean difference between MIPAS and ground station data should be compared to these lines. The total systematic error of the comparison is calculated as the sum of MIPAS systematic error and the systematic bias due to non-perfect collocation (spatial/temporal distance, as explained in Sect. 4.1.2). The yellow block delimited by dashed red lines depicts the total random error of the comparison. This value should be compared with the $1 \sigma$ standard deviation of the differences. This total random error of the comparison is calculated as the quadratic sum of MIPAS random error, ground-based random error, random contribution of spatial/temporal distance and LOS inhomogeneity. 

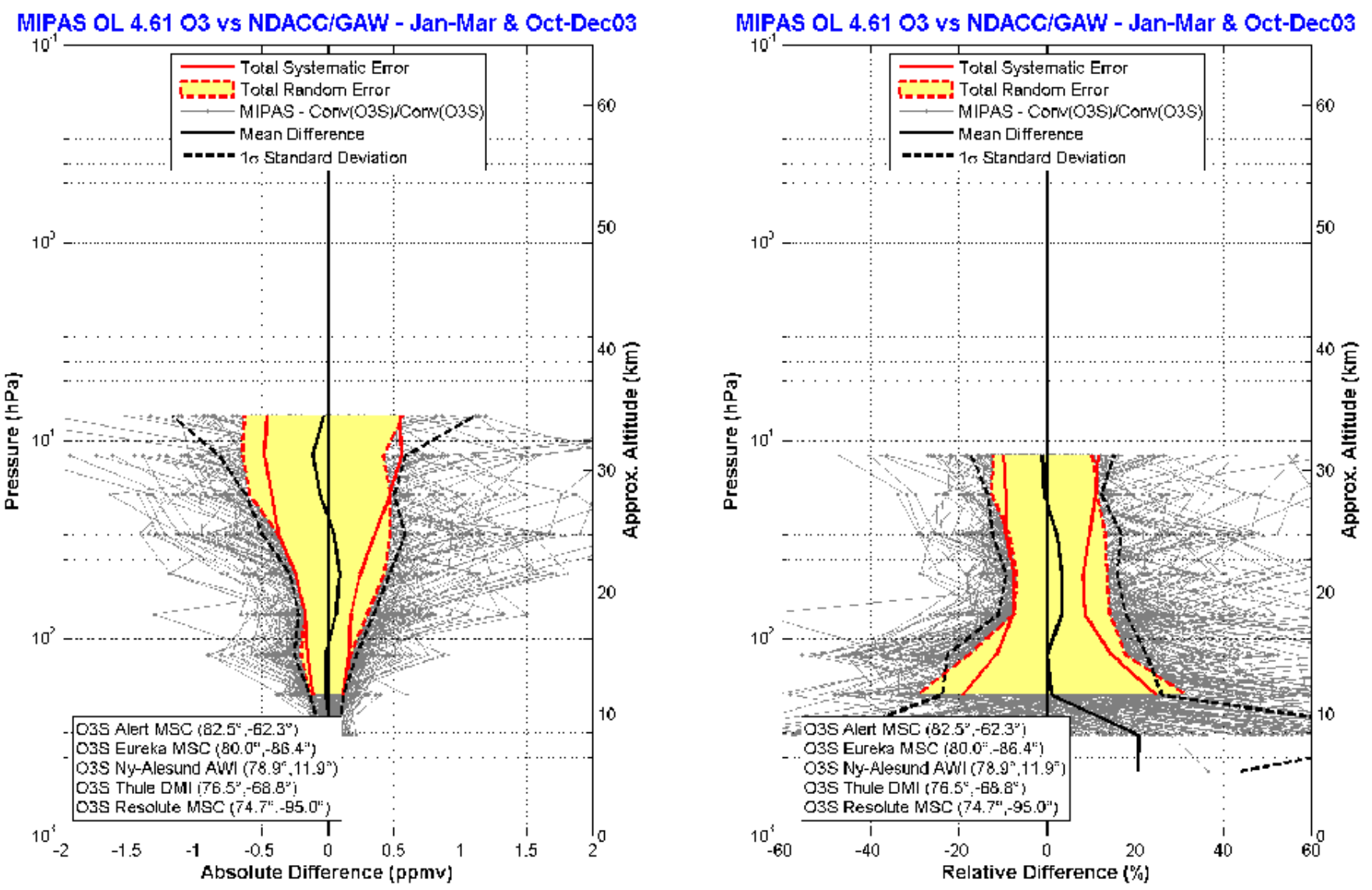

Fig. 2. Vertically resolved statistics of the absolute differences between MIPAS $\mathrm{O}_{3}$ data and NDACC and WOUDC measurements in the Arctic (see main text for explanations).

Figures $3 \mathrm{a}$ and $\mathrm{b}$ show the results of the comparison, with ozone sonde and lidar respectively, in terms of relative differences. These results are similar to those obtained from the absolute difference comparisons, but should be considered carefully:

- The total error budget of the comparison is firstly calculated for absolute difference and secondly a percentage is estimated.

- Low ozone concentrations lead to large relative difference although absolute differences are small. In these cases, mean and standard deviation of relative difference are not relevant. The percentages obtained below $12-15 \mathrm{~km}$ at middle and high latitudes, below $20 \mathrm{~km}$ at tropical and equatorial station, and during "ozone hole" in Antarctica shouldn't be considered.

An overall summary of the results obtained from the comparison of $\mathrm{O}_{3}$ vertical profiles is presented in Table 2 , with a detailed assessment of the quality of the agreement between MIPAS and ground-based measurements (O3S, LID and MWR) for each altitude region and synoptic or regional system.

\subsection{Comparison with NDACC/EQUAL lidar network}

\subsubsection{The EQUAL $\mathrm{O}_{3}$ validation data set}

A purely statistical analysis of the differences between MI$\mathrm{PAS} \mathrm{O}_{3}$ vertical profiles and lidar data was carried out by the groups involved in the EQUAL (Envisat QUality Assessment with Lidar) project, based substantially on the same NDACC data set adopted by the BIRA team for the pseudo-global intercomparison described in Sect. 4.1, i.e. the measurements from the ground-based lidar stations listed in Table 1, with the addition of the Eureka (Lat. $80.05^{\circ} \mathrm{N}$; Lon. $86.42^{\circ} \mathrm{W}$ ) site. The selection of collocated pairs of MIPAS and lidar observations was based on matching criteria slightly relaxed with respect to the agreed baseline, in order to get a sufficient number of coincident profiles for a statistically meaningful comparison: the useful matches were chosen within a $400 \mathrm{~km}, 10 \mathrm{~h}$ window. A total of 627 matching pairs was identified and was used to validate MIPAS $\mathrm{O}_{3}$ level 2 offline data v4.61 and v4.62 in the period from 6 July 2002 to 26 March 2004. The comparison was based on a statistical analysis of the differences between profiles of $\mathrm{O}_{3}$ number density measured as a function of altitude by MIPAS and by 
Table 2. Results of the comparison between MIPAS v4.61 ozone profiles and NDACC ground-based measurements.

\begin{tabular}{|c|c|c|c|}
\hline 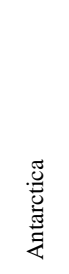 & 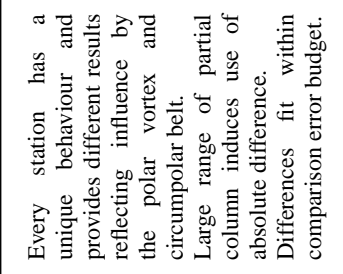 & 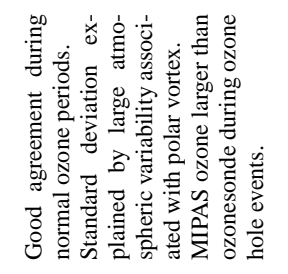 & 1 \\
\hline 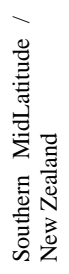 & 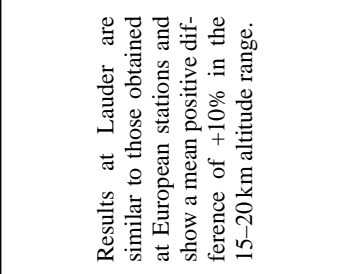 & 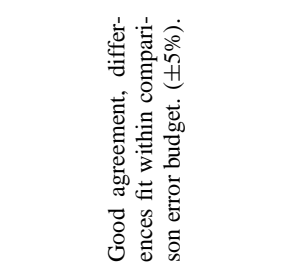 & 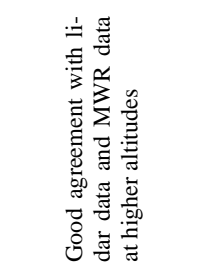 \\
\hline 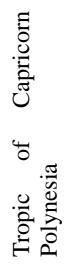 & 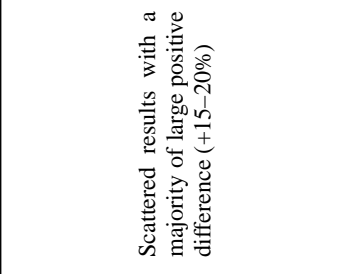 & 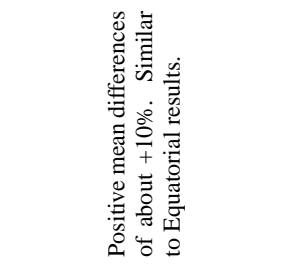 & 1 \\
\hline 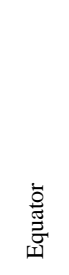 & 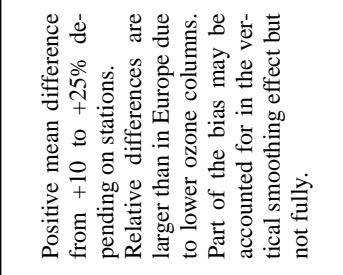 & 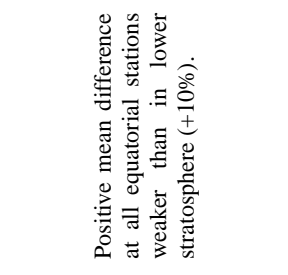 & 1 \\
\hline 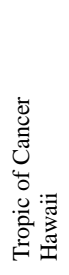 & 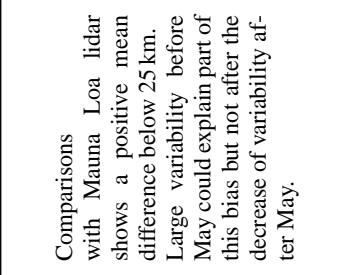 & 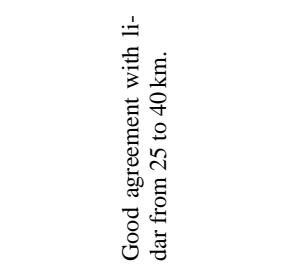 & 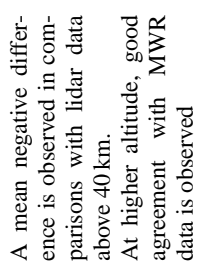 \\
\hline 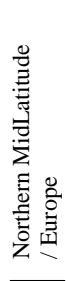 & 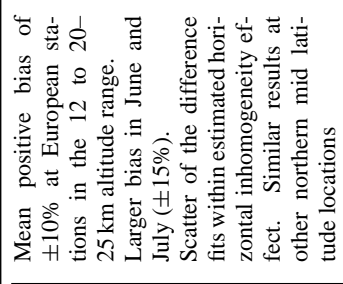 & 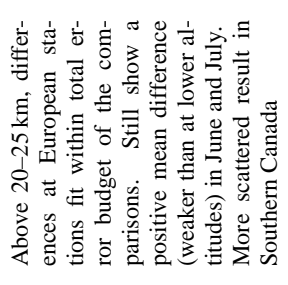 & 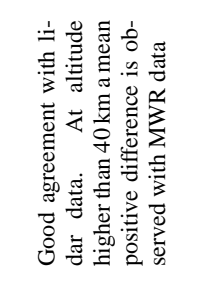 \\
\hline 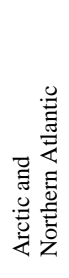 & 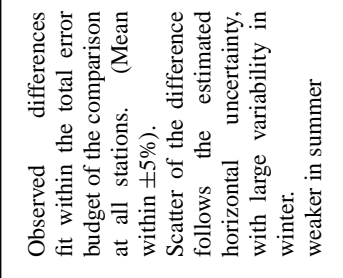 & 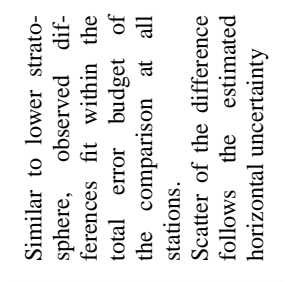 & 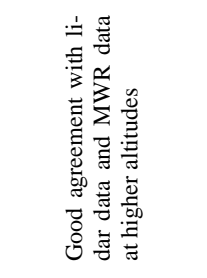 \\
\hline & 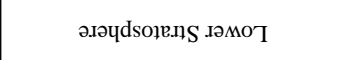 & 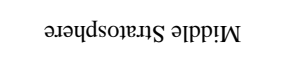 & ә.ə૫גsołe.nS .ədd \\
\hline
\end{tabular}



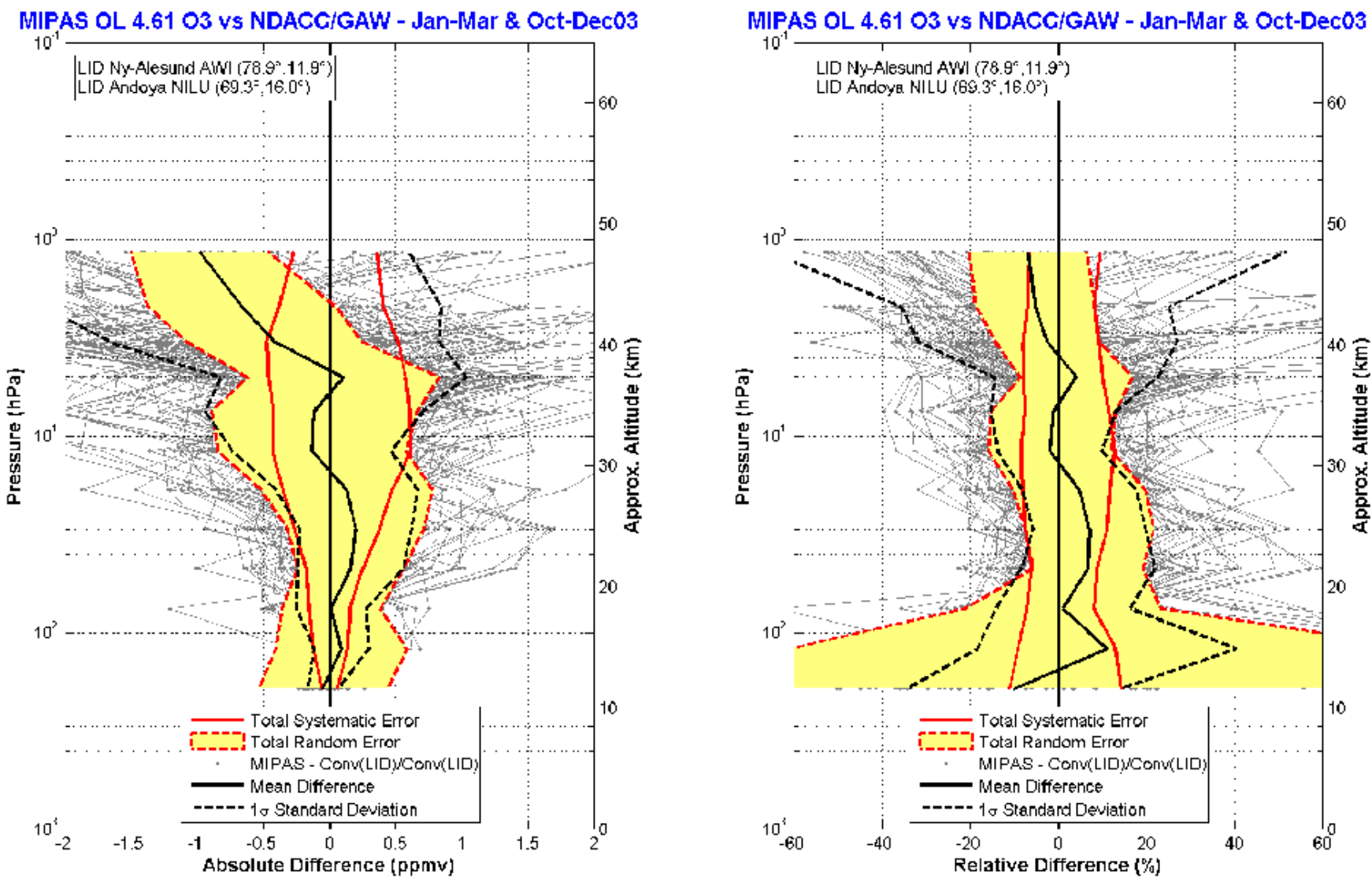

Fig. 3. Vertically resolved statistics of the relative differences between MIPAS $\mathrm{O}_{3}$ data and NDACC and WOUDC measurements in the Arctic (see main text for explanations).

lidar stations in the range from $10 \mathrm{~km}$ to $50 \mathrm{~km}$. The vertical co-ordinate for MIPAS profiles was transferred from pressure to altitude by using ECMWF data: we interpolated ECMWF pressure and geo-potential height (GPH) to the MIPAS retrieval pressure grid and converted the resulting GPH values to geometric altitude.

\subsubsection{Results and discussion}

The results of the comparison for the whole set of collocated pairs are summarised in Fig. 4. On the left panel, the mean profiles of $\mathrm{O}_{3}$ number density measured by MIPAS and by lidars are displayed, along with the corresponding $1 \sigma$ standard deviations. The mean and the median of the percentage differences between MIPAS and lidar $\mathrm{O}_{3}$ profiles relative to the lidar values are plotted in the middle panel. On the same graph, we show the mean relative difference $\pm 1 \sigma$ standard deviation (light green profiles) and indicate, for some of the altitude levels, the number of MIPAS and lidar pairs taken into account by the statistics at that level. On the right panel, the standard deviation of the relative differences is compared with the standard deviations of the selected MIPAS and lidar profiles. The mean relative difference is lower than $\pm 5 \%$ be- tween 15 and $40 \mathrm{~km}$, whilst slightly larger values of positive and negative bias (up to $\pm 15 \%$ ) are obtained outside this altitude range, respectively above $40 \mathrm{~km}$ and below $15 \mathrm{~km}$. The quality of the agreement in the lower and middle stratosphere is confirmed by the substantial match between the mean and the median of the differences at these altitudes. The occurrence of outliers in the distribution of the relative differences leads to an increase of the standard deviation and, when asymmetric, introduces a discrepancy between the mean and the median values, as it happens, in our case, at altitudes below $20 \mathrm{~km}$ and - to a lesser extent - above $35-40 \mathrm{~km}$. To better identify possible sources of the observed discrepancies, we have extended the statistical analysis of MIPAS and lidar $\mathrm{O}_{3}$ collocated profiles, by investigating their latitude dependency. No distinction was found between Southern and Northern Hemisphere. We calculated the mean and the median of the relative differences, as well as their standard deviations, for three latitude bands corresponding to the Tropical (from the Equator to latitude $23.5^{\circ}$ ), to Mid-latitude (from latitude $23.5^{\circ}$ to $66.5^{\circ}$ ) and to the Polar (from latitude $66.5^{\circ}$ to the Pole) regions; the results are displayed in Fig. 5. A small positive bias (less than 5\%) is generally found between 20 and $40 \mathrm{~km}$ both in the Mid-latitude and in the Tropical 

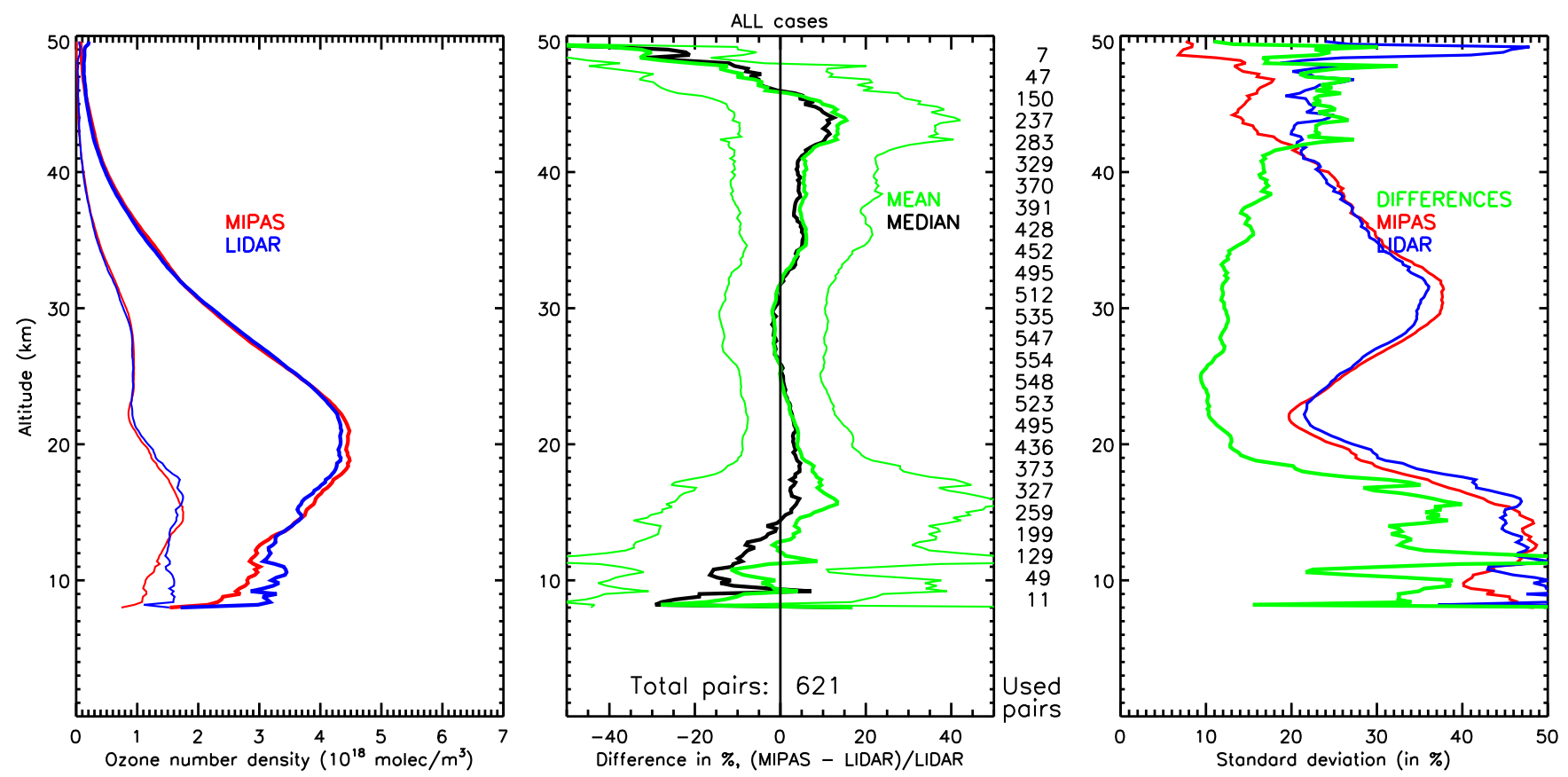

Fig. 4. Results of the comparison between MIPAS $\mathrm{O}_{3}$ profiles and ground-based lidar measurements matching the coincidence criteria of $400 \mathrm{~km}$ and $10 \mathrm{~h}$. On the left, MIPAS and lidar mean profiles are shown by bold red and blue line, respectively; the same colour code is used for the thin lines representing the $1 \sigma$ standard deviations. The plot in the middle panel shows the mean (bold green) and the median (bold black) of the relative differences, with the thin green lines indicating the $\pm 1 \sigma$ standard deviations from the mean difference; on the right side of the plot, the number of coincident pairs that have been used in the calculations are reported for some of the altitude levels. On the right panel, we display the standard deviations of the relative differences (bold green) and of MIPAS (bold red) and lidar (bold blue) $\mathrm{O}_{3}$ profiles.

regions, with the exception of the $21-24 \mathrm{~km}$ range in the latter, where the mean difference increases up to $10 \%$. At the tropics larger values of the mean relative differences (up to $50 \%$ ) are found below $20 \mathrm{~km}$, associated with a standard deviation of the differences that exceeds those of the individual instruments. At high latitudes, MIPAS $\mathrm{O}_{3}$ data are biased low with respect to the lidar measurements, with differences that remain always below $7 \%$ from $15 \mathrm{~km}$ up to $40 \mathrm{~km}$ altitude. Once again, the discrepancy increases at the lowest tangent altitude of MIPAS (below $12 \mathrm{~km}$ ), with a negative bias up to $-20 \%$ and a standard deviation of the mean relative differences comparable to the ones of MIPAS and lidar profiles. Notably, the larger differences between the mean and the median of the distribution observed below $20 \mathrm{~km}$ are mostly localised at mid-latitude, while elsewhere remain either small (less than a few percent in the Polar region) or negligible (at the tropics) for the whole altitude range.

\subsection{Comparison with NDACC FTIR network}

\subsubsection{FTIR data}

MIPAS v4.61 ozone data in the period 6 July 2002 to 26 March 2004 are compared with ground-based Fourier Transform InfraRed (FTIR) measurements at five stations: Kiruna, Sweden $\left(67.8^{\circ} \mathrm{N}, 20.4^{\circ} \mathrm{E}\right)$ and Jungfraujoch, Switzerland $\left(46.5^{\circ} \mathrm{N}, 8.0^{\circ} \mathrm{E}\right)$ in the Northern Hemisphere, and Lauder, New Zealand $\left(45.0^{\circ} \mathrm{S}, 169.7^{\circ} \mathrm{E}\right)$, Wollongong, Australia $\left(34.4^{\circ} \mathrm{S}, 150.5^{\circ} \mathrm{E}\right)$, and Arrival Heights, Antarctica $\left(77.5^{\circ} \mathrm{S}\right.$, $166.4^{\circ} \mathrm{E}$ ) in the Southern Hemisphere. These instruments are all operated within the NDACC. Quality control is applied according to the NDACC guidelines. In addition to column amounts of $\mathrm{O}_{3}$, low vertical resolution profiles are obtained from solar absorption spectra by using the Optimal Estimation Method of Rodgers (2000) in the inversion programs, namely PROFFIT (PROFile FIT) for Kiruna station, described by Hase et al. (2000) and by Hase et al. (2004) and based on the forward model KOPRA (Karlsruhe Optimized Precise Radiative transfer Algorithm, Höpfner et al., 1998), and SFIT2 (Pougatchev et al., 1995; Rinsland et al., 1998) for the other stations. The SFIT2 and PROFITT codes have been cross-validated successfully by Hase et al. (2004). The retrieval process, in both codes, involves the selection of retrieval parameters: spectral microwindows, spectroscopic parameters, a priori information, and model parameters. The choice of these retrieval parameters has been optimized independently at each station. An exception was made for the spectroscopic database: all stations agreed in using the HITRAN 2004 database (Rothman et al., 2005) in order to avoid biases due to different spectroscopic parameters. For 49 infrared bands of $\mathrm{O}_{3}$ the line positions and intensities have 

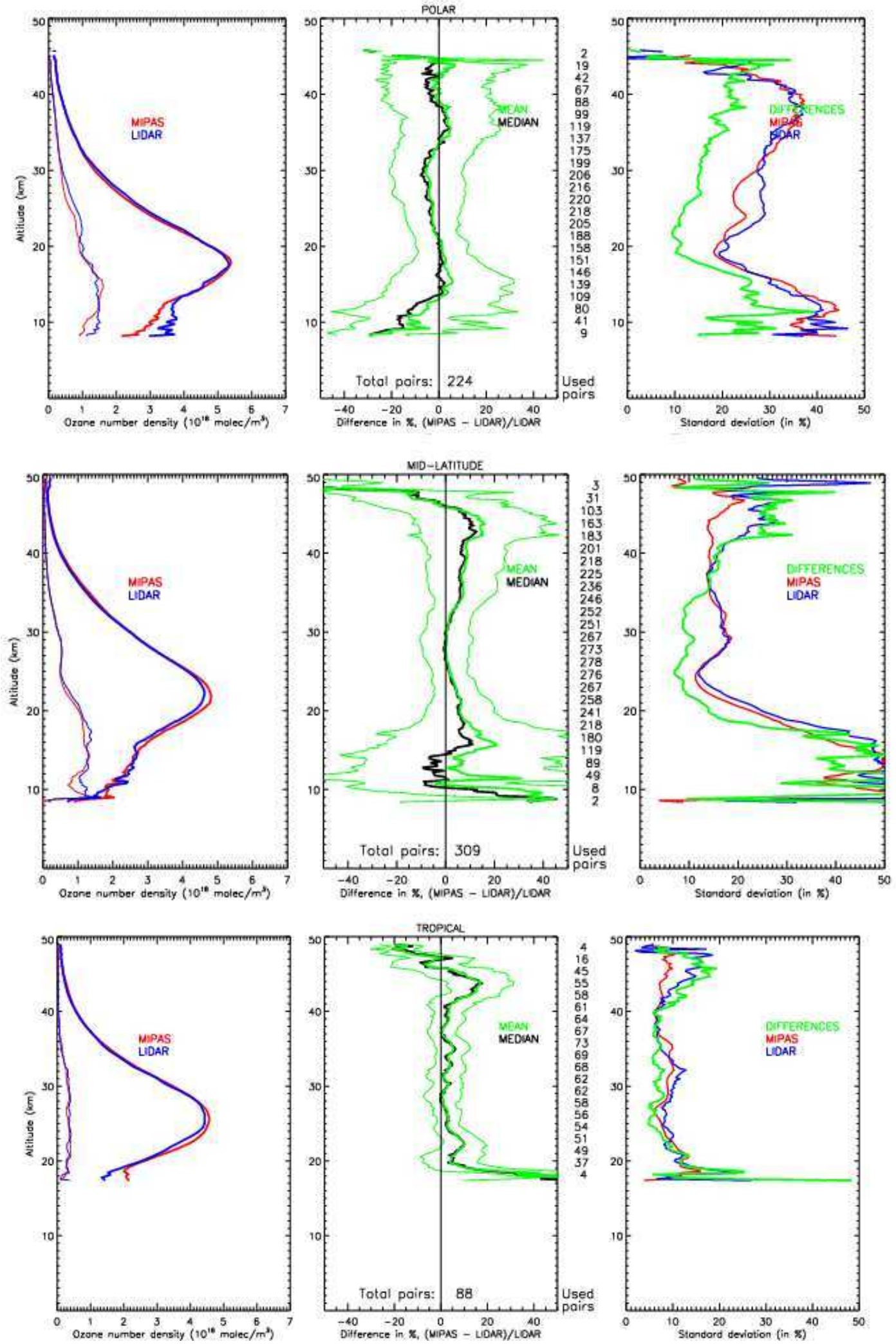

Fig. 5. Results of the comparison between MIPAS $\mathrm{O}_{3}$ profiles and ground-based lidar measurements: zonal averages. The same format is used as for the plots in Fig. 4. 
Table 3. Statistical means (MRD) and standard deviations (SD) of the relative differences (X-FTIR)/mean(FTIR) in percent of the $\mathrm{O}_{3}$ partial columns defined by the given pressure limits. $\mathrm{X}$ is the MIPAS $\mathrm{O}_{3}$ partial column collocated within $3 \mathrm{~h}$ and $300 \mathrm{~km}$ from the ground-based FTIR measurements. The number $\mathrm{N}$ of comparison pairs for each station, the combined random error, and the $3 \sigma$ standard error on the mean (SEM) are also reported.

\begin{tabular}{llllll}
\hline Station & $\begin{array}{l}\text { Pressure Range } \\
{[\mathrm{hPa}]}\end{array}$ & $\begin{array}{l}\mathrm{O}_{3} \text { Partial Column } \\
\mathrm{MRD} \pm \mathrm{SD}[\%]\end{array}$ & $\begin{array}{l}\text { Random Error } \\
{[\%]}\end{array}$ & $\mathrm{N}$ & $\begin{array}{l}\text { SEM } \\
{[\%]}\end{array}$ \\
\hline Kiruna & $2-168$ & $+1.3 \pm 6.3$ & 5.6 & 24 & 3.9 \\
Jungfraujoch & $2-214$ & $-3.5 \pm 6.1$ & 5.5 & 12 & 5.3 \\
Wollongong & $1-196$ & $-0.4 \pm 2.3$ & 6.1 & 4 & 3.5 \\
Lauder & $3-185$ & $-5.6 \pm 2.9$ & 5.5 & 17 & 2.1 \\
Arrival Heights & $2-163$ & $-7.1 \pm 8.1$ & 7.1 & 16 & 6.1 \\
\hline
\end{tabular}

been indeed updated in the HITRAN 2004 database following those of the MIPAS database (mipas-pf-3.1 for the v4.61 products) (Raspollini et al., 2006).

\subsubsection{Methodology of the comparison}

Pairs of coincident ozone profiles from MIPAS and from each of the five FTIR stations are selected for comparison according to the baseline criteria $( \pm 3 \mathrm{~h}, 300 \mathrm{~km})$, with spatial separation between satellite and ground-based observations evaluated at the MIPAS nominal tangent height of $21 \mathrm{~km}$. Each spatially collocated MIPAS scan is compared with the mean of the FTIR measurements recorded within the chosen temporal coincidence criterion. The comparison is made on a pressure grid. The MIPAS profiles are degraded to the lower vertical resolution of the ground-based FTIR measurements, following:

$x_{s}=x_{a}+A\left(x_{m}-x_{a}\right)$

where $x_{m}$ and $x_{s}$ are the original and the smoothed MIPAS profiles and $x_{a}$ and A are the FTIR a priori profile and averaging kernel matrix, respectively.

For the sake of homogeneity, a common approach was agreed for the calculation of $\mathrm{O}_{3}$ partial columns and vertical profile differences in the comparisons.

Vertical profiles - we calculated the absolute difference (MIPAS-FTIR) between MIPAS smoothed profiles and the low vertical resolution FTIR measurements. The mean relative difference in percent and the associated $1 \sigma$ standard deviation were then obtained by dividing the mean absolute differences and standard deviation, respectively, by the mean of the FTIR $\mathrm{O}_{3}$ profiles.

Partial Columns - the boundaries of partial columns, defined by pressure levels as indicated in Table 3, were chosen taking into account:

- the ground-based FTIR sensitivity, which is reasonable up to around $40 \mathrm{~km}$ for $\mathrm{O}_{3}$;
- the lowest altitudes of valid MIPAS profiles which have a mean of about $12 \mathrm{~km}$ over the data set selected for comparison;

As for the vertical profiles, we first calculated the absolute differences between MIPAS and FTIR $\mathrm{O}_{3}$ partial columns and then divided these by the mean of the FTIR partial columns to obtain the relative differences. In Table 3 , the mean and the standard deviation of the partial column relative differences are reported for each station, along with the number $\mathrm{N}$ of coincident pairs and the estimated random error on the $\mathrm{O}_{3}$ partial column differences. We have evaluated the random error covariance matrix of the difference MIPAS FTIR, using the work of Rodgers and Connor (2003) for the comparison of remote sounding instruments and of Calisesi et al. (2005) for the re-gridding between the MIPAS and the FTIR data (see Vigouroux et al., 2006, for more details). The FTIR random error budget has been estimated for a typical measurement at Kiruna (F. Hase, IMK, private communication). There are different contributions to the MIPAS random error covariance matrix. The error covariance matrix due to the noise is given in the MIPAS level 2 products for each profile. We have chosen to use, as the noise contribution to the MIPAS random error matrix, the mean of the covariance matrices of the coincident MIPAS profiles. Two coincident MIPAS profiles at Lauder have been removed from the comparisons, because their random errors were especially large. Following the approach adopted for MIPAS comparison with other satellite measurements, we have added to the MIPAS random error budget the systematic errors with random variability (i.e. error due to propagation of pressure and temperature random covariance into the ozone retrieval), as explained in detail in Sect. 6 .

\subsubsection{Results of $\mathrm{O}_{3}$ partial column intercomparison}

Time series of $\mathrm{O}_{3}$ partial columns at the five ground-based stations are displayed in Fig. 6. For each station, the upper panel in the plot shows the results of FTIR measurements and of collocated MIPAS data. In the lower panel, 

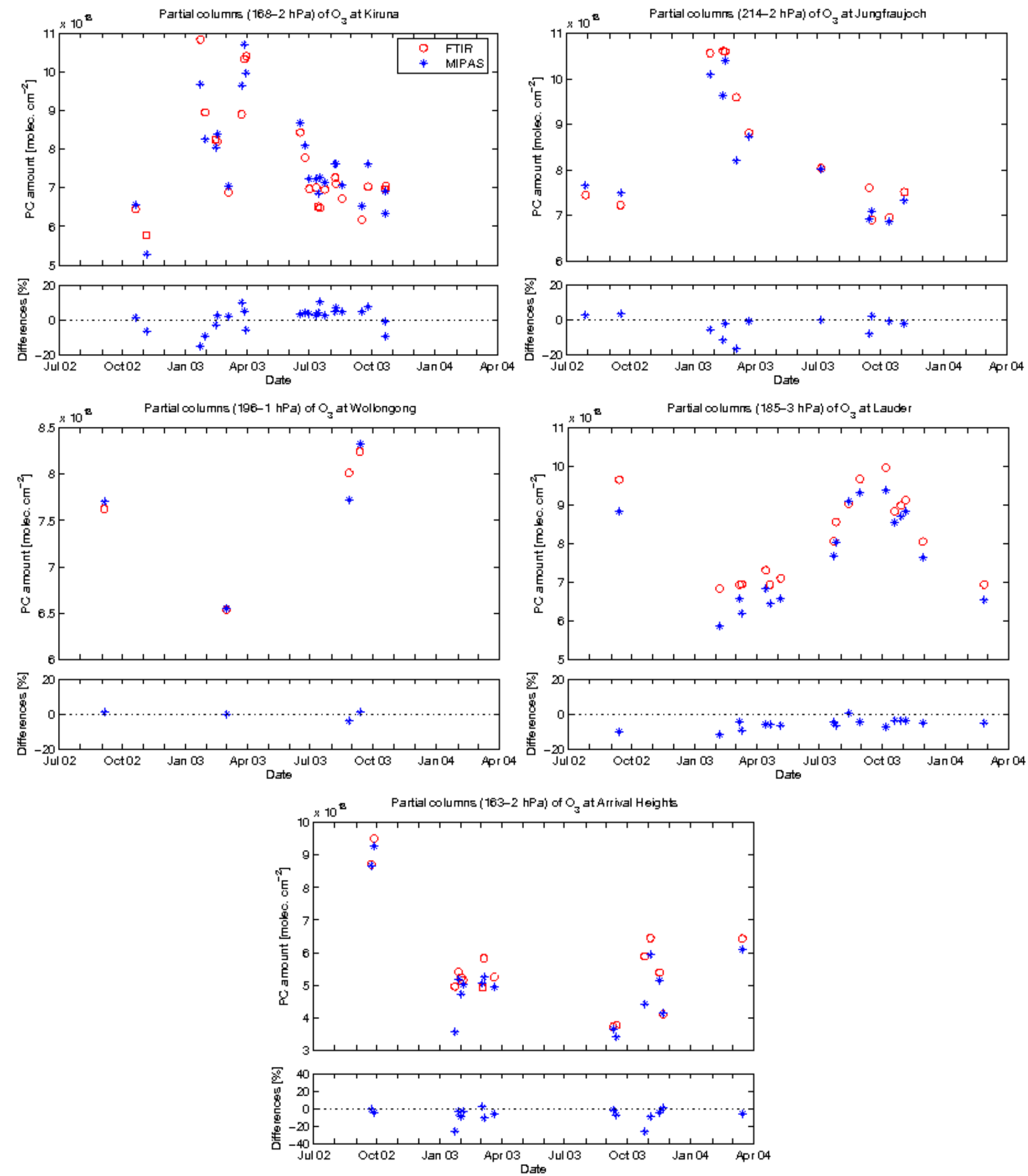

Fig. 6. Time series of ozone partial columns. Upper panel: ground-based FTIR (circles) and MIPAS v4.61 (stars) $\mathrm{O}_{3}$ partial columns for collocated measurements at the five stations. Lower panel: relative differences between MIPAS and ground-based FTIR $\mathrm{O}_{3}$ partial columns. 
Table 4. Results of the comparison with mid-latitude ozone soundings.

\begin{tabular}{ccccccccc}
\hline $\begin{array}{c}\text { Altitude range } \\
{[\mathrm{km}]}\end{array}$ & $n_{i}$ & $\begin{array}{c}b_{i} \\
{[\mathrm{ppmv}]}\end{array}$ & $\begin{array}{c}\sigma_{b_{i}} \\
{[\mathrm{ppm}]}\end{array}$ & $\begin{array}{c}\sigma_{b_{i}, \text { sys }} \\
{[\mathrm{ppmv}]}\end{array}$ & $\begin{array}{c}p_{i} \\
{[\mathrm{ppmv}]}\end{array}$ & $\begin{array}{c}\sigma_{d_{i}, \mathrm{rnd}} \\
{[\mathrm{ppmv}]}\end{array}$ & $\begin{array}{c}\chi_{R, i}^{2} \\
{[\mathrm{ppmv}]}\end{array}$ & $L_{i}$ \\
\hline $0.0-7.5$ & 5 & -0.04 & 0.01 & 0.17 & 0.03 & 0.02 & 1.69 & 0.890 \\
$7.5-10.5$ & 9 & -0.01 & 0.02 & 0.20 & 0.06 & 0.03 & 2.77 & 0.973 \\
$10.5-13.5$ & 19 & -0.07 & 0.03 & 0.16 & 0.13 & 0.06 & 7.97 & 0.987 \\
$13.5-15.5$ & 21 & -0.09 & 0.04 & 0.20 & 0.18 & 0.13 & 5.01 & 1.000 \\
$16.5-19.5$ & 19 & -0.05 & 0.05 & 0.15 & 0.24 & 0.21 & 1.71 & 1.000 \\
$19.5-22.5$ & 19 & 0.15 & 0.11 & 0.22 & 0.49 & 0.23 & 3.70 & 1.000 \\
$22.5-25.5$ & 18 & 0.15 & 0.08 & 0.33 & 0.33 & 0.35 & 0.84 & 1.000 \\
$15.5-28.5$ & 17 & -0.37 & 0.12 & 0.41 & 0.49 & 0.47 & 1.13 & 1.000 \\
$28.5-31.5$ & 15 & -0.42 & 0.17 & 0.55 & 0.67 & 0.63 & 1.35 & 1.000 \\
$31.5-34.5$ & 9 & -0.18 & 0.34 & 0.70 & 1.04 & 0.73 & 1.91 & 0.993 \\
$34.5-37.5$ & 6 & -0.01 & 0.43 & 0.78 & 1.07 & 0.82 & 1.75 & 0.941 \\
$37.5-40.5$ & 4 & -0.53 & 0.50 & 0.74 & 0.99 & 0.70 & 1.98 & 0.793 \\
\hline
\end{tabular}

the mean relative differences between MIPAS and FTIR partial columns are plotted. In Table 3, we report the mean and the standard deviation of these relative differences for each station. The estimated random error on the relative difference of $\mathrm{O}_{3}$ partial columns, combining the ground-based FTIR and MIPAS error budgets, is around $6 \%$ for all the stations except Arrival Heights (7\%). The agreement is good for Kiruna, Jungfraujoch and Wollongong, where there is no statistically significant bias, as can be seen in Table 4 by comparing the mean of the differences to the $3 \sigma$ standard error on the mean $(\mathrm{SEM}=3 \cdot \mathrm{SD} / \sqrt{N})$. A small negative bias of MI$\mathrm{PAS} \mathrm{O}_{3}$ partial column is observed in the comparison with Lauder and Arrival Heights data, which is presently not explained by known contributions to the systematic error budget of the comparison. It must be noticed, however, that a spectral micro-window region at $2100 \mathrm{~cm}^{-1}$ was selected for $\mathrm{O}_{3}$ retrieval at Lauder and Arrival Heights and that a high bias in ozone total column (on average, $4.5 \%$ ) was observed when comparing these results with those obtained from the analysis of Arrival Heights spectra in retrievals employing micro-windows in the $1000 \mathrm{~cm}^{-1}$ region. Differences, of up to $4 \%$, have been observed in retrievals of total column $\mathrm{O}_{3}$ when employing different micro-window spectral regions (Rinsland et al., 1996). This suggests that different choices of spectral micro-windows might explain the different biases observed at different stations.

For all the stations, except Arrival Heights, the standard deviations are within $6 \%$, which is comparable to the estimated random error on the difference. For Arrival Heights, the standard deviation $(8.1 \%)$ is larger than the estimated random error of $7.1 \%$. This is not surprising considering the potential vorticity differences between the observed MIPAS and ground-based air masses that can occur at the pole during the spring. The stronger atmospheric gradient at the poles during spring has not only an effect on the error due to the colloca- tion of air masses; it also increases the horizontal smoothing error as already seen in Sect. 4.1. For comparison with Kiruna measurements, a PV criterion has been applied, so that critical coincidences with relative differences in potential vorticity larger than $15 \%$ have been neglected. For Arrival Heights, tests performed by applying the same criterion resulted in a reduction of the standard deviation, but showed no influence on the bias.

\subsubsection{Results of $\mathrm{O}_{3}$ vertical profiles intercomparison}

Results of the comparison between $\mathrm{O}_{3}$ vertical profiles retrieved from collocated measurements of MIPAS and each of the five ground-based FTIR stations are displayed in Fig. 7. The individual plots show the mean and $1 \sigma$ standard deviation of the relative differences (MIPAS-FTIR) in ozone volume mixing ratio versus pressure. The combined random error associated with the $\mathrm{O}_{3}$ mean difference is represented by the shaded grey area. The $3 \sigma$ standard error on the mean is also reported to facilitate the discussion of the statistical significance of the observed bias. The black solid lines in each plot mark the pressure levels adopted as the lower and upper limits for the calculations of ozone partial columns. We notice in Fig. 7 that, except of Kiruna, the profile differences are oscillating. First, one should remember that the retrieval of vertical profiles from ground-based FTIR solar absorption spectra is an ill-posed problem. Therefore, the inversion needs to be constrained by some a priori information and the inversion results depend on this information and on some additional retrieval parameters, as mentioned in Sect. 4.3.1. The number of degrees of freedom for signal of the retrieved profiles between 12 and $40 \mathrm{~km}$ is only about 3.5. In the present exercise we did not define a common retrieval strategy for the five stations. Only for Lauder and Arrival Heights similar retrieval parameters have been used. This latter fact probably explains why we observe similar 

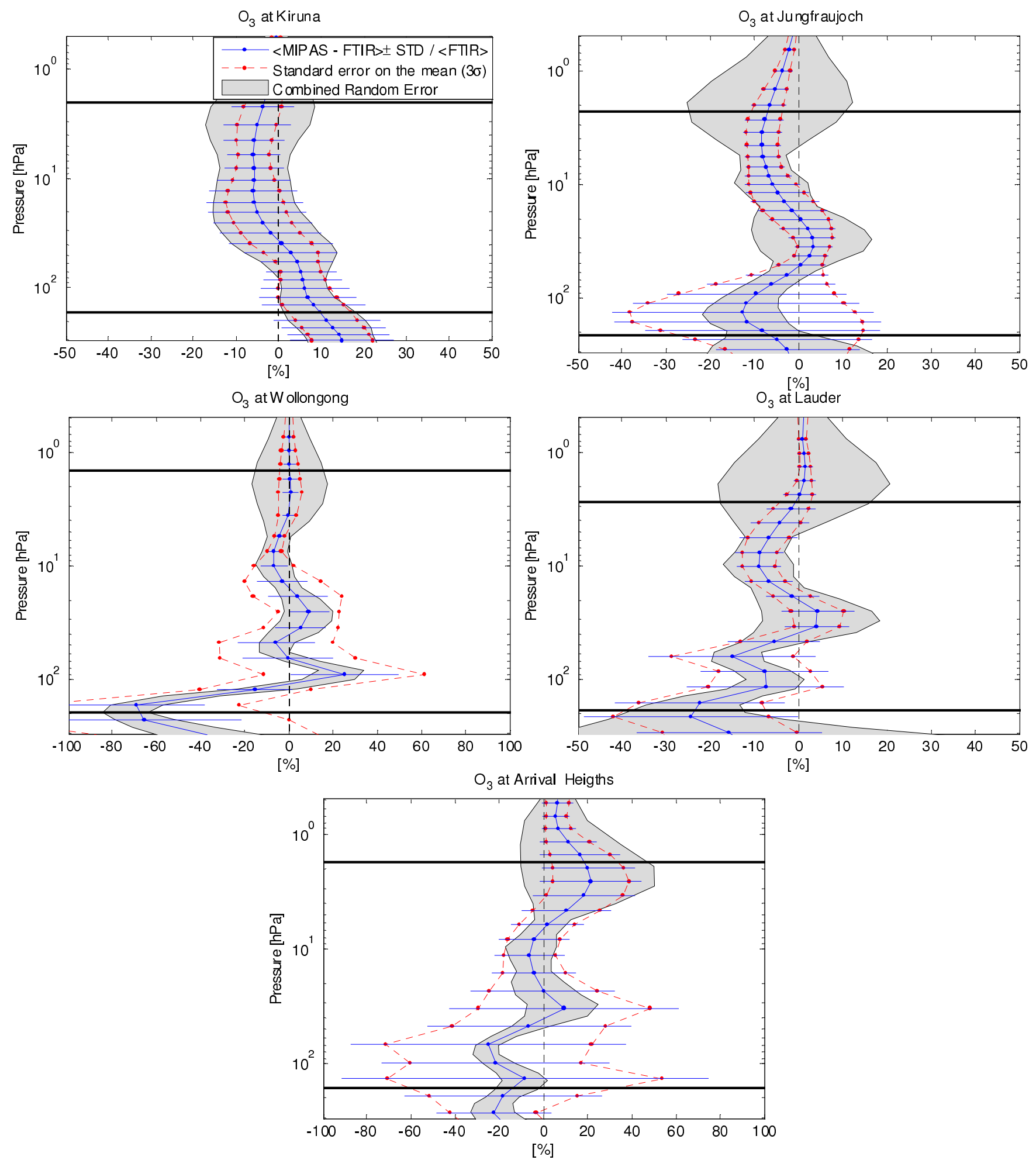

Fig. 7. Statistical means (blue line) and standard deviations (error bars) of the relative differences between MIPAS and FTIR $\mathrm{O}_{3}$ profiles (MIPAS-FTIR)/mean(FTIR), with red dots indicating the $3 \sigma$ standard error on the mean; the shaded areas correspond to the estimated random error on the relative differences. The two black horizontal bars show the pressure ranges used for the partial columns of Table 3 . 
oscillations in the difference profiles at Lauder and Arrival Heights.

The bias is below $10 \%$ at Kiruna in the whole altitude range and usually not significant taking into account the $3 \sigma$ standard error on the mean. The bias is below $10 \%$ for Jungfraujoch, and $15 \%$ for Lauder and Wollongong, at pressures lower than $80 \mathrm{hPa}$. The bias is below $25 \%$ at Arrival Heights in the whole altitude range. The error can be statistically significant at some pressure levels, but, as previously pointed out, the FTIR profiles have to be interpreted with care considering their small degrees of freedom. Regarding the standard deviations, in Fig. 7, we can see that they are roughly in agreement with the combined random error in the middle stratosphere, whereas they are greater than the random error in the lower stratosphere, especially at Arrival Heights where the variability of $\mathrm{O}_{3}$ is expected to be larger.

4.4 Comparison with ozone soundings at individual midlatitude stations

4.4.1 Mid-latitude ozone sounding data and comparison methodology

A statistical analysis of the differences between coincident $\mathrm{O}_{3}$ profiles obtained by MIPAS and by mid-latitude ozone sondes was conducted using the methodology suggested by von Clarmann (2006) for bias and precision determination with matching pairs of measurements. The correlative data considered here consisted of ozone soundings from four sites, that were not included as part of the NDACC data sets selected in Sect. 4.1 and that were provided by.

- the team of University of L'Aquila, that contributed to the MIPAS validation activity by operating a VAISALA balloon sounding system from L'Aquila, Italy $\left(42.38^{\circ} \mathrm{N}, 13.31^{\circ} \mathrm{E}\right)$, with ECC ozone sondes having a precision of $4-12 \%$ in the troposphere and $3-4 \%$ between 100 and $10 \mathrm{hPa}$. The various sources of systematic errors are also altitude dependent and are between $\pm 12 \%$ (Komhyr et al., 1995);

- the team of University of Athens, that performed measurements of the $\mathrm{O}_{3}$ vertical profiles for the location of Athens, Greece $\left(37.60^{\circ} \mathrm{N}, 23.40^{\circ} \mathrm{E}\right)$, by using electrochemical concentration cells (ECC, EN-SCI, Inc.), with corrections based on observations of the total ozone content made with the DOBSON spectrophotometer Nr. 118 installed at the campus of the Athens University;

- the team from Environment Canada and the University of Toronto that obtained $\mathrm{O}_{3}$ profiles in coincidence with MIPAS overpasses from ozone sondes launches in Vanscoy, Canada $\left(52.02^{\circ} \mathrm{N}, 107.05^{\circ} \mathrm{W}\right)$ during the MANTRA (Middle Atmosphere Nitrogen TRend Assessment) balloon campaign in 2002;
- the team of the Institute of Atmospheric Physics of the Chinese Academy of Science, providing results of the ozone soundings from Beijing, China $\left(39.48^{\circ} \mathrm{N}\right.$, $116.28^{\circ} \mathrm{E}$ ) in the period 2002-2004.

Coincident pairs of MIPAS and ozone sondes profiles were selected by applying the baseline criteria of $300 \mathrm{~km}$ and $3 \mathrm{~h}$ for maximum spatial and temporal separation. The comparison was then carried out according to the procedure employed by Ridolfi et al. (2007) to validate MIPAS temperature data against radiosondes measurements from L'Aquila and Potenza. Here below we briefly summarise the basic steps of this approach, while referring to the above mentioned papers for a precise definition of the terminology and validation strategy (von Clarmann, 2006) and for a more detailed explanation of the individual steps of the comparison and of the underlying approximations (Ridolfi et al., 2007):

Vertical smoothing - First of all, we took into account the effects of MIPAS vertical smoothing on the comparison. Correlative ozone data on the same pressure grid of the MIPAS matching profile were obtained, by convolving the original high vertical resolution measurement of the ozone sonde $\mathrm{x}_{\text {ref,hires }}$, with the MIPAS averaging kernels and a priori profile:

$\hat{x}_{\text {ref,smoothed }}=\hat{x}_{0}+A\left(x_{\text {ref,hires }}-x_{0}\right)$

where $\hat{x}_{\text {ref,smoothed }}$ is the smoothed ozone sonde profile, $\mathrm{A}$ is the MIPAS averaging kernel matrix and $x_{0}$ is the a priori profile that was used as the linearisation point for the calculation of the averaging kernels. Both $\mathrm{A}$ and $\mathrm{x}_{0}$ in Eq. (7) were represented over the vertical grid of the matching MIPAS profile by using the shrinking/streching and interpolation methods described in Raspollini et al. (2006). $\hat{x}_{0}$ is the ozone vertical distribution retrieved from MIPAS measurements when the true state of the atmosphere is equal to the a priori profile $\left(x_{\text {ref,hires }}=x_{0}\right)$.

Time and space collocation error - In order to correct for the temporal and spatial mismatch between MIPAS and the ozone sonde measurement of each comparison pair, we followed Eq. (15) in von Clarmann (2006) using assimilated ozone fields from ECMWF:

$\hat{x}_{\text {ref }}=\hat{x}_{\text {ref, smoothed }}+X_{\text {mipas }}^{\text {ecmwf }}-x_{\text {ref }}^{\text {ecmwf }}$

where $x_{\text {ref }}^{\text {ecmwf }}$ is the ECMWF ozone field interpolated at the location and time of the ozone sounding, whilst the term $X_{\text {mipas }}^{\text {ecmwf }}$ is the ECMWF field at the location and time of MIPAS scan (see below).

Horizontal smoothing - in order to include the effects of MIPAS horizontal smoothing, the following expression was used for the calculation of $X_{\text {mipas }}^{\text {ecmwf. }}$

$X_{\text {mipas }}^{\mathrm{ecmwf}}=\operatorname{diag}\left|A x_{\text {mipas }}^{\mathrm{ecmwf}}\right|$ 
where $x_{\text {mipas }}^{\text {ecmwf }}$ is a matrix whose columns represent ECMWF $\mathrm{O}_{3}$ values interpolated at the time of each MIPAS scan and at the points along the MIPAS line of sight that we used to calculate A. A detailed description of the procedure adopted for the calculation of $x_{\text {mipas }}^{\text {ecmwf }}$ can be found in (Ridolfi et al., 2007).

Binning in pressure - MIPAS $\mathrm{O}_{3}$ measurements and ozone sonde corrected values from the selected pairs of coincident profiles were binned in pressure according to the vertical grid defined by MIPAS nominal retrieval levels, so that no more than a single entry per profile could be associated to each pressure bin. This allowed us to discard vertical correlations between values of the individual profiles and to perform a statistical analysis over the binned pairs, in the hypothesis that horizontal correlation between measurements are negligible after debiasing, as suggested in Sect. 8 of the paper by von Clarmann (2006).

Determination of the bias - The bias $b_{i}$ at the $i$-th pressure bin was computed from the expression:

$b_{i}=\frac{1}{n_{i}} \sum_{k=1}^{n_{i}}\left[x_{\text {mipas }, i}(k)-x_{\mathrm{ref}, i}(k)\right]$

with the associated standard deviation given by:

$\sigma_{b_{i}}=\sqrt{\frac{\sum_{k=1}^{n_{i}}\left[x_{\text {mipas }, i}(k)-x_{\mathrm{ref}, i}(k)-b_{i}\right]^{2}}{n_{i}\left(n_{i}-1\right)}}$

where the sums extend over the $n_{i}$ comparison pairs that provide a valid entry for the $i$-th bin. The validation of our current estimate of MIPAS systematic error $\sigma_{\text {mipas,sys, }}$, obtained from the a priori values provided by University of Oxford, requires that the bias $b_{i}$ is equal to zero within its total uncertainty $\sigma_{b_{i}, \text { tot }}$, expressed by:

$\sigma_{b_{i}, \text { tot }}=\sqrt{\sigma_{b_{i}}^{2}+\sigma_{b_{i}, \text { sys }}^{2}}$

where $\sigma_{b_{i}}$,sys is the systematic error on the bias that we evaluated from the root-sum-square of $\sigma_{\text {mipas,sys }}$ and of the ozone sonde systematic error $\sigma_{\text {ref, sys }}$ (associated with the corrected value $x_{r e f}$ and calculated from the estimated bias of the ozone sonde):

$\sigma_{b_{i}, \mathrm{sys}}=\sqrt{\sigma_{\text {mipas }, i, \mathrm{sys}}^{2}+\sigma_{\mathrm{ref}, i, \mathrm{sys}}^{2}}$

Determination of the precision - we calculated the precision $p_{i}$ of the result of the comparison at each pressure bin:

$p_{i}=\sigma_{b_{i}} \sqrt{n_{i}}$

and compared it with the random error of the difference $d_{i}(k)=x_{\text {mipas }, i}(k)-x_{\text {ref }, i}(k)$ given by:

$\sigma_{d_{i}, \text { rnd }}=\sqrt{\sigma_{\text {mipas }, i, \text { rnd }}^{2}+\sigma_{\text {ref }, i, \text { rnd }}^{2}}$ where $\sigma_{\text {mipas, } i \text {,rnd }}$ and $\sigma_{\text {ref, } i, \text { rnd }}$ are the random errors of MIPAS and of the ozone sonde respectively. In order to validate MIPAS random error, we must verify that the precision $p_{i}$ is consistent with the random error of the comparison $\sigma_{d_{i} \text {,rnd }}$.

\subsubsection{Results of the comparison}

The statistical analysis described in Sect. 4.4.1 was applied to a validation data set consisting of 22 matching pairs of MIPAS and ozone sonde profiles. The results obtained from the application of Eqs. (7) through (15) are presented in Table 4 , where we report for each altitude bin the bias $b_{i}$ and its standard deviation $\sigma_{b_{i}}$, the systematic error $\sigma_{b_{i}, \text { sys }}$ on the bias, the precision $p_{i}$ and the random error $\sigma_{d_{i}, \text { rnd }}$ on the difference $d_{i}$.

The quantifiers $\chi_{R, i}^{2}$ and $L_{i}$ in the last two columns of Table 4 characterise the significance levels of these results. The reduced chi-square $\chi_{R, i}^{2}$, with expectation value equal to 1.0 , is defined by:

$\chi_{R, i}^{2}=\frac{1}{\left(n_{i}-1\right)} \sum_{k=1}^{n_{i}} \frac{\left[x_{\text {mipas }, i}(k)-x_{\text {ref }, i}(k)-b_{i}\right]^{2}}{\sigma_{d_{i}, \text { rnd }}^{2}}$

and tests the consistency of the differences $d_{i}(k)$ with their expectation value $b_{i}$ within their random error $\sigma_{d_{i} \text {, rnd }} . L_{i}$ is the probability that a new comparison might yield a smaller value of the reduced chi-square $\chi_{R, i}^{2}$.

In the left panel of Fig. 8, the vertical profile of the bias $b_{i}$ is shown as a function of the approximate center altitude of each pressure bin (solid line), with error bars corresponding to the $95 \%$ confidence interval derived from the t-statistics for each altitude bin (see Ridolfi et al., 2007, and reference therein). For comparison, the curves $\pm \sigma_{b_{i}}$,sys of the systematic error of the bias (dashed lines) are overplotted. A statistically significant bias (i.e. a bias that is different from zero beyond the $95 \%$ confidence interval defined above) is found for most of the altitude bins. This bias is, however, consistently lower than the combined systematic error of the comparison, as expected to validate the current estimate of MIPAS systematic uncertainties.

In the right panel of Fig. 8, the precision $p_{i}$ (solid line) is compared with the random error $\sigma_{d_{i}}$,nd on the difference $d_{i}$ (dashed line); here, the error bars represent the $95 \%$ confidence interval computed from the chi square statistics of each altitude bin. We observe a reasonable agreement between the two curves over the whole range of the comparison, with significant discrepancies found for the altitude bins at 21, 15 and $12 \mathrm{~km}$, where in any case the precision value never exceeds the combined random error by a factor larger than 2 . 

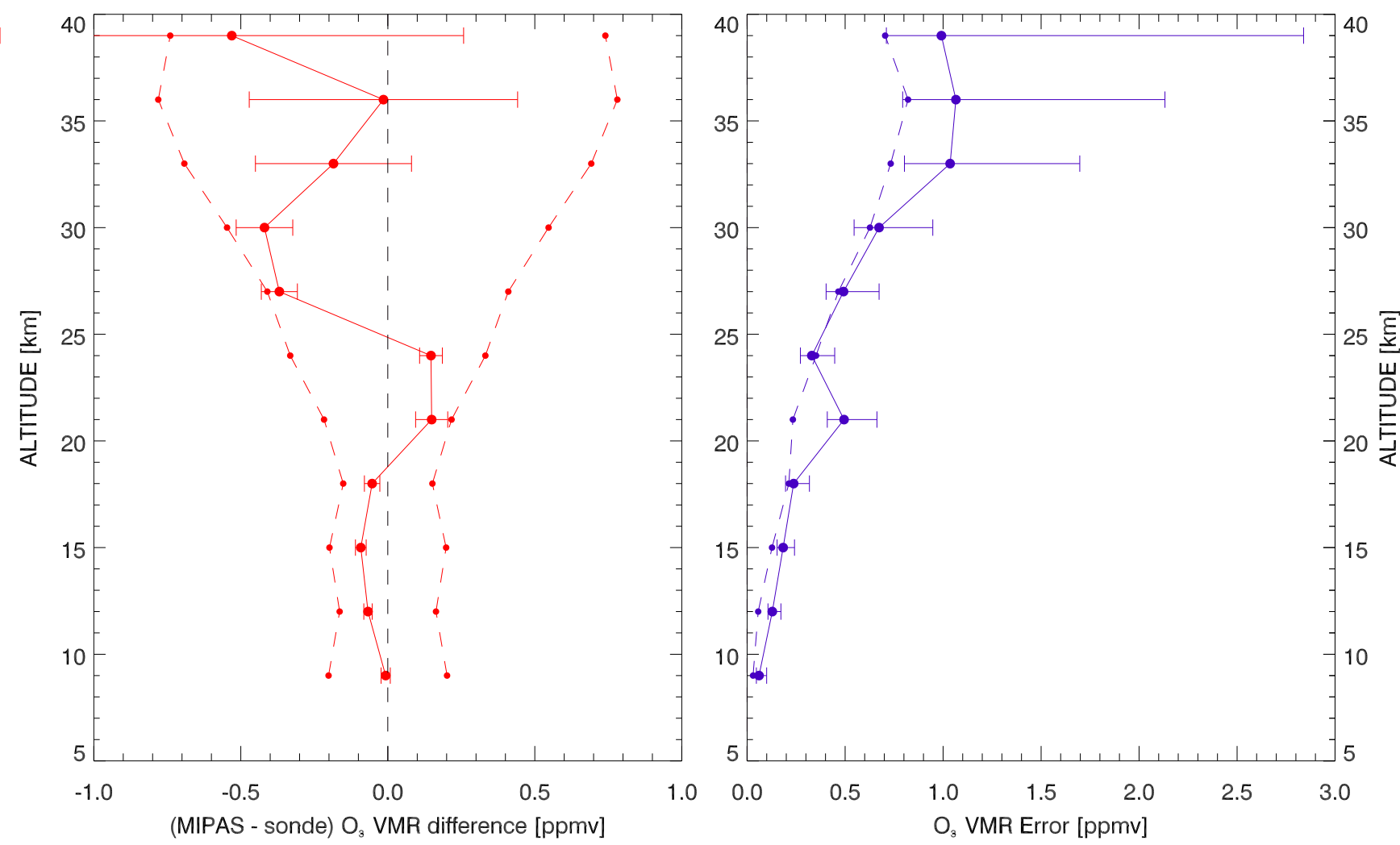

Fig. 8. Results of the statistical analysis for MIPAS $\mathrm{O}_{3}$ bias and precision determination by comparison with matching measurements from mid-latitude ozone soundings. See text in Sect. 4.4.1 for explanations.

\section{Comparison with stratospheric balloon and aircraft measurements}

\subsection{MIPAS-B2}

\subsubsection{MIPAS-B2 data and comparison methodology}

A balloon-borne version of the MIPAS-ENVISAT instrument, MIPAS-B2, operated by a team of Forschungszentrum Karlsruhe (IMK-FZK), was flown during mid-latitude (Aire sur l'Adour, France, 24 September 2002) and Arctic (Kiruna, Sweden, 20-21 March 2003 and 3 July 2003) validation flights and obtained a set of correlative data in very good spatial and temporal coincidence with the satellite measurements (Oelhaf et al., 2003). The high quality of the collocations, combined with several features of the MIPASB2 instrument configuration that are closely matching those of MIPAS-ENVISAT (spectral coverage, spectral resolution, sensitivity and radiometric accuracy, etc.), offer an unique opportunity for the validation of the vertical profiles of ozone and other MIPAS target species. A detailed description of the MIPAS-B2 spectrometer is given in Friedl-Vallon et al. (2004). The limb-sounding observations acquired during the ENVISAT validation flights were processed using a least squares fitting algorithm based on the forward model $\mathrm{KO}$ -
PRA (Karlsruhe Optimized and Precise Radiative transfer Algorithm) together with a Tikhonov-Phillips regularisation procedure (Höpfner et al., 2002). A total of 34 ozone microwindows have been chosen in the mid-infrared spectral region to infer vertical ozone profiles from the measured spectra. The resulting vertical resolution of the profiles lies typically between 2 and $3 \mathrm{~km}$ and is therefore comparable to MIPAS. The error estimation includes random noise, temperature errors, line of sight inaccuracies, and spectroscopic data errors. A detailed description of the level 2 MIPAS-B2 data analysis is given in Wetzel et al. (2006) and references therein. Table 5 provides an overview of the coincidences used in this paper for the comparison between MIPAS-B2 and MIPAS-ENVISAT ozone measurements. For MIPAS-B2 flights 11 and 13, a close to perfect coincidence with MIPASENVISAT could be reached in time and space. For flight 14, this is true only for the coincidence in space while the time difference amounts several hours. However, both observations were carried out in the same air mass. We used exclusively MIPAS-ENVISAT ozone data version 4.61 for our comparison. 

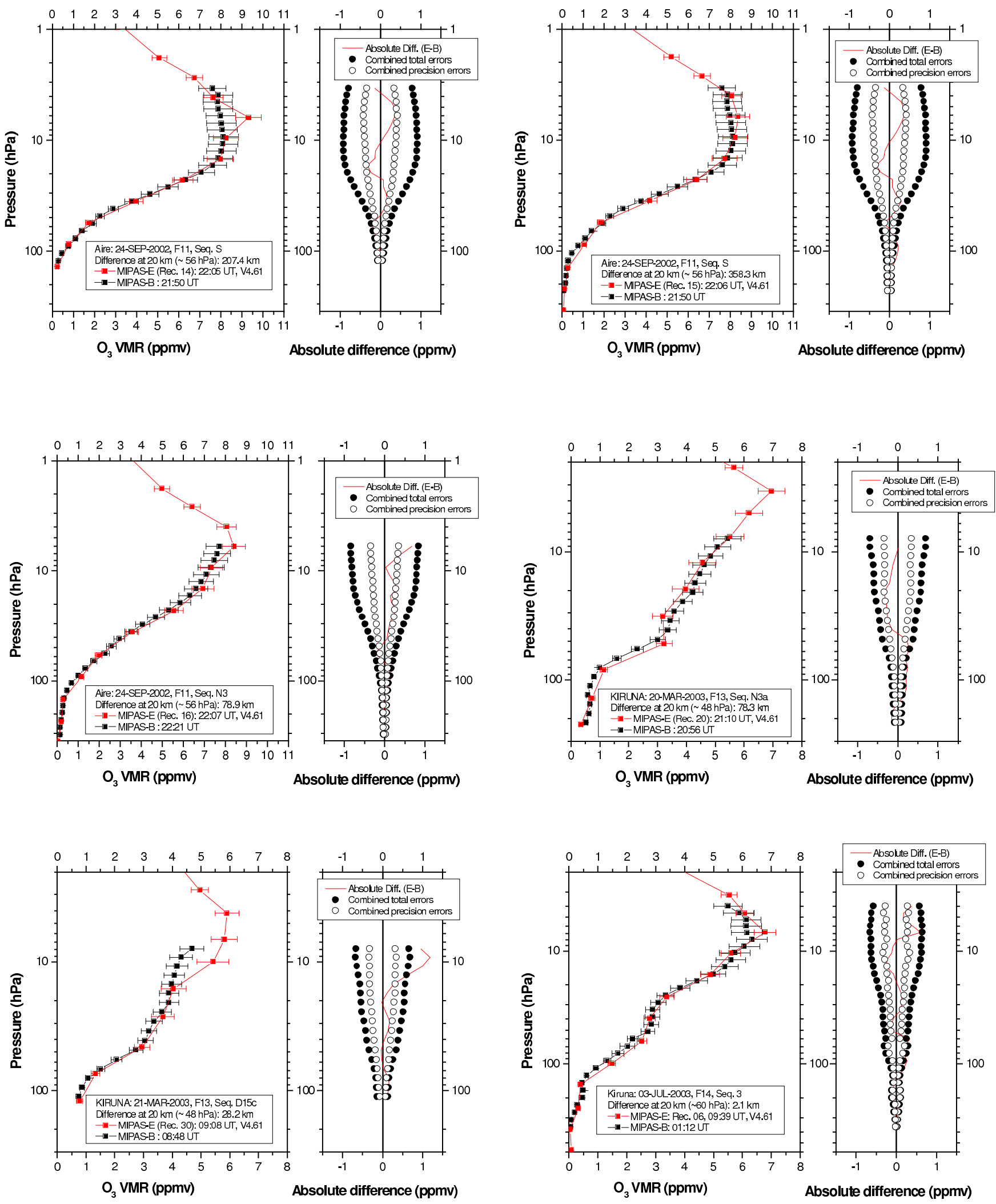

Fig. 9. Results of the comparison between coincident MIPAS-ENVISAT and MIPAS-B2 ozone measurements at mid-latitude and in the Arctic region. 
Table 5. Summary of the coincidences between MIPAS-ENVISAT and MIPAS-B2. Temporal and spatial separation between MIPASENVISAT and MIPAS-B2 scans for each of the available comparison pairs. The distance between the coincident scans is calculated at $20 \mathrm{~km}$.

\begin{tabular}{llcccc}
\hline Location & Date & $\begin{array}{c}\text { MIPAS-ENVISAT } \\
\text { [orbit, scan] }\end{array}$ & $\begin{array}{c}\text { MIPAS-B2 } \\
\text { [flight, scan] }\end{array}$ & $\begin{array}{c}\text { Distance } \\
{[\mathrm{km}]}\end{array}$ & $\begin{array}{c}\text { Time diff. } \\
{[\mathrm{min}]}\end{array}$ \\
\hline Aire sur l'Adour & 24 Sep 2002 & 2975, scan 14 & F11, scan S & 207 & 14 \\
Aire sur l'Adour & 24 Sep 2002 & 2975, scan 15 & F11, scan S & 358 & 15 \\
Aire sur l'Adour & 24 Sep 2002 & 2975, scan 16 & F11, scan N3 & 79 & 14 \\
Kiruna & 20 March 2003 & 5508, scan 20 & F13, scan N3a & 78 & 14 \\
Kiruna & 21 March 2003 & 5515, scan 30 & F13, scan D15c & 28 & 20 \\
Kiruna & 3 July 2003 & 7004, scan 6 & F14, scan 3 & 2 & 506 \\
\hline
\end{tabular}

\subsubsection{Results}

In Fig. 9, we present the results of the comparison between all the available pairs of $\mathrm{O}_{3}$ matching profiles listed in Table 5. Each panel shows on the left side the MIPASENVISAT and MIPAS-B2 ozone VMR profiles, retrieved from the coincident limb scanning sequences and on the right their absolute difference with over-plotted combined random and total errors. The MIPAS-B2 measurements have been cross checked with ozone sondes launched shortly after the launch of the MIPAS-B2 instrument. These comparisons have shown a general good agreement between MIPAS-B2 and the sondes (see, e.g., Wetzel et al., 2006). In general, an excellent agreement is obtained both for the mid-latitude as well as for the high latitude measurements over the whole range of vertical overlap, with significant discrepancies occasionally observed at the lowest levels (below $\sim 100 \mathrm{hPa}$ ) or in proximity of the peak of the $\mathrm{O}_{3}$ vertical distribution (above $\sim 10 \mathrm{hPa}$, where MIPAS-ENVISAT overestimates the ozone content). The absolute difference between MIPASENVISAT and MIPAS-B2 ozone values is mostly within the combined total error, often remaining below its random component. An overall statistics of the comparison, showing mean profiles of the $\mathrm{O}_{3}$ absolute difference and corresponding total, random and systematic errors is displayed in Fig. 10. Average values have been calculated over all the pairs of coincident profiles: the mean absolute difference is shown (solid red line), along with the standard error of the mean (error bars). A bias between MIPAS-ENVISAT and MIPAS-B2 ozone values, that is marginally higher than the combined systematic errors, is only observed, at some pressure level, below $100 \mathrm{hPa}$. Moreover, the standard deviation never exceeds the combined random error value, except for a few levels above $10 \mathrm{hPa}$.

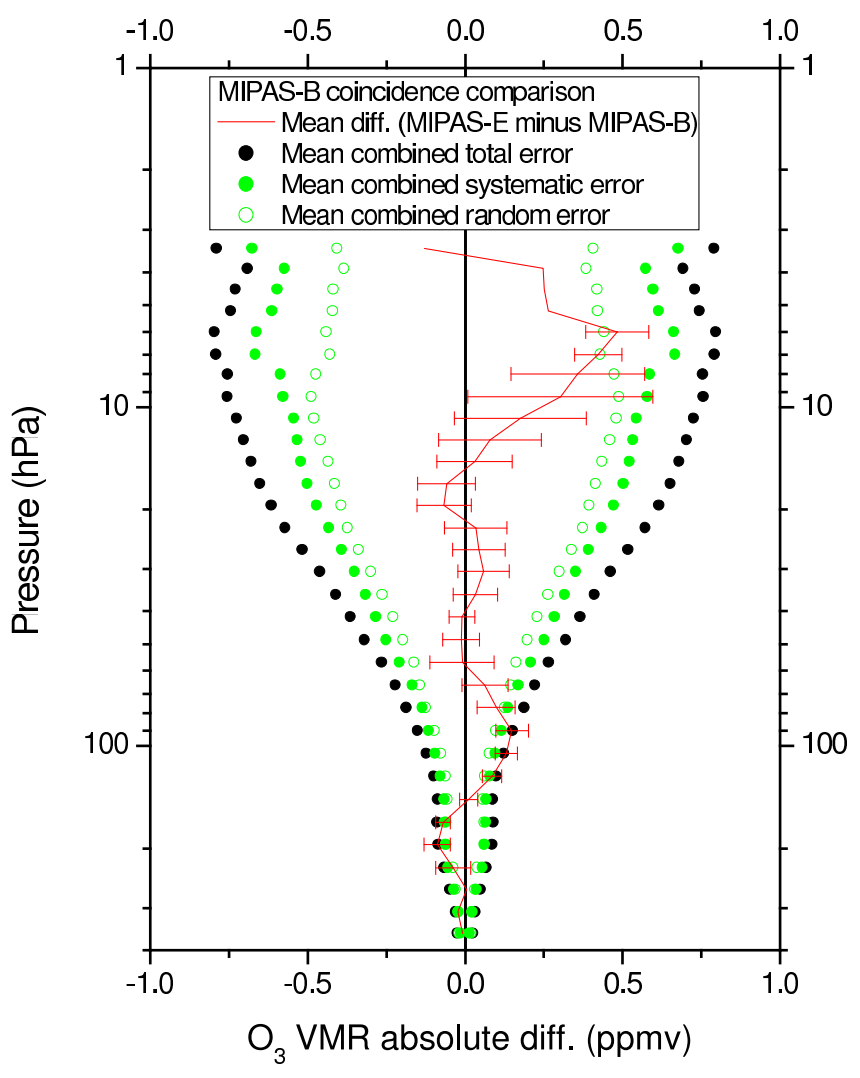

Fig. 10. Absolute difference between MIPAS-ENVISAT and MIPAS-B2 ozone volume mixing ratio averaged over all the available collocations.

\subsection{FIRS-2 and IBEX}

5.2.1 Balloon-borne FT-FIR measurements and comparison methodology

Two balloon-borne high resolution Fourier transform FarInfrared (FT-FIR) spectrometers were deployed in field campaigns for the validation of the ENVISAT chemistry payload: the Far InfraRed Spectrometer (FIRS-2) of the 

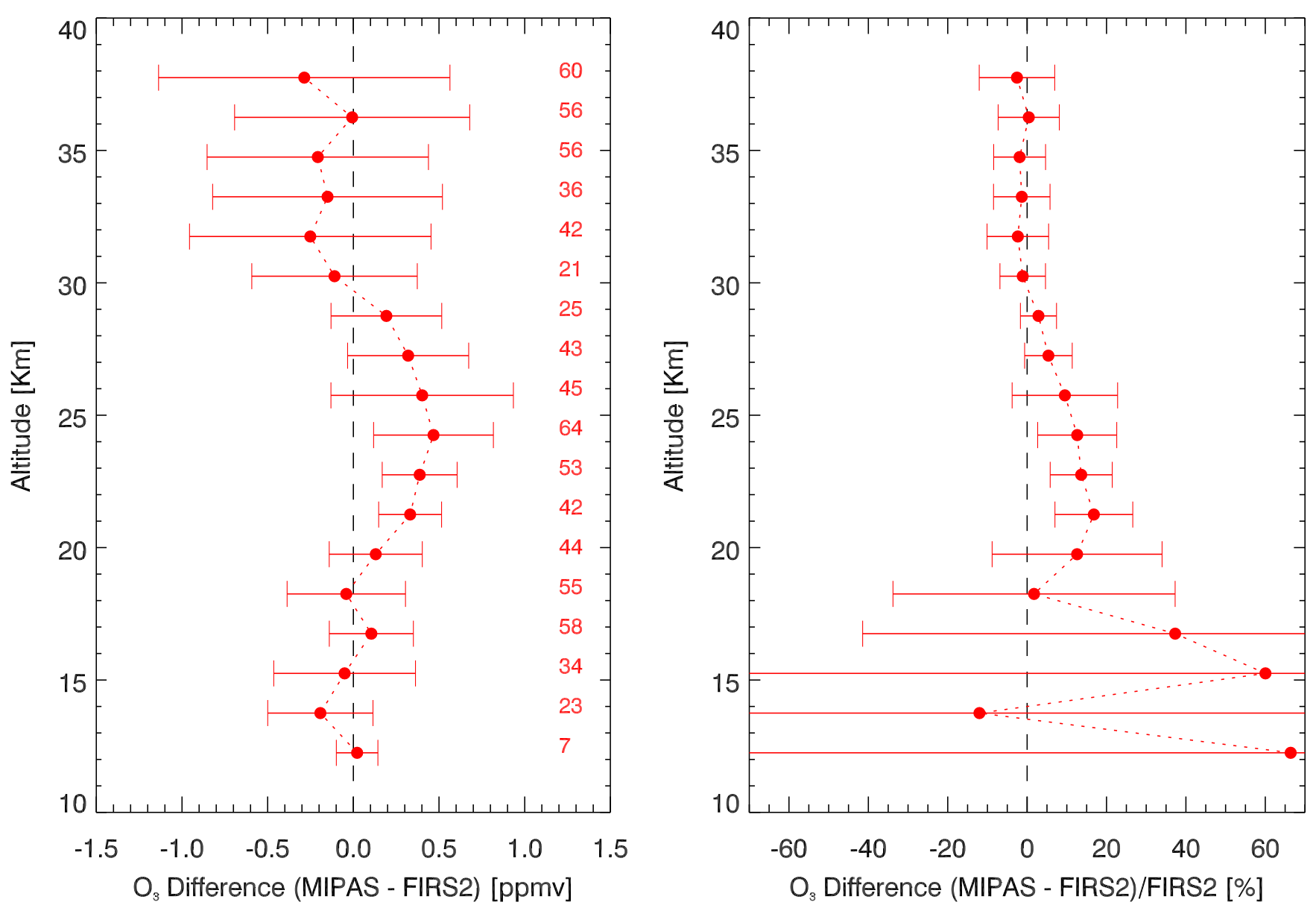

Fig. 11. Comparison between MIPAS v4.61 and FIRS-2 (30 October 2002 and 19/20 September 2003) ozone measurements. Mean absolute and relative differences between MIPAS and FIRS-2 $\mathrm{O}_{3}$ VMR reconstructed using trajectory analysis and averaged in altitude bins of $\Delta \mathrm{h}=1.5 \mathrm{~km}$ are shown on the left and right panel, respectively. Error bars represent $1 \sigma$ standard deviations. The number of elements per altitude bin is also displayed.

Harvard-Smithsonian Center for Astrophysics, Cambridge, MA, USA (Johnson et al., 1995) and the Infrared Balloon Experiment (IBEX) operated by the Institute for Applied Physics "Nello Carrara" (IFAC-CNR), Firenze, Italy (Bianchini et al., 2006).The FIRS-2 and IBEX instruments are capable of retrieving the vertical distributions of a number of trace gases from float altitude (approximately 35$40 \mathrm{~km})$ down to the tropopause, with vertical resolutions of $\sim 2-3 \mathrm{~km}$, from limb sounding observations of the atmospheric emission spectrum. FIRS-2 measurements cover the spectral region of 80 to $1220 \mathrm{~cm}^{-1}$, while IBEX operates in photon noise limited conditions and acquires spectra in narrow bands (typically $2 \mathrm{~cm}^{-1}$ wide) within the interval $10-250 \mathrm{~cm}^{-1}$. FIRS- 2 observations of $\mathrm{O}_{3}$ concentrations use transitions both in the rotational band between 80 and $130 \mathrm{~cm}^{-1}$ and the $\nu_{2}$ band between 730 and $800 \mathrm{~cm}^{-1}$. The former lend the most weight above $25 \mathrm{~km}$, while the latter contributes almost entirely below $20 \mathrm{~km}$. In this section we compare MIPAS $\mathrm{O}_{3}$ data v4.61 with the ozone profiles re- trieved from FIRS-2 measurements during flights from the National Scientific Balloon Facility balloon launch site at Fort Sumner, NM, USA (Lat. $34^{\circ} \mathrm{N}$, Lon. $104^{\circ} \mathrm{W}$ ) on 20 October 2002 and on 19-20 July 2003 and with those obtained by IBEX in the trans-Mediterranean flight from Trapani, Italy (Lat. $38^{\circ} \mathrm{N}$, Lon. $12^{\circ} \mathrm{E}$ ) to Spain on 29-30 July 2002. In both cases, useful coincidences between MIPAS observations and measurements of the two FT-FIR spectrometers could be obtained only after substantial relaxation of the spatial-temporal matching criteria, as shown for instance in previous analyses carried out for MIPAS $\mathrm{O}_{3}$ validation (Cortesi et al., 2004). No matching pair is available for comparison, if we apply our baseline criteria for maximum temporal and spatial separation. As a consequence, we decided in the current work to exploit the two sets of correlative balloon data, using a Trajectory Hunting Technique (THT) (Danilin et al., 2002) that launches backward and forward trajectories from the locations of measurements and finds air parcels sampled at least twice within a prescribed 

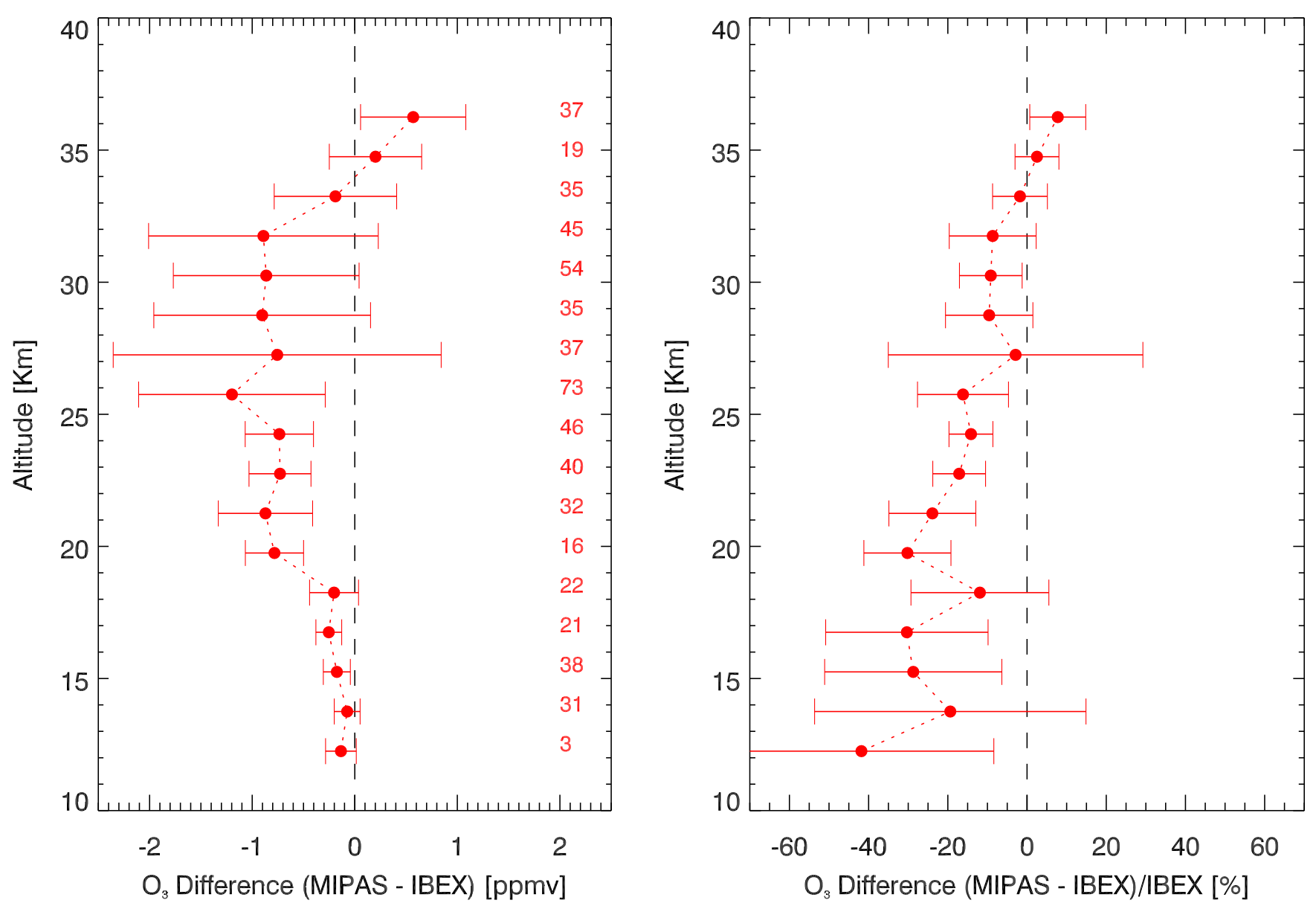

Fig. 12. Comparison between MIPAS v4.61 and IBEX (29-30 July 2002) ozone measurements. Mean absolute and relative differences between MIPAS and IBEX $\mathrm{O}_{3}$ VMR are plotted as in Fig. 11.

match criterion during the course of several days. A similar procedure was applied for comparison of MIPAS ozone profiles with both FIRS-2 and IBEX measurements, relying on isentropic trajectories calculated using the University of L'Aquila Global Trajectory Model (Redaelli, 1997; Dragani et al., 2002), on the base of ECMWF meteorological fields. Four days backward and forward isentropic trajectories, departing from the geolocations of FIRS-2 and IBEX retrieved profiles were calculated and MIPAS $\mathrm{O}_{3}$ profiles at locations within 2 degrees in longitude, 2 degrees in latitude and $2 \mathrm{~h}$ in time along these trajectories were identified and vertically interpolated in Potential Temperature, to obtain the $\mathrm{O}_{3}$ volume mixing ratio value to be compared with the corresponding FT-FIR measurements. The resulting comparison pairs were then binned by altitude, in steps of $\Delta \mathrm{h}=1.5 \mathrm{~km}$ and averaged, and $1 \sigma$ RMS values of the differences (MIPAS - FT-FIR data) in $\mathrm{O}_{3}$ volume mixing ratios were calculated. Preliminary results of a so called "self-hunting" analyses of MIPAS data that matches satellite observation with themselves, providing a test for the precision of the instrument products and the quality of the calculated trajectories and thus assessing the noise in the technique and providing estimates to its possible extension to multi-platform comparison for the selected time period, can be found in Taddei et al. (2006).

\subsubsection{Results of the comparison with FIRS- $2 \mathrm{O}_{3}$ data}

Results of the comparison between MIPAS $\mathrm{O}_{3}$ measurements and data from the FIRS-2 flights on 20 October 2002 and on 19-20 July 2003 are shown in Fig. 11. Mean absolute and relative differences between MIPAS v4.61 and FIRS-2 $\mathrm{O}_{3}$ VMR calculated with THT and binned by altitude values $(\Delta \mathrm{h}=1.5 \mathrm{~km})$ are displayed on the left and right panel, respectively; $1 \sigma$ error bars and total number of reconstructed data in each bin are also indicated. Very good agreement within $1 \sigma$ error bars, with relative differences within $\pm 10 \%$, is found down to about $24 \mathrm{~km}$. At lower levels the mean relative difference increases, mainly resulting from the small values of ozone mixing ratio at these altitudes, although the absolute difference remains reasonably small. 


\section{3_03m_4678_6}
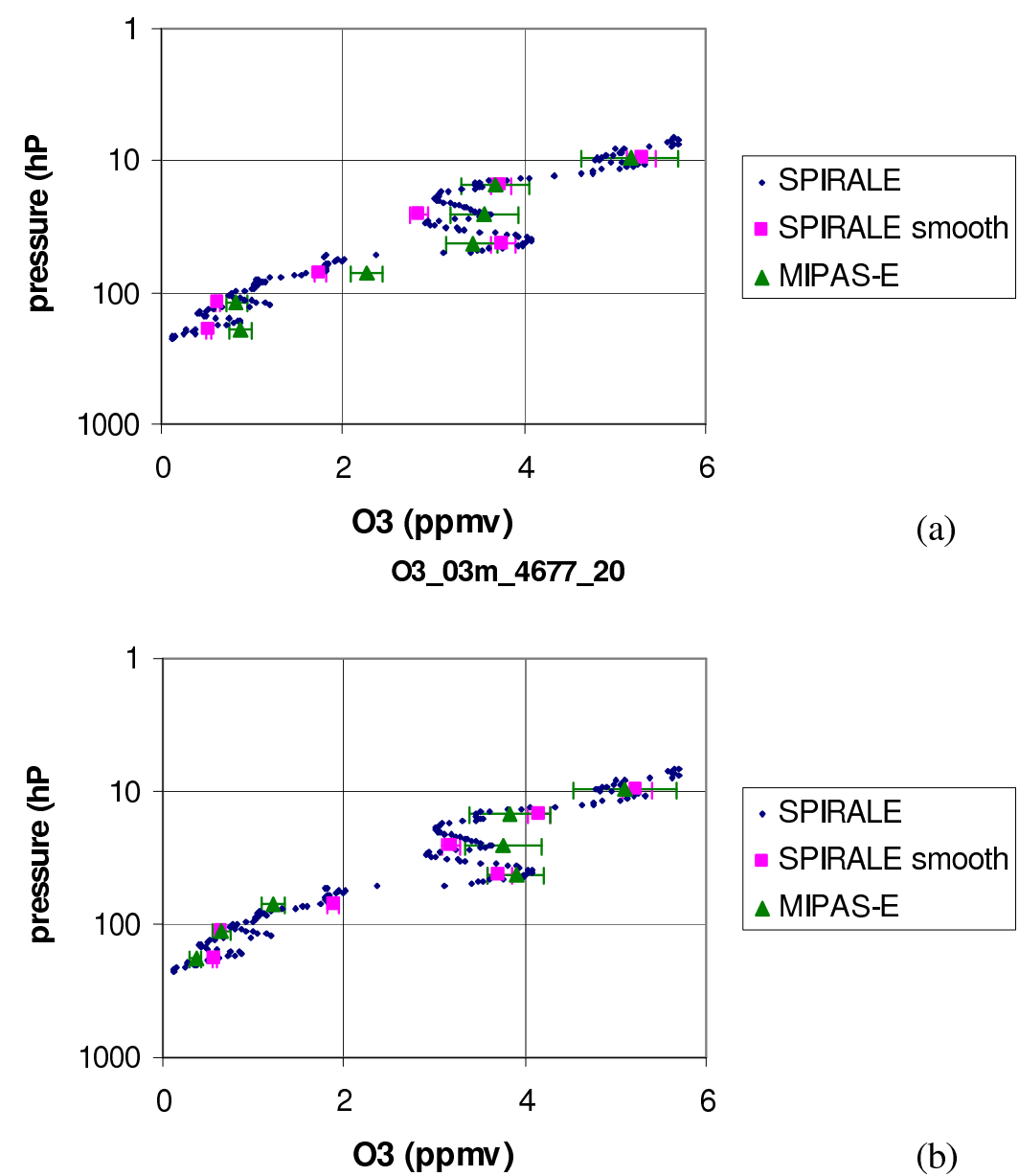

Fig. 13. Comparison of MIPAS $\mathrm{O}_{3}$ profiles from orbit 4678, scan 6 (a) and from orbit 4677, scan 20 (b) with the in situ profiles acquired during the SPIRALE flight.

\subsubsection{Results of the comparison with IBEX O$_{3}$ data}

Mean absolute and relative differences between MIPAS v4.61 and IBEX $\mathrm{O}_{3}$ data obtained during the transMediterranean flight of 29-30 July 2002 are presented in Fig. 12. MIPAS measurements agree reasonably well with the balloon profile down to approximately $27 \mathrm{~km}$ (mean relative differences within $\pm 10 \%$ ). At lower altitudes, MIPAS appears to underestimate the ozone content by up to $30-40 \%$ with respect to IBEX

\subsection{SPIRALE}

\subsubsection{SPIRALE data and comparison methodology}

SPIRALE (SPectroscopie InfraRouge par Absorption de Lasers Embarqués) is a balloon-borne instrument operated by LPCE-CNRS (Laboratoire de Physique et Chimie de
l'Environment, Orléans, France) and employing the technique of tunable diode laser absorption spectroscopy to perform simultaneous in situ measurements of several minor atmospheric constituents (Moreau et al., 2005). The instrument, contributed to the ESABC programme with a midlatitude and with a high latitude flight, carried out, respectively, from Aire sur l'Adour on 2 October 2002 and from Kiruna on 21 January 2003 to measure $\mathrm{O}_{3}, \mathrm{CH}_{4}, \mathrm{~N}_{2} \mathrm{O}, \mathrm{CO}$, $\mathrm{NO}, \mathrm{NO}_{2}, \mathrm{HNO}_{3}$ and $\mathrm{HCl}$ VMR profiles. MIPAS ozone data versions 4.61 and 4.62 have been compared with SPIRALE $\mathrm{O}_{3}$ profiles obtained during the descent phases of the October 2002 flight and during the ascent phase of the January 2003 flight. For the Arctic flight, direct coincidences with two MIPAS scans (orbit 4677, scan 20, v4.62 and orbit 4678, scan 6, v4.61), whose temporal separation from the SPIRALE measurements satisfied the baseline matching criterion $\Delta t<3 \mathrm{~h}$, were available. The location of this flight 
was close to the vortex edge and although the spatial separation does not satisfy the baseline criterion $\Delta s<300 \mathrm{~km}$ (300-500 km for scan 20, 600-800 km for scan 6), MIPAS and SPIRALE measurements were made at locations close in PV (5 to $25 \%$ for scan 20,5 to $35 \%$ for scan 6 ). Direct coincidences were not possible in the case of the midlatitude flight. For the latter, the comparison was carried out, by means of trajectory analysis with MIPAS profiles from orbit 3019, scans 14 and 15 (v4.61) on 27 September at 23:52:50 UT and 23:54:11 UT, respectively.

Estimations of the uncertainties on SPIRALE measurements have been previously described in detail (Moreau et al., 2005). In brief, random errors mainly come from the signal-to-noise ratio and from fluctuations of the laser emission signal, which have more important effects at lower altitudes $(6 \%$ below $18 \mathrm{~km})$ than at higher altitudes $(2 \%)$. Systematic errors originate from the laser line width (increasing from $1 \%$ at lower altitudes to $3 \%$ at higher altitudes) and the spectroscopic parameters which are well determined $(5 \%)$ at the used wave numbers $\left(2081.7-2082.5 \mathrm{~cm}^{-1}\right)$. Adding quadratically the random errors and the systematic errors results in total uncertainties of $6 \%$ at altitudes above $18 \mathrm{~km}$ $(p<80 \mathrm{hPa})$ and $8 \%$ below $18 \mathrm{~km}(>80 \mathrm{hPa})$. MIPAS systematic errors have been computed by the Oxford University: Polar winter night time conditions and day and night mid-latitude conditions have been used, respectively, for the Arctic case and the mid-latitude case.

\subsubsection{Results of direct comparison}

In Fig. 13, the $\mathrm{O}_{3}$ profile obtained by SPIRALE during the Kiruna 2003 flight is compared with coincident MIPAS $\mathrm{O}_{3}$ profiles from orbit 4678, scan 6 and from orbit 4677, scan 20. Both the SPIRALE original high vertical resolution profile and its smoothed version after the application of MIPAS averaging kernels are displayed. In general, a good agreement is observed in both cases, with MIPAS $\mathrm{O}_{3}$ data from orbit 4677, scan 20 mostly matching SPIRALE smoothed values within the error bars (with the only notable exception of the level above $100 \mathrm{hPa}$, where MIPAS $\mathrm{O}_{3}$ is closer to SPIRALE raw data). Slightly larger discrepancies are found in the comparison with MIPAS orbit 4678, scan 6, possibly due to increased comparison errors introduced by the greater spatial separation (600-800 km, PV differences up to $35 \%$ ).

\subsubsection{Results of trajectory-based comparison}

The feasibility of using long trajectories for MIPAS validation by comparison with data of the SPIRALE flight on 2 October 2002 at Aire sur l'Adour was investigated by means of a PV analysis of sets of trajectories ending close to each point of the SPIRALE profile. For each point of the SPIRALE profile (with potential temperature steps of $\Delta \Theta=25 \mathrm{~K}$ ), seven backward trajectories have been calculated:
- the trajectory ending at the point of the SPIRALE profile;

- four trajectories ending close to this point on the same isentropic surface $\left( \pm 0.5^{\circ}\right.$ in latitude and $\pm 0.5^{\circ}$ in longitude);

- two trajectories ending $\pm 6.25 \mathrm{~K}$ (about $250 \mathrm{~m}$ ) above and below the point of the SPIRALE profile.

For each trajectory, PV at 00:00 UT on 28 September has then been computed, along with mean PV and standard deviation for each set of 7 trajectories. Finally, we calculated the difference between the mean value and the PV at the end of the trajectories (SPIRALE profile) as a function of potential temperature.

We found that between $400 \mathrm{~K}$ and $600 \mathrm{~K}$ and between $700 \mathrm{~K}$ and $900 \mathrm{~K}$, standard deviation is very low $(<2-3 \%)$ and PV is conserved relatively well on the 4.5 days trajectories (the differences are less than $10 \%$ ). This is not the case below $400 \mathrm{~K}$, between $600 \mathrm{~K}$ and $700 \mathrm{~K}$ and above $900 \mathrm{~K}$. Air masses mixing probably occurs on these isentropic surfaces. SPIRALE data are therefore no longer representative of the measurements made by MIPAS on the same isentropic surface. Moreover, by comparing the PV values of SPIRALE and MIPAS profiles, we found that PV differences are lower than $10 \%$ between $400 \mathrm{~K}$ and $600 \mathrm{~K}$ for both profiles and above $700 \mathrm{~K}$ for profile 14 . We conclude, therefore, that SPIRALE data may be used to validate:

- MIPAS profile 14 of orbit 3019 on the potential surfaces between $400 \mathrm{~K}$ and $600 \mathrm{~K}$ and between $700 \mathrm{~K}$ and $900 \mathrm{~K}$, which corresponds to the retrieval nominal MIPAS altitudes 18, 21, 24, 30 and $33 \mathrm{~km}$;

- MIPAS profile 15 of orbit 3019 on the potential surfaces between $400 \mathrm{~K}$ and $600 \mathrm{~K}$, which corresponds to the nominal MIPAS altitudes: 18,21 and $24 \mathrm{~km}$

The results of the comparison are shown in Fig. 14, highlighting an almost perfect overlapping between MIPAS and SPIRALE $\mathrm{O}_{3}$ measurements.

\subsection{MIPAS-STR, SAFIRE-A and FOZAN on-board the M- 55 Geophysica aircraft}

\subsubsection{Ozone data of the M-55 Geophysica remote-sensing and in situ payload}

Simultaneous measurements of the ozone vertical distribution in strict coincidence with MIPAS-ENVISAT overpasses were obtained by the in situ and remote-sensing instruments of the M-55 Geophysica high altitude aircraft during dedicated flights at mid-latitude (Forlí, Italy, July and October 2002) and in the Arctic region (Kiruna, Sweden, February-March 2003), aiming at the validation of the satellite chemistry sensors, as reported in details by Cortesi et al. 
03_03m_4678_6
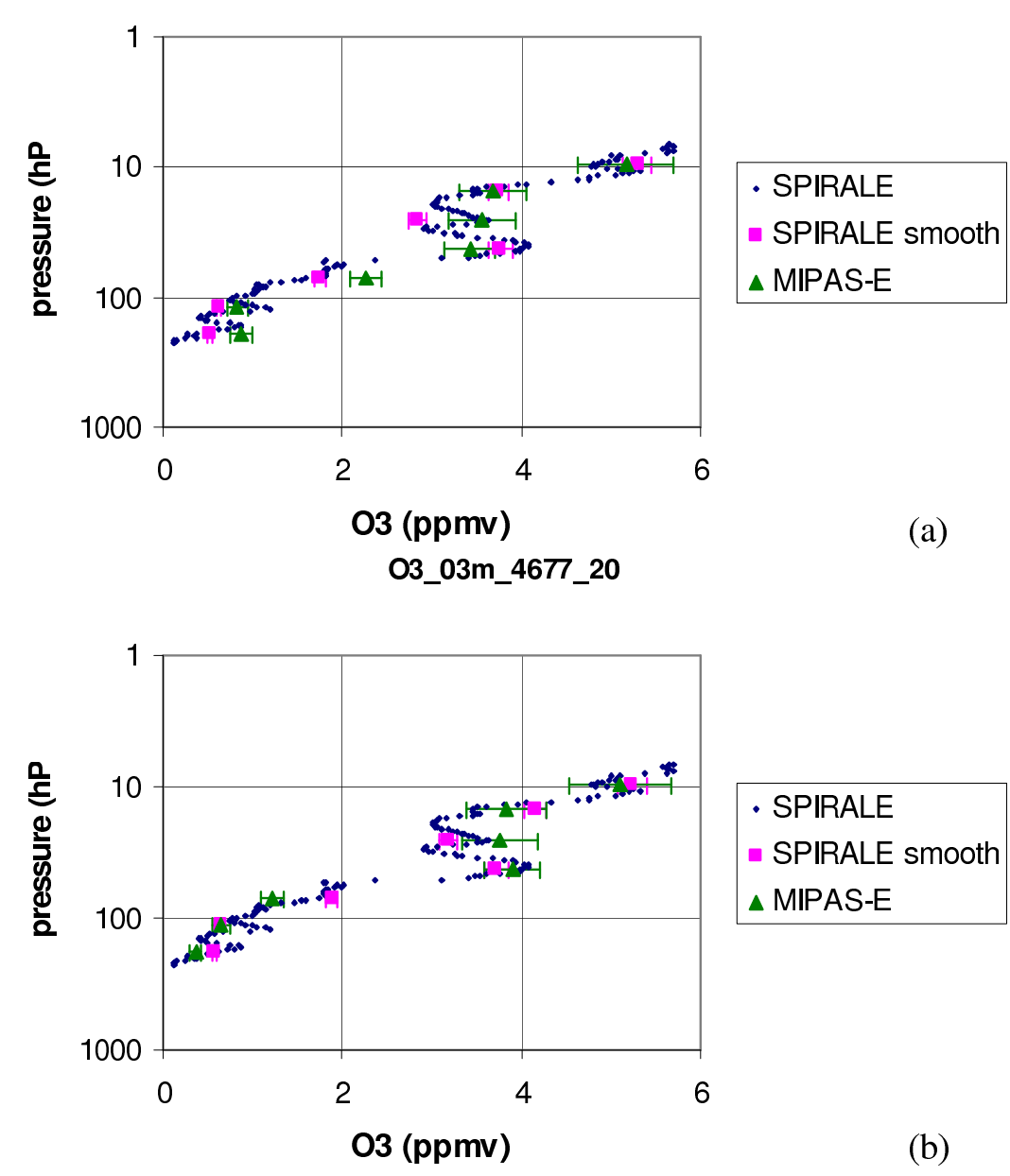

(a)

Fig. 14. Comparison of MIPAS $\mathrm{O}_{3}$ profiles orbit 3019, scan 14 (a) and scan 15 (b) with SPIRALE data.

(2004). The remote-sensing payload embarked aboard the M-55 stratospheric platform during these missions consisted of two FT spectrometers operating in limb sounding geometry and capable of retrieving the ozone VMR profile from the upper troposphere up to the flight altitude and the total ozone column above: MIPAS-STR (MIPAS STRatospheric aircraft, FZK-IMK, Karlsruhe, Germany) and SAFIRE-A (Spectroscopy of the Atmosphere by using Far-InfraRed Emission - Airborne, IFAC-CNR, Firenze, Italy). MIPAS-STR is an aircraft version of the satellite spectrometer and operates in the middle infrared spectral region with similar characteristics and performances (Piesch et al., 1996). SAFIRE-A is a high-resolution FT instrument, performing limb emission measurements in narrow bands $\left(\Delta \mathrm{s} \sim 1-2 \mathrm{~cm}^{-1}\right)$ within the far-infrared spectral region $\left(10-250 \mathrm{~cm}^{-1}\right)$, as described in Bianchini et al. (2004). Both instruments obtain ozone profiles with a vertical resolution (approximately $1-2 \mathrm{~km}$ ) that is slightly better, but still comparable with the one of MIPAS-
ENVISAT v4.61/v4.62 data and are, therefore, directly compared with the satellite measurements without correcting for the vertical smoothing effects.

The chemiluminescent ozone sonde FOZAN (Fast OZone ANalyzer), jointly operated by ISAC-CNR (Bologna, Italy) and CAO (Central Aerological Observatory, Moscow, Russia) teams, provides in situ measurements of the ozone concentration at flight altitude (Yushkov et al., 1999) with a sampling rate of $1 \mathrm{~Hz}$ and precision and accuracy equal to $8 \%$ and 0.01 ppmv, respectively. High resolution vertical profiles (typically, a vertical resolution of about $10 \mathrm{~m}$ is obtained during ascent and descent phases of the flight) of $\mathrm{O}_{3}$ are reconstructed from FOZAN measurements acquired during takeoff and landing, as well as during occasional dives performed by the aircraft close to the geolocation of MIPAS-ENVISAT scans. MIPAS averaging kernels are applied to FOZAN high resolution $\mathrm{O}_{3}$ data to obtain the smoothed profile to be compared with the satellite retrieved values. We report results of 
Table 6. Best temporal and spatial coincidences selected for MIPAS-ENVISAT ozone validation with the M-55 Geophysica aircraft measurements. For each MIPAS scan, we report the interval of the scans used to calculate the MIPAS-STR and SAFIRE-A collocated mean profiles and the corresponding UTC time window, along with the flight segment of the closest FOZAN profile. N.A. indicates cases for which either no data or no coincidence within $300 \mathrm{~km}$ and $3 \mathrm{~h}$ are available.

\begin{tabular}{|c|c|c|c|c|c|c|c|}
\hline \multirow{4}{*}{$\begin{array}{l}\text { Date } \\
22 \text { July } 2002\end{array}$} & \multicolumn{2}{|c|}{ MIPAS-ENVISAT } & \multirow{2}{*}{\multicolumn{2}{|c|}{$\begin{array}{l}\text { MIPAS-STR } \\
\text { Scan interval (UT) }\end{array}$}} & \multirow{2}{*}{\multicolumn{2}{|c|}{$\begin{array}{l}\text { SAFIRE-A } \\
\text { Scan interval (UT) }\end{array}$}} & \multirow{3}{*}{$\begin{array}{l}\text { FOZAN } \\
\text { Flight segment (UT) } \\
\text { landing (09:30-10:12) }\end{array}$} \\
\hline & Orbit & Scan (UT) & & & & & \\
\hline & \multirow[t]{2}{*}{2051} & $12(09: 19)$ & $\begin{array}{l}11-22 \\
07: 59)\end{array}$ & (07:28- & \multicolumn{2}{|l|}{ N.A. } & \\
\hline & & $13(09: 20)$ & $\begin{array}{l}39-47 \\
09: 27)\end{array}$ & $(09: 06-$ & \multicolumn{2}{|l|}{ N.A. } & take-off (06:01-06:28) \\
\hline \multirow{2}{*}{24 Oct 2002} & \multirow{2}{*}{3403} & $14(21: 22)$ & N.A. & & \multicolumn{2}{|c|}{ 5-9 (19:36-20:26) } & dive (19:50-20:28) \\
\hline & & $15(21: 23)$ & N.A. & & $\begin{array}{l}10-15 \\
21: 22)\end{array}$ & $(20: 33-$ & $\begin{array}{l}\text { take-off (18:41-19:06) } \\
\text { landing }(21: 58-22: 36)\end{array}$ \\
\hline \multirow[t]{3}{*}{2 March 2003} & \multirow[t]{3}{*}{5250} & $19(20: 34)$ & $\begin{array}{l}21-26 \\
20: 40) \\
\end{array}$ & $(20: 28-$ & \multicolumn{2}{|c|}{$13-14(20: 36-20: 45)$} & dive $(19: 43-20: 26)$ \\
\hline & & $20(20: 36)$ & $\begin{array}{l}45-50 \\
21: 30) \\
\end{array}$ & $(21: 18-$ & $\begin{array}{l}14-19 \\
21: 25)\end{array}$ & $(20: 45-$ & take-off (18:40-19:10) \\
\hline & & $21(20: 37)$ & $\begin{array}{l}64-65 \\
22: 09)\end{array}$ & $(22: 06-$ & $\begin{array}{l}20-23 \\
21: 53)\end{array}$ & $(21: 34-$ & landing (22:24-23:05) \\
\hline \multirow{5}{*}{12 March 2003} & \multirow{3}{*}{5386} & $27(08: 46)$ & $\begin{array}{l}42-47 \\
08: 01) \\
\end{array}$ & $(07: 47-$ & $\begin{array}{l}15-16 \\
09: 30) \\
\end{array}$ & $(09: 21-$ & N.A. \\
\hline & & $28(08: 47)$ & $\begin{array}{l}31-36 \\
08: 58)\end{array}$ & $(08: 45-$ & $9-14(0$ & $-09: 13)$ & N.A. \\
\hline & & $29(08: 49)$ & $6-11(0$ & $-09: 30)$ & $2-8(07$ & $-08: 24)$ & $\begin{array}{l}\text { take-off }(07: 13-07: 44) \\
\text { landing }(11: 00-11: 47)\end{array}$ \\
\hline & \multirow[t]{2}{*}{5387} & $21(10: 27)$ & $\begin{array}{l}42-47 \\
08: 01) \\
\end{array}$ & $(07: 47-$ & $\begin{array}{l}15-16 \\
09: 30)\end{array}$ & $(09: 21-$ & N.A. \\
\hline & & $22(10: 28)$ & $\begin{array}{l}54-59 \\
10: 06)\end{array}$ & $(09: 53-$ & $\begin{array}{l}17-20 \\
10: 02)\end{array}$ & (09:39- & N.A. \\
\hline
\end{tabular}

our comparison based on the use of both the high resolution and smoothed FOZAN data.

\subsubsection{Comparison methodology}

A total of 11 flights and about 45 flight hours was performed with the M-55 Geophysica for the validation of the ENVISAT chemistry payload in the frame of the 2002-2003 ESABC field campaigns. The results of these airborne measurements have been stored and are now accessible at the ENVISAT Cal/Val database of the Norwegian Institute for Air Research (NILU, http://nadir.nilu.no/calval/). Using these data, multiple coincidences can be identified - based on the agreed matching criteria $(\Delta s<300 \mathrm{~km}, \Delta t<3 \mathrm{~h})$ - between MIPAS-ENVISAT and the remote-sensing and in situ aircraft observations, thus obtaining a comprehensive set of collocated $\mathrm{O}_{3}$ profiles to be considered for validation purposes.
Here, we have selected a sub-set of the above comparison pairs including only those flights for which at least two sensors of the M-55 Geophysica payload provided useful ozone measurements (for mutual data quality check) and choosing, for each MIPAS scan, the $\mathrm{O}_{3}$ profiles measured with the best spatial and temporal coincidence by MIPAS-STR, SAFIRE-A and FOZAN. The resulting validation data set is shown in Table 6, illustrating the combinations of MIPASENVISAT, MIPAS-STR, SAFIRE-A and FOZAN profiles that have been used for our comparison. All the comparisons with correlative data provided by the M-55 Geophysica payload have been carried out using MIPAS-ENVISAT data v4.61. In the case of the aircraft remote-sensing measurements, we have compared the $\mathrm{O}_{3}$ vertical distribution retrieved from the individual MIPAS-ENVISAT scans with the mean VMR profile of MIPAS-STR (or SAFIRE-A) obtained by averaging over all the limb scanning sequences collocated 
Table 7. Statistics over all comparisons of MIPAS to SAGE II: (a) Zonal averages, (b) Seasonal averages for the Southern (SH) and Northern Hemisphere $(\mathrm{NH})$ and (c) all collocations.

(a)

\begin{tabular}{llllll}
\hline $\begin{array}{l}\text { Latitude } \\
\text { Band }\end{array}$ & $\begin{array}{l}\text { Pressure } \\
\text { Range }\end{array}$ & $\begin{array}{l}\text { Mean Relative } \\
\text { Difference }\end{array}$ & $\begin{array}{l}\text { Root Mean } \\
\text { Square }\end{array}$ & N & Month of Year \\
\hline $90^{\circ} \mathrm{S}-60^{\circ} \mathrm{S}$ & $70-0.75 \mathrm{hPa}$ & $+2 \% \leftrightarrow+9 \%$ & $+5 \% \leftrightarrow+11 \%$ & 69 & 3 Dec, 4 Feb \\
$60^{\circ} \mathrm{S}-30^{\circ} \mathrm{S}$ & $70-0.75 \mathrm{hPa}$ & $-7 \% \leftrightarrow+11 \%$ & $+9 \% \leftrightarrow+18 \% *$ & 64 & 3/4 Jan, April-3 May, 3 July \\
$30^{\circ} \mathrm{N}-60^{\circ} \mathrm{N}$ & $70-0.75 \mathrm{hPa}$ & $-6 \% \leftrightarrow+4 \%$ & $+5 \% \leftrightarrow+12 \%$ & 29 & Jan+3 Mar, 3 Apr, 2/3 (22) July \\
$60^{\circ} \mathrm{N}-90^{\circ} \mathrm{N}$ & $70-0.75 \mathrm{hPa}$ & $-4 \% \leftrightarrow+4 \%$ & $+5 \% \leftrightarrow+7 \%$ & 169 & April+3 June, 2/3 July, 3 Sep \\
\hline
\end{tabular}

* except at $\mathrm{p}>45 \mathrm{hPa}$ close to $40 \%$

(b)

\begin{tabular}{|c|c|c|c|c|c|}
\hline Hemisphere & Season & $\begin{array}{l}\text { Pressure } \\
\text { Range }\end{array}$ & $\begin{array}{l}\text { Mean Relative } \\
\text { Difference }\end{array}$ & $\begin{array}{l}\text { Root Mean } \\
\text { Square }\end{array}$ & $\mathrm{N}$ \\
\hline \multirow{4}{*}{$\mathrm{SH}$} & Spring & $70-0.75 \mathrm{hPa}$ & $0 \% \leftrightarrow+9 \%$ & $+4 \% \leftrightarrow+12 \%$ & 32 \\
\hline & Summer & $70-0.75 \mathrm{hPa}$ & $-5 \% \leftrightarrow+14 \%$ & $+5 \% \leftrightarrow+15 \% \dagger$ & 45 \\
\hline & Autumn & $70-0.75 \mathrm{hPa}$ & $-5 \% \leftrightarrow+7 \%$ & $+5 \% \leftrightarrow+15 \%$ & 25 \\
\hline & Winter & $70-0.75 \mathrm{hPa}$ & $-10 \% \leftrightarrow+12 \%$ & $+6 \% \leftrightarrow+15 \%$ & 26 \\
\hline \multirow{2}{*}{$\mathrm{NH}$} & Spring & $70-0.75 \mathrm{hPa}$ & $-4 \% \leftrightarrow+4 \%$ & $+5 \% \leftrightarrow+10 \%$ & 101 \\
\hline & Summer & $110-0.75 \mathrm{hPa}$ & $-5 \% \leftrightarrow+3 \%$ & $+5 \% \leftrightarrow+10 \%$ & 95 \\
\hline
\end{tabular}

\begin{tabular}{lllll} 
(c) & & & \\
\hline Collocations & $\begin{array}{l}\text { Pressure } \\
\text { Range }\end{array}$ & $\begin{array}{l}\text { Mean Relative } \\
\text { Difference }\end{array}$ & $\begin{array}{l}\text { Root Mean } \\
\text { Square }\end{array}$ & $\mathrm{N}$ \\
\hline ALL & $100-0.75 \mathrm{hPa}$ & $-4 \% \leftrightarrow+4 \%$ & $+5 \% \leftrightarrow+14 \%$ & 326 \\
\hline
\end{tabular}

with the selected satellite overpass. SAFIRE-A mean profiles have been calculated over fixed pressure levels, corresponding approximately to a regular altitude grid with steps of $1.0 \mathrm{~km}$. MIPAS-STR $\mathrm{O}_{3}$ profiles have been retrieved on a fixed altitude grid. The VMRs of one altitude have been averaged to get the mean profile (Höpfner et al., 2001; Keim et al., 2004). The UTC time interval covered by SAFIRE-A and MIPAS-STR averages is indicated in Table 6. Total error budget estimates are reported for both instruments, combining the random error contributions (measurement noise and retrieval error) and the systematic uncertainties. For the mean MIPAS-STR profiles three sources dominate the error budget. The detector noise in the individual spectra leads to about $2 \%(1 \sigma)$ in a single profile. This is in good agreement with the standard deviation of the average. The second error source is connected to the use of HITRAN spectral line data for the radiative transfer calculation in the forward model. This error is estimated to be below $10 \%$. The third er- ror stems from the retrieved temperatures used to obtain the trace gases. A temperature error of $2 \mathrm{~K}$ results in an upper limit VMR error for $\mathrm{O}_{3}$ of $<10 \%$. Effects such as non-LTE, uncertainties in the pointing of the instrument, horizontal atmospheric inhomogeneity along the line of sight can cause further errors, which were considered of minor importance. As the three dominating error sources are independent they sum up to below $14 \%$. The estimate of the systematic error in SAFIRE-A ozone profiles takes into account the contribution of the assumed pressure and temperature profile $(\sim 2 \%)$ and the spectroscopic error $(\sim 5 \%)$.

In situ vertical profiles, measured by FOZAN during ascent or descent phases of the flight, are compared with collocated MIPAS-ENVISAT measurements and with the remotesensing data recorded on-board the aircraft when flying at level (flight altitude between 17 and $20 \mathrm{~km}$ ) immediately before/after the M-55 ascent/descent. As previously stated, the comparison is made using both high vertical resolution in situ 
data and the smoothed profile obtained by convolution with MIPAS averaging kernels.

The comparisons cover the altitude range between $\sim 25 \mathrm{~km}$ (slightly above the maximum flight altitude) and MIPASENVISAT lowest tangent altitude. The aircraft measurements conducted in the polar region aimed at validating MIPAS-ENVISAT products in presence of strong vertical and horizontal gradients. Consequently, the corresponding data set (February-March 2003 data) generally includes data acquired at the border of the polar vortex, with vertical and horizontal inhomogeneities much larger than those encountered at mid-latitude (July and October 2002 data). To avoid strong gradients along the line of sight of the remote sensing instruments, which decrease the quality of the measured profiles, the flights were planned with long north south legs. The aircraft measurements have been performed in west east direction, while the MIPAS-ENVISAT measured north south along the gradients. Very high quality coincidences, both in the spatial and in the temporal domain, characterize the correlative data set available from the M-55 Geophysica campaigns; particularly for the remote-sensing measurements, considering that the time difference between MIPASSTR/SAFIRE-A and MIPAS-ENVISAT is on average less than $1 \mathrm{~h}$ (see Table 6 ).

\subsubsection{Comparison results}

Results of the comparison between MIPAS-ENVISAT ozone profiles and the M-55 correlative measurements obtained during Northern mid-latitude flights (Forlí, Italy, 22 July 2002 and 24 October 2002) and during the Arctic campaign (Kiruna, Sweden, 2 March 2003 and 12 March 2003) are shown in Fig. 15 and Fig. 16, respectively. Each plot displays the ozone vertical distribution retrieved by MIPASENVISAT for one of the selected overpasses and the collocated $\mathrm{O}_{3}$ profiles measured by the remote-sensing and in situ sensors of the aircraft. Ozone VMR values are plotted versus pressure, in a range roughly corresponding to the $6-25 \mathrm{~km}$ interval, as indicated by the approximate altitude scale reported on the right axis of the plots. The error bars on MIPASENVISAT, MIPAS-STR and SAFIRE-A profiles indicate the total uncertainty on the corresponding ozone values.

Very good agreement is found at mid-latitude, with aircraft $\mathrm{O}_{3}$ measurements and satellite data generally matching within their total error bars (with the only exception of the MIPAS-ENVISAT orbit 2051/ scan 12, that overestimates the $\mathrm{O}_{3}$ VMR below $100 \mathrm{hPa}$ compared to MIPASSTR, still matching, however, the in situ measurements acquired by FOZAN during landing). Reasonably good results are found, on the other hand, also from the comparison of the ozone profiles from the Arctic flights, despite the larger atmospheric inhomogeneities that characterize the measurement scenario at higher latitudes. The occurrence of strong vertical gradients is highlighted in the comparison with in situ measurements (see, for instance, plots of MIPAS-
ENVISAT orbit 5250/scan 19 and orbit 5386/scan 29) and can account for the observed differences with remote-sensing data, whilst horizontal gradients encountered at the border of the polar vortex might at least partially justify the discrepancy in ozone values retrieved by the airborne and satellite limb-sounders. We can notice from Fig. 16, that MIPASENVISAT normally tends to be in a very good agreement with MIPAS-STR and only occasionally to show significant differences, mostly in terms of a slight overestimate of the ozone VMR. The latter trend is more pronounced in comparison with SAFIRE-A mean profiles, that are almost consistently lower than MIPAS-ENVISAT $\mathrm{O}_{3}$ values.

In order to investigate the origin of the observed differences, we must remember that our selection of collocated ozone profiles was based on standard criteria for the maximum separation, in space and in time, between pairs of satellite and aircraft measurements and did not take into account any further requirement for the proximity of the observed air masses. This implies, for observation performed across strong vertical and horizontal gradients, that matching measurements, satisfying the spatial and temporal coincidence criteria, can be associated with substantially different conditions and thus explain the observed discrepancy between ozone mixing ratio retrieved from airborne and satellite data.

We can look, for instance, at the Potential Vorticity field on the isentropic surface $\Theta=420 \mathrm{~K}$ (approximately $18 \mathrm{~km}$ ) in the region covered by the M-55 flight on 12 March 2003 (from NCEP data at 12:00 UTC), as displayed in the map of Fig. 17. And we can notice the geolocation of a particular set of collocated measurements from MIPAS-ENVISAT (orbit 5386 - scan 28), MIPAS-STR (scans 31-36) and SAFIRE-A (scans 9-14): MIPAS-ENVISAT and MIPASSTR limb measurements mostly overlap on a region with PV values of about $(25 \pm 1) \mathrm{pvu}\left(1 \mathrm{pvu}=10^{-6} \mathrm{~K} \mathrm{~m}^{2} \mathrm{~kg}^{-1} \mathrm{~s}^{-1}\right)$, whilst SAFIRE-A mean profile results from averaging over a more extended area including air masses with PV values as high as $\sim 30$ pvu. In the plot of Fig. 16, we observe, correspondingly, matching ozone values retrieved at $\sim 18 \mathrm{~km}$ by MIPAS-ENVISAT and MIPAS-STR (approximately 1.82.0 ppmv) and lower $\mathrm{O}_{3}$ VMR measured by SAFIRE-A (approximately $1.6 \mathrm{ppmv}$ ). This example, as well as similar checks performed using different combinations of coincident data, confirm that whenever a significant difference is found between simultaneous ozone measurements of MIPAS and one of the M-55 Geophysica sensors this is mostly due to sampling of different air masses across a region of strong horizontal (and vertical) gradients. A more comprehensive and quantitative analysis of the $\mathrm{O}_{3}$ differences in the (PV, $\Theta)$ space is currently in progress (Redaelli et al., 2006), based on the entire $\mathrm{O}_{3}$ data set available from the SAFIREA/ENVISAT validation campaigns and will be presented in a dedicated paper. 
Table 8. Statistics over all comparisons of MIPAS to HALOE: (a) Zonal averages, (b) Seasonal averages and (c) all collocations.

\begin{tabular}{llllll}
\hline $\begin{array}{l}\text { Latitude } \\
\text { Band }\end{array}$ & $\begin{array}{l}\text { Pressure } \\
\text { Range }\end{array}$ & $\begin{array}{l}\text { Mean Relative } \\
\text { Difference }\end{array}$ & $\begin{array}{l}\text { Root Mean } \\
\text { Square }\end{array}$ & N & Month of Year \\
\hline $90^{\circ} \mathrm{S}-60^{\circ} \mathrm{S}$ & $73-0.20 \mathrm{hPa}$ & $+4 \% \leftrightarrow+13 \%$ & $+7 \% \leftrightarrow+20 \%$ & 49 & 2 July, May-Jun-3 July \\
$60^{\circ} \mathrm{S}-30^{\circ} \mathrm{S}$ & $68-0.10 \mathrm{hPa}$ & $-14 \% \leftrightarrow+22 \%$ & $+20 \% \leftrightarrow+30 \%$ & 17 & 2 Nov, 3 Nov \\
$30^{\circ} \mathrm{N}-60^{\circ} \mathrm{N}$ & $81-0.10 \mathrm{hPa}$ & $-8 \% \leftrightarrow+14 \%$ & $+28 \% \leftrightarrow+30 \%$ & 25 & 3 May, 4 Jan \\
$60^{\circ} \mathrm{N}-90^{\circ} \mathrm{N}$ & $65-0.20 \mathrm{hPa}$ & $+14 \% \leftrightarrow+24 \%$ & $+23 \% \leftrightarrow+31 \%$ & 50 & 3/4 Jan, 2/3 July, 3 Aug, 3 Nov \\
\hline
\end{tabular}

\begin{tabular}{lllll} 
(b) & & & \\
\hline Season & $\begin{array}{l}\text { Pressure } \\
\text { Range }\end{array}$ & $\begin{array}{l}\text { Mean Relative } \\
\text { Difference }\end{array}$ & $\begin{array}{l}\text { Root Mean } \\
\text { Square }\end{array}$ & $\mathrm{N}$ \\
\hline Spring & $88-0.20 \mathrm{hPa}$ & $-0.08 \% \leftrightarrow+6 \%$ & $+8 \% \leftrightarrow+21 \%$ & 24 \\
Summer & $70-0.20 \mathrm{hPa}$ & $+5 \% \leftrightarrow+9 \%$ & $+12 \% \leftrightarrow+20 \%$ & 48 \\
Autumn & $94-0.10 \mathrm{hPa}$ & $+31 \% \leftrightarrow+64 \%$ & $+38 \% \leftrightarrow+94 \%$ & 28 \\
Winter & $70-0.20 \mathrm{hPa}$ & $+2.5 \% \leftrightarrow+22 \%$ & $+20 \% \leftrightarrow+26 \%$ & 41 \\
\hline
\end{tabular}

(c)

\begin{tabular}{lllll}
\hline Collocations & $\begin{array}{l}\text { Pressure } \\
\text { Range }\end{array}$ & $\begin{array}{l}\text { Mean Relative } \\
\text { Difference }\end{array}$ & $\begin{array}{l}\text { Root Mean } \\
\text { Square }\end{array}$ & $\mathrm{N}$ \\
\hline ALL & $70-0.20 \mathrm{hPa}$ & $+7 \% \leftrightarrow+16 \%$ & $+21 \% \leftrightarrow+25 \%$ & 141 \\
\hline
\end{tabular}

\subsection{ASUR}

\subsubsection{ASUR data and methodology of the comparison}

Measurements of the ozone VMR profile gathered by the Airborne Sub-millimetre Radiometer ASUR (Mees et al., 1995) during the SCIAMACHY Validation and Utilization Experiment SCIAVALUE (Fix et al., 2005) are used in this study to validate MIPAS ozone data products v4.61. ASUR is a passive heterodyne radiometer for middle atmospheric sounding, operating in the frequency range $604-662 \mathrm{GHz}$ and flying on-board an aircraft to avoid signal absorption due to tropospheric water vapour. Mixing ratio profiles of stratospheric trace gases $\mathrm{O}_{3}, \mathrm{ClO}, \mathrm{HCl}, \mathrm{HNO}_{3}, \mathrm{~N}_{2} \mathrm{O}$, etc. are retrieved on a $2 \mathrm{~km}$ altitude grid using the optimal estimation method (Rodgers, 1990). The retrieved ozone profiles from $16 \mathrm{~km}$ to $50 \mathrm{~km}$ have a vertical resolution of $7-10 \mathrm{~km}$, decreasing with altitude and a horizontal resolution of about $20 \mathrm{~km}$. An error in instrument calibration led to systematically high values in earlier ASUR publications. This error has been rectified for this paper, and the measurement accuracy is now better than 10\% (Kuttippurath et al., 2007). We compared the collocated ozone profiles obtained by MIPAS and ASUR within the baseline coincidence criteria $\Delta s<300 \mathrm{~km}$ and $\Delta t<3 \mathrm{~h}$. The MIPAS ozone profiles were convoluted with the ASUR averaging kernels, to ac- count for the lower vertical resolution of the ASUR measurements. The smoothed MIPAS values were used to calculate the absolute and relative differences with the collocated ASUR measurements. Mean profiles of the differences were finally obtained by averaging over the available coincidences in different latitude bands (the tropics, Mid-latitude and the Arctic).

\subsubsection{Results}

Mean profiles of the absolute difference between ASUR and MIPAS $\mathrm{O}_{3} \mathrm{VMR}$ and of their relative difference with respect to the ASUR values, calculated from the available data set of direct coincidences, are reported in Fig. 18 for three latitude bands, corresponding to the tropics $\left(5^{\circ} \mathrm{S}-30^{\circ} \mathrm{N}\right)$, midlatitude $\left(30^{\circ} \mathrm{N}-60^{\circ} \mathrm{N}\right)$, and the $\operatorname{Arctic}\left(60^{\circ} \mathrm{N}-80^{\circ} \mathrm{N}\right)$, as well as for all of these regions combined. Both the absolute and relative differences are plotted as a function of altitude, with an approximate pressure scale derived from the U.S. Standard Atmosphere displayed on the right axis. The yellow shaded area represents the $1 \sigma$ standard deviation from the mean profile. The total number of coincidences is 50 with the majority, 22 instances, in the Arctic, 7 instances in midlatitudes, and 21 instances in the tropics. The MIPAS-ASUR deviation is -0.9 to $+0.4 \mathrm{ppmv}$ or -40 to $+4 \%$ in the tropics at $20-40 \mathrm{~km}$, whereas at mid-latitudes the difference is 

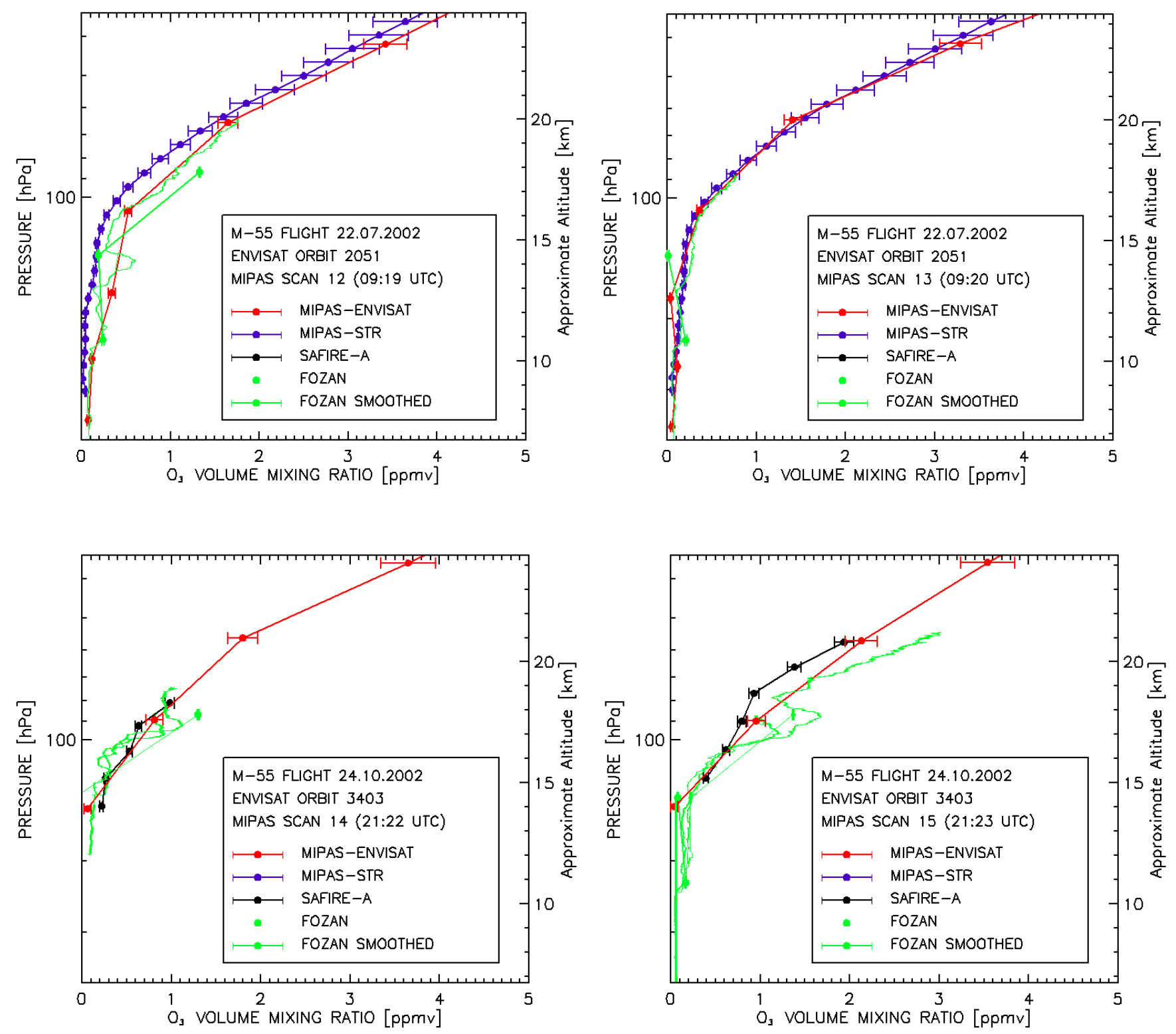

Fig. 15. Results of the comparison between MIPAS-ENVISAT v4.61 ozone data and correlative measurements performed by the remotesensing and in situ payload of the M-55 Geophysica during the mid-latitude flights on 22 July 2002 and on 24 October 2002 from Forlì, Italy (Lat. $42^{\circ} \mathrm{N}$, Lon. $12^{\circ} \mathrm{E}$ ).

within 0.9 ppmv or -15 to $+25 \%$. The agreement between the profiles is very good in the Arctic between 20 and $40 \mathrm{~km}$, where the difference is within \pm 0.4 ppmv or -6 to $+4 \%$.

\section{Comparison with satellite measurements}

Correlative measurements of the ozone vertical distribution are obtained by several satellite sensors operating simultaneously with the MIPAS-ENVISAT spectrometer and employing different observation modes. In this section we check the validity of MIPAS $\mathrm{O}_{3}$ data against coincident profiles retrieved by four solar occultation instruments (SAGE II, HALOE, POAM III and ACE), by a nadir-viewing sensor (GOME) and by a limb-emission sounder (ODIN-SMR).

A common strategy was followed for the validation of MI$\mathrm{PAS}_{3}$ profiles by comparison with these space-borne sensors, using the key concepts of the scheme for statistical bias and precision determination with matching pairs of measurements described in von Clarmann (2006) and based on the comparison:

1. between the mean percentage difference (MIPASREFERENCE) $\mathrm{O}_{3}$ VMR and the combined systematic 

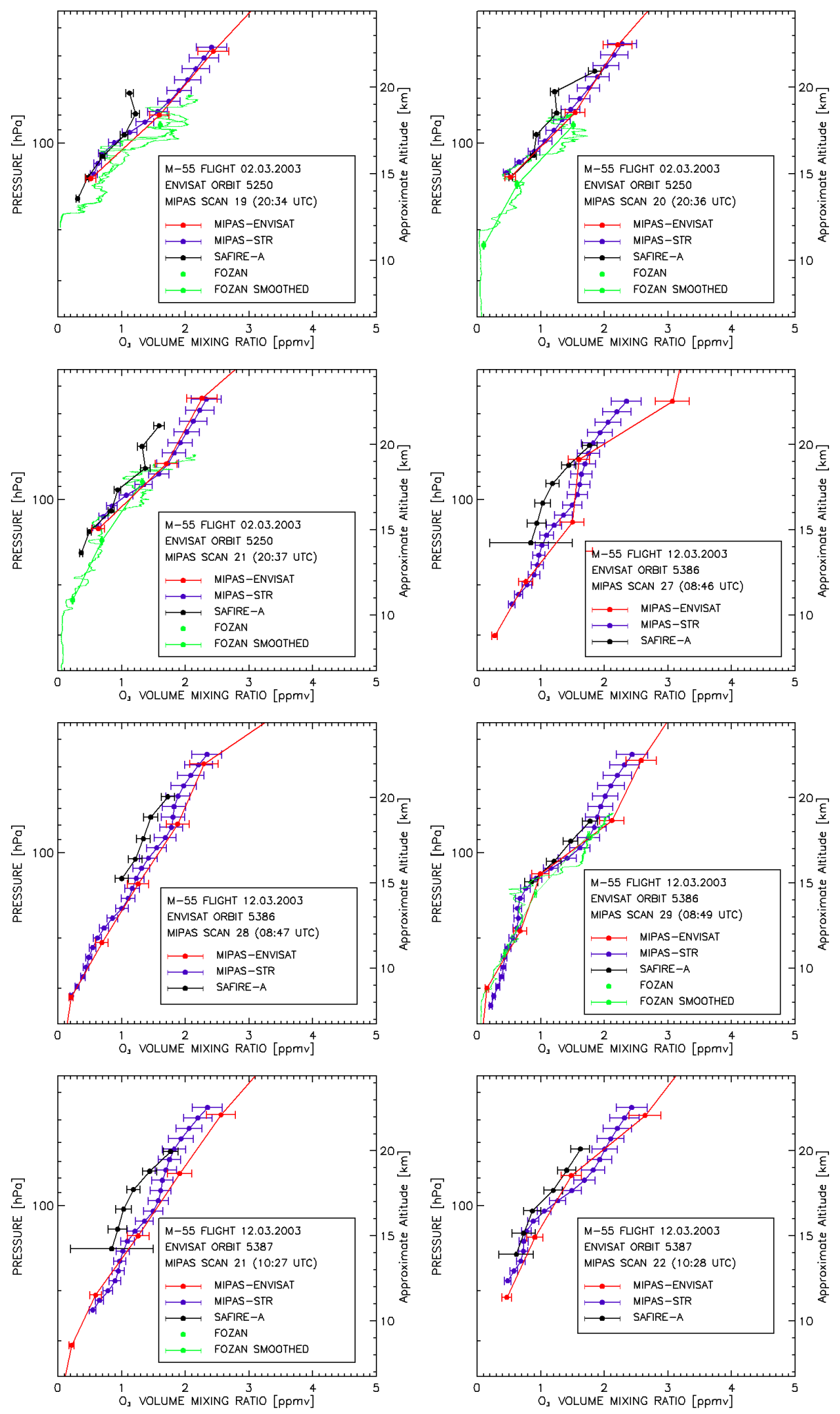

Fig. 16. Results of the comparison between MIPAS-ENVISAT v4.61 ozone data and correlative measurements performed by the remotesensing and in situ payload of the M-55 Geophysica during the high-latitude flights on 2 March 2003 and 12 March 2003 from Kiruna, Sweden (Lat. $68^{\circ} \mathrm{N}$, Lon. $20^{\circ} \mathrm{E}$ ). 


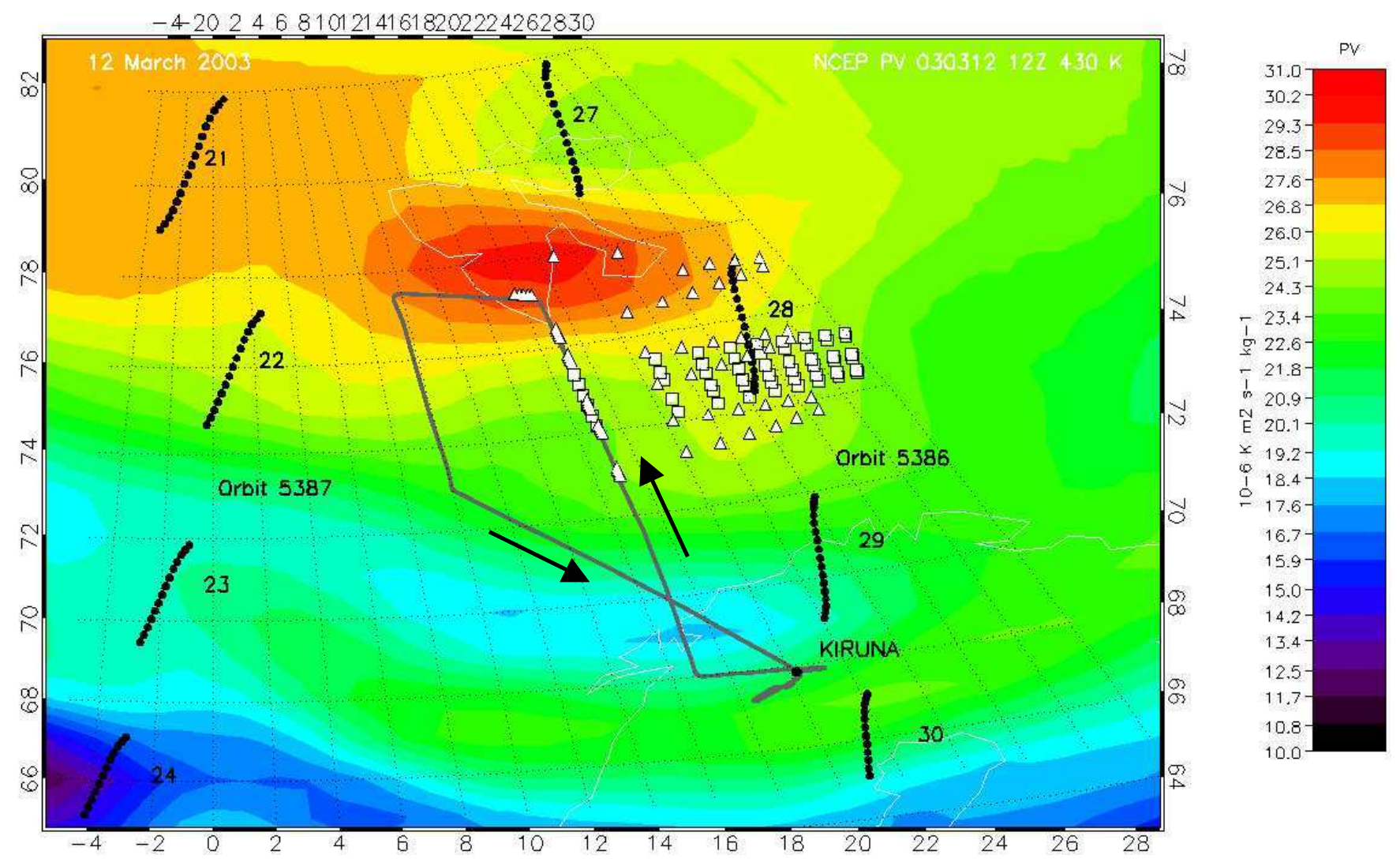

Fig. 17. False color map of Potential Vorticity on the isentropic surface $\Theta=420 \mathrm{~K}$ and $\mathrm{M}-55$ Geophysica route during the ENVISAT validation flight from Kiruna on 12 March 2003. The geolocation of MIPAS-ENVISAT tangent points for the selected overpasses (orbit 5386 and 5387) is indicated (black circles). The geographical coverage of collocated aircraft measurements, in coincidence with MIPAS-ENVISAT orbit 5386, scan 28 is also displayed, with white triangles and white squares corresponding, respectively, to $\mathrm{O}_{3}$ mean profiles measured by SAFIRE (scans 9-14) and MIPAS-STR (scans 31-36).

error of the two instruments, in order to identify unexplained biases in MIPAS ozone measurements

2. between the standard deviation of the mean relative difference and the combined random error, in order to validate the precision of MIPAS.

Details of the procedure for the implementation of this scheme were agreed and slightly adapted in the individual cases, to better exploit the specific features of each data set. Unless otherwise noted, the standard criteria for maximum space and time separation of $300 \mathrm{~km}$ and $3 \mathrm{~h}$ with the reference measurements were strictly applied, to select the comparison pairs available during the overlapping period of operation of MIPAS and the validating instrument.

For each of the selected pairs, both MIPAS and the reference instrument $\mathrm{O}_{3}$ profiles were interpolated on a common pressure grid, to enable a statistical analysis of collocated measurements having different vertical resolutions: the interpolation grid was generally defined by averaging the pressure values of the selected MIPAS scans (details about interpolation of $\mathrm{O}_{3}$ vertical profiles are provided in the relevant sub- sections, whenever a different choice has been made, like for instance in the case of MIPAS/POAM comparison). With the only exception of the comparison with the GOME observations, no averaging kernels have been applied, because of the similar vertical resolution of MIPAS and the reference instruments.

The interpolated profiles were used to calculate the relative deviation, $\mathrm{RD}$, in ozone VMR values retrieved by MIPAS and by the correlative sensor at each pressure level (p) using Eq. (17):

$$
R D(p)=100 \times \frac{\operatorname{MIPAS}\left[\mathrm{O}_{3}\right]_{p}-\operatorname{REFERENCE}\left[\mathrm{O}_{3}\right]_{p}}{\operatorname{REFERENCE}\left[\mathrm{O}_{3}\right]_{p}}
$$

The mean relative deviation (MRD) and root mean square (RMS) of the relative deviation between all MIPAS and correlative sensor pairs were determined, along with corresponding quantities averaged over subsets of latitudinal or seasonal bands, whenever further investigation was required to isolate the source of discrepancies identified in the global average or to diagnose zonal and seasonal patterns in the $\mathrm{O}_{3}$ mean differences. 


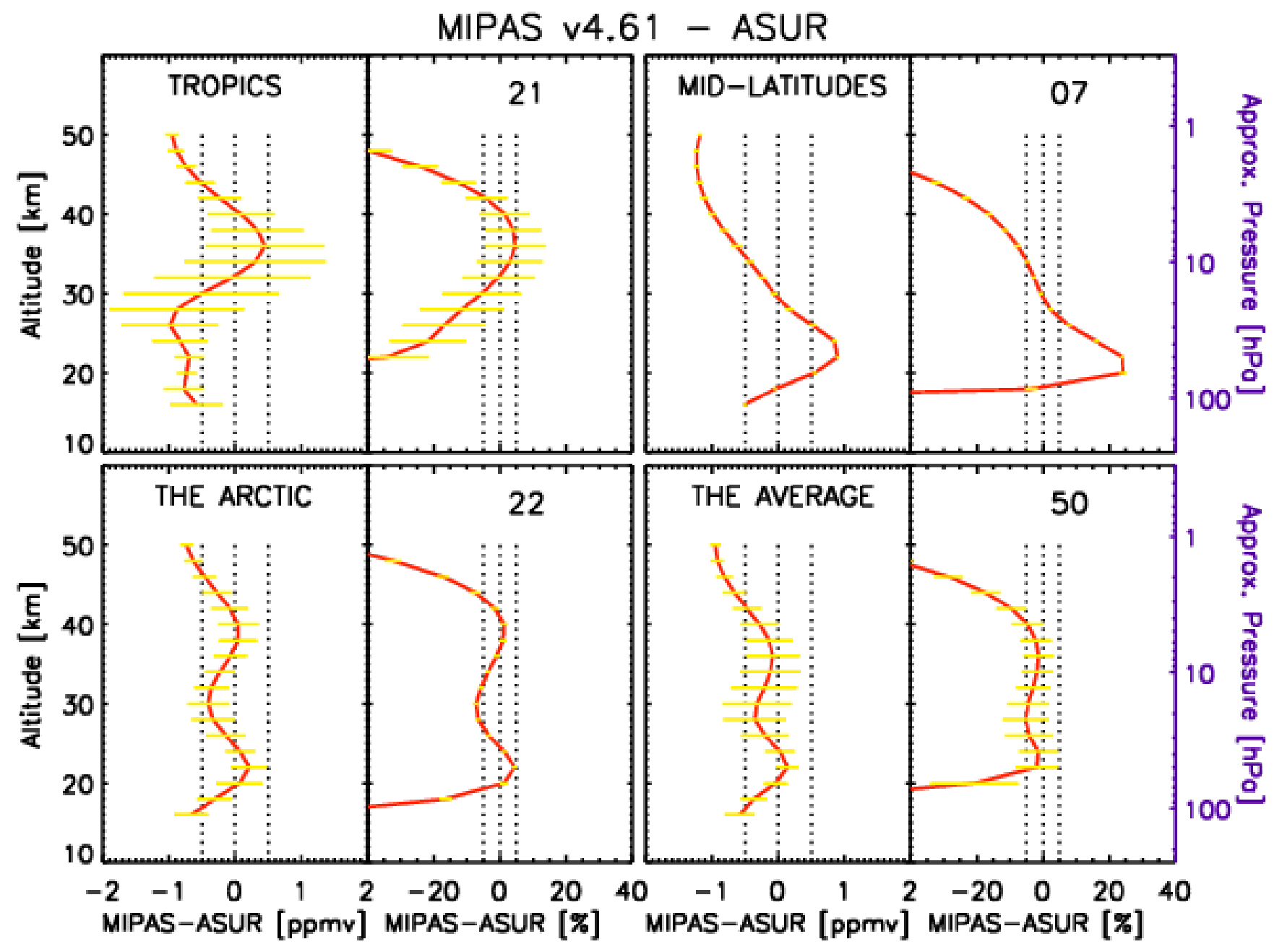

Fig. 18. The absolute (MIPAS-ASUR ozone VMR in ppm) and percentage ( $\triangle$ VMR/MIPAS VMR in \%) difference between the MIPAS and ASUR ozone profiles in the tropics (top left), mid-latitude (top right), the Arctic (bottom left) and the average of all these latitude sections (bottom right). The thick red line indicates the mean $\Delta$ profile at each section and the yellow shaded area represents the standard deviation from the mean profile. The dotted line stands for $\pm 0.5 \mathrm{ppm}$ or $\pm 5 \%$. The number of averaged $\Delta$ profiles at each climatic region is also noted in the plots.

In all cases, beside the MRD over all the available coincidences, mean profiles of both MIPAS and the reference instrument are displayed in the plots of the global average.

Combined random and systematic error estimates on the $\mathrm{O}_{3}$ VMR difference between matching profiles were based on the expected uncertainties of MIPAS measurements and on validated precision and accuracy of the correlative data.

As far as MIPAS errors are concerned, we refer, in general, to the ESA level 2 products for the random error due to propagation of the instrument noise through the retrieval and to the a priori estimate of systematic errors provided by University of Oxford.

An important point we made, to properly evaluate the combined error budget associated with the mean relative difference of collocated $\mathrm{O}_{3}$ profiles, is that some of the components, listed in the Oxford University data set as systematic error on the individual profiles, show a random variability over the longer time-scale involved when averaging different MIPAS scans and/or orbits and tend to contribute to the standard deviation of the mean difference rather than to the bias. Taking this into account, for the purpose of our comparisons with concurrent satellite sensors, we have considered the error contribution due to propagation of pressure and temperature (pT) random covariance into the retrieval of $\mathrm{O}_{3}$ VMR (taken from the Oxford Univ. data set) as a randomly variable component and combined it with the measurement noise - using the root-sums-square method - to obtain MIPAS random error. MIPAS systematic error was conversely calculated by subtracting the $\mathrm{pT}$ propagation error from the overall systematic error given in the Oxford Univ. files.

In the following sub-sections, details of individual comparison with the above listed satellite sensors are provided. 

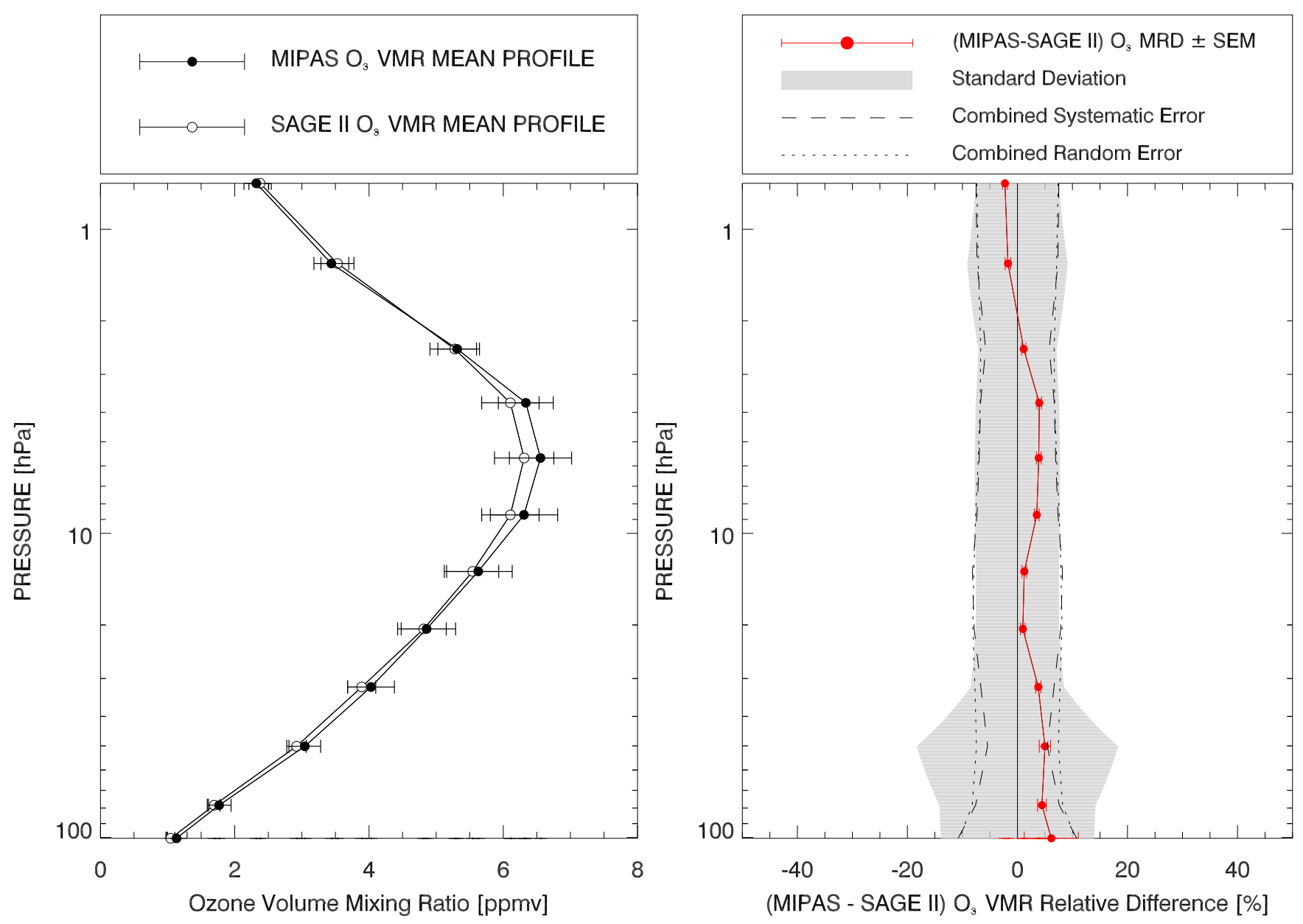

Fig. 19. Comparison between MIPAS and SAGE II: statistics over all the collocated $\mathrm{O}_{3}$ profiles. On the left panel, MIPAS and SAGE II O mean profiles with total error bars are shown; on the right, mean relative differences and standard deviations, along with combined random and systematic error, are plotted.

A very brief description of the instrument and of the correlative data set is given in each case, specifying the data version adopted for the comparison with MIPAS v4.61 and/or v4.62 profiles and referring to the most recent publications and updated information for details about their measurements validation and quality assessment. Results of the comparison with each of the validating sensors are presented and discussed.

\subsection{Comparison with $\mathrm{SAGE} \mathrm{II} \mathrm{O}_{3}$ profiles}

\subsubsection{SAGE II data}

The Stratospheric Aerosol and Gas Experiment II (SAGE II) (McCormick, 1987), launched on 5 October 1984 aboard the Earth Radiation Budget Satellite (ERBS), is a sevenchannel sunphotometer, at visible and near-infrared wavelengths ranging from $1.02 \mu \mathrm{m}$ to $0.385 \mu \mathrm{m}$, that uses the solar occultation technique to measure aerosol volume extinction coefficients, $\mathrm{O}_{3}, \mathrm{NO}_{2}$ and $\mathrm{H}_{2} \mathrm{O}$ mixing ratio. The limb mea- surements of absorption by trace gases are inverted (Chu et al., 1989) to provide vertical profiles with a horizontal resolution of about $200 \mathrm{~km}$ and a vertical resolution of $1 \mathrm{~km}$ in the range $8-38 \mathrm{~km}$ and of $5 \mathrm{~km}$ in the range $38-50 \mathrm{~km}$ (Mauldin et al., 1985). The latitude coverage of SAGE II measurements is from $80^{\circ} \mathrm{N}$ to $80^{\circ} \mathrm{S}$. SAGE II ozone concentration profiles are retrieved using spectra from the $0.60 \mu \mathrm{m}$ wavelength channel. Validation of SAGE II data version 6.1 (Wang, 2002) shows an agreement within $10 \%$ with ozone sonde measurements from the tropopause up to $30 \mathrm{~km}$, with SAGE II slightly overestimating $(<5 \%)$ the ozone content between 15 to $20 \mathrm{~km}$. A former version of SAGE II (v5.96) had been extensively validated within $7 \%$ at 20 to $50 \mathrm{~km}$ (Cunnold et al., 1989). The version 6.2 of SAGE II was improved by adjustment to the aerosol clearing and by the correction of channels 520 and $1020 \mathrm{~nm}$ for absorption of the oxygen dimer. 

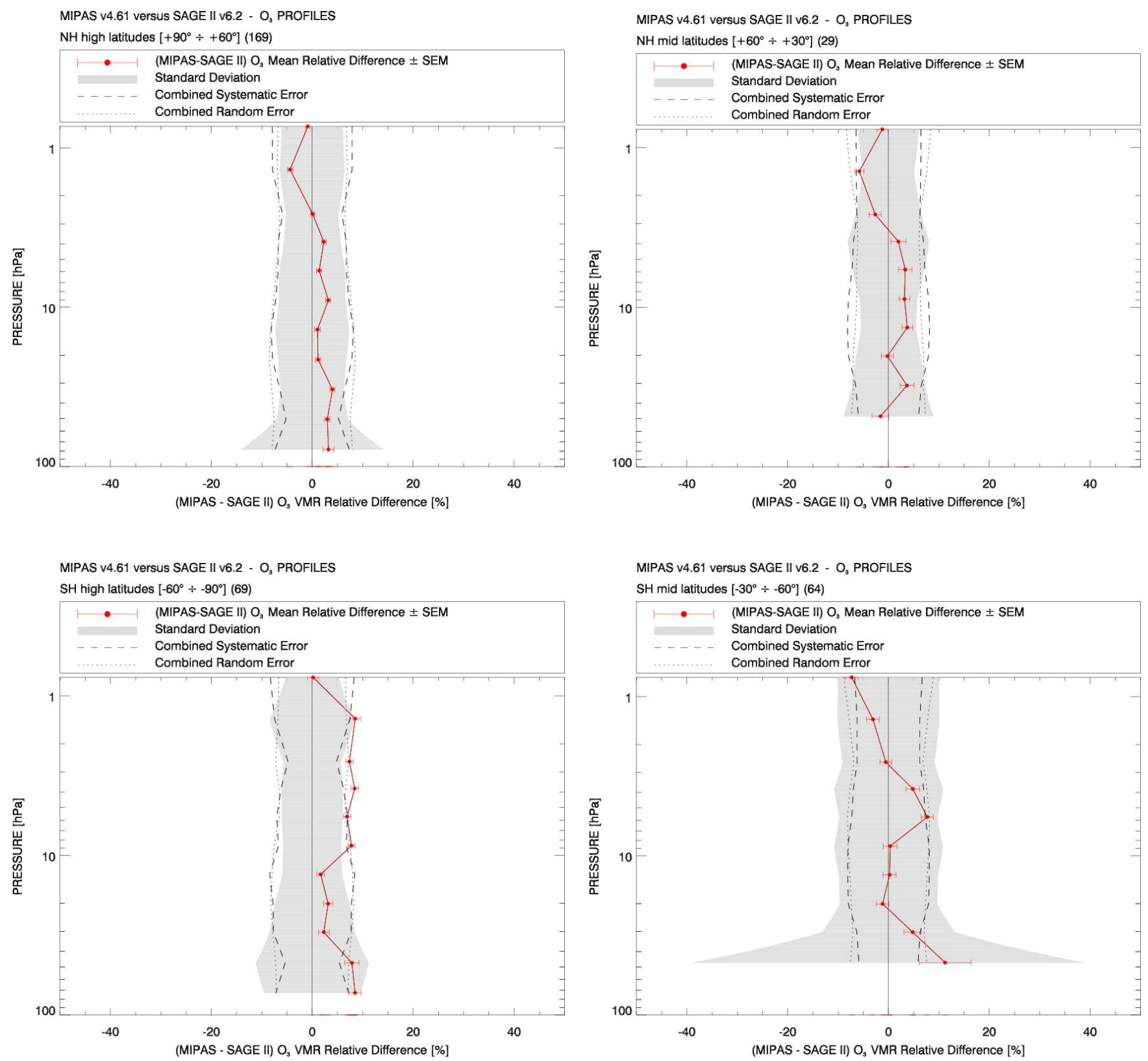

Fig. 20. Comparison between MIPAS and SAGE II: zonal averages. Relative differences and comparison errors averaged over four latitude bands. The number of coincident pairs in each zone is indicated in parenthesis.

\subsubsection{Comparison methodology}

In this work, SAGE II ozone data v6.2 are used to validate MIPAS data $\mathrm{v} 4.61 / \mathrm{v} 4.62$ for the period of the instrument full spectral resolution mission. The baseline coincidence criteria (spatial separation $<300 \mathrm{~km}$ and temporal separation $<3 \mathrm{~h}$ ) are applied, to select the SAGE II and MIPAS ozone profiles to be compared. A total of 326 pairs of matching profiles is identified. For the estimate of the error budget of the comparison, we have used the values for precision and accuracy of SAGE II ozone data given in Cunnold et al. (1989): in the range from 16 to $53 \mathrm{~km}$ accuracy is between $5 \%$ and $7 \%$, precision between $4.1 \%$ and $6.7 \%$, systematic error is between $1.5 \%$ and $6.2 \%$.

\subsubsection{Results}

In Fig. 19, the statistics of the comparison between MIPAS and SAGE II collocated ozone profiles over all the available collocations (total number $=326$ ) is presented. The solid red line represents the mean relative difference, with error bars indicating the standard error on the mean. (i.e. $1 \sigma$ 

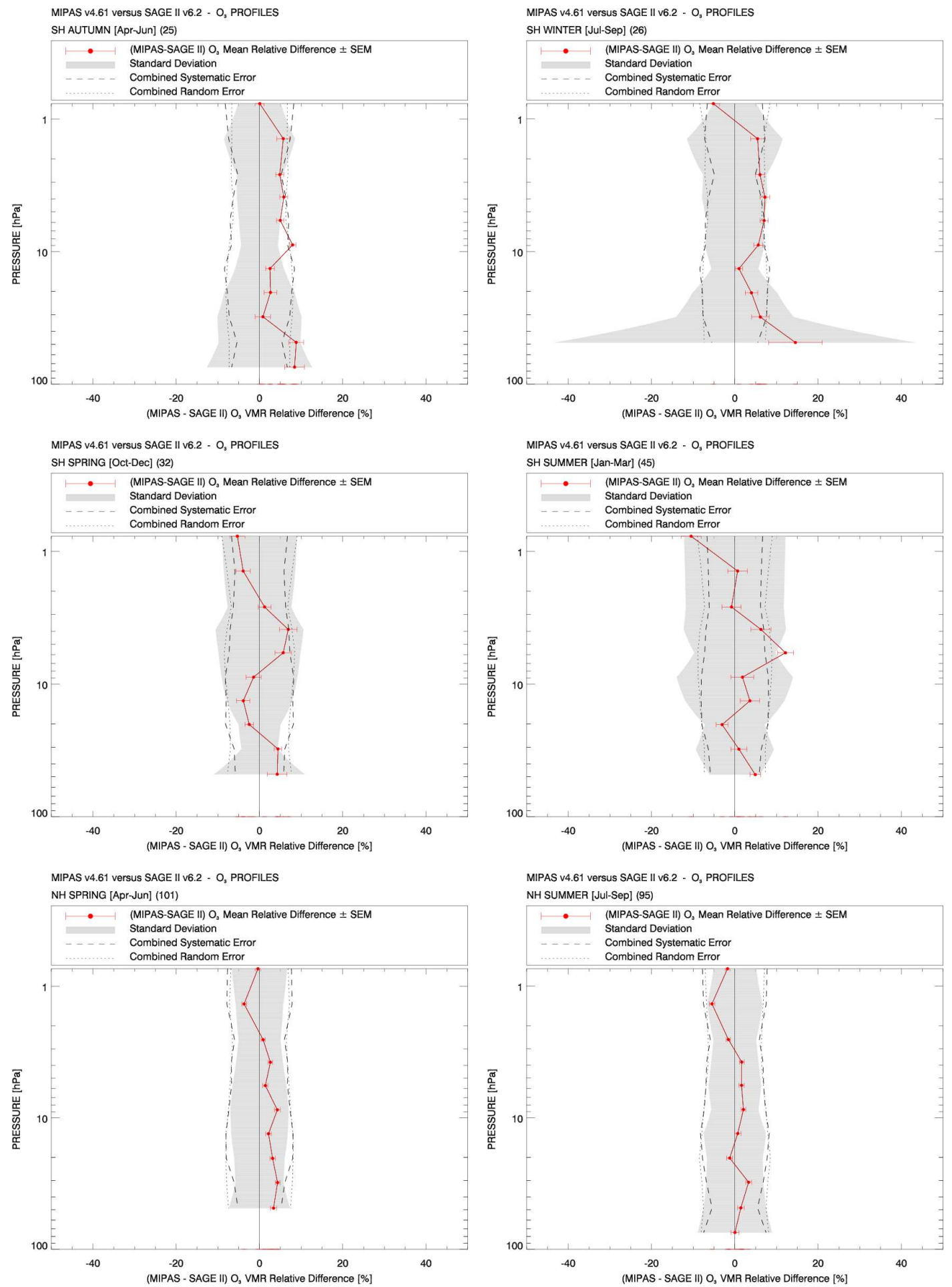

Fig. 21. Comparison between MIPAS and SAGE II: seasonal averages. Relative differences and comparison errors averaged over different seasons in the Northern and Southern Hemisphere. The number of coincident pairs in each season/hemisphere is indicated in parenthesis.

standard deviation of the MRD divided by the square root of the number of matching pairs in the sample). The combined random and systematic error are represented as dotted and dashed lines respectively, whilst the shaded area corresponds to the MRD $\pm 1 \sigma$ standard deviation. In the entire pressure range from the lower stratosphere to the upper stratosphere 
(approximately from $100 \mathrm{hPa}$ to $1 \mathrm{hPa}$ ), the mean deviation of MIPAS $\mathrm{O}_{3}$ VMR relative to SAGE II is within $\pm 5 \%$, mostly reflecting a positive bias of MIPAS to SAGE II that never exceeds the combined systematic error. The good agreement between the two data sets is confirmed by the root mean square of their mean difference that is significantly larger than the combined random error only at lower altitudes, for pressure values higher than $\sim 30 \mathrm{hPa}$. Mean relative differences for different latitude bands are plotted in Fig. 20, highlighting the fact that the main source of discrepancy is concentrated in the Southern Hemisphere mid and high latitudes with evidence of a significant high bias of MIPAS in the $60^{\circ}-$ $90^{\circ} \mathrm{S}$ above $10 \mathrm{hPa}$. The seasonal dependency of the relative differences has also been investigated, as shown by the plots in Fig. 21. A complete seasonal coverage is obtained only for the Southern Hemisphere, where the observed bias is (marginally) higher than the systematic uncertainties on the MRD between approximately 10 and $2 \mathrm{hPa}$ and below $\sim 30 \mathrm{hPa}$ in autumn and winter, and for a peak centred around $\sim 45 \mathrm{hPa}$ in spring and summer. In the Northern Hemisphere, on the other hand, the available collocations provide smaller values of the mean difference with no evidence of significant biases throughout the whole stratosphere.

\subsection{Comparison with POAM III O $\mathrm{O}_{3}$ profiles}

\subsubsection{POAM III data}

The Polar Ozone and Aerosol Measurement III (POAM III) instrument (Lucke et al., 1999), operating on the SPOT4 spacecraft since 23 March 1998, is a nine-channel photometer, that performs solar occultation measurements in selected bands from 0.354 to $1.018 \mu \mathrm{m}$, to derive profiles of $\mathrm{O}_{3}, \mathrm{NO}_{2}, \mathrm{H}_{2} \mathrm{O}$, as well as temperature and wavelengthdependent aerosol extinction. Ozone profiles are primarily retrieved from spectra recorded by the channel centered at $603 \mathrm{~nm}$, near the peak of the Chappuis absorption band. The vertical resolution of the ozone retrieval is $1 \mathrm{~km}$ throughout the stratosphere, but degrades rather quickly to $2-3 \mathrm{~km}$ in the upper troposphere. The horizontal resolution is estimated to be approximately $30 \mathrm{~km}$ perpendicularly to the line of sight (i.e. parallel to the terminator) and about $200 \mathrm{~km}$ parallel to the line of sight. Details of the retrieval algorithm and error analysis for POAM III version 3.0 can be found in Lumpe et al. (2002). Validation of POAM III ozone has been performed in Randall et al. (2003).

Ozone data version 4.0 from the POAM III instrument are used for comparison and validation of MIPAS data version v4.61/v4.62. The selection of collocated MIPAS and POAM profiles was based on the standard criteria of $300 \mathrm{~km}$ and $3 \mathrm{~h}$ for the maximum spatial and temporal separation of matching measurements and resulted in a total of 1571 comparison pairs within the three latitude bands $\left[90^{\circ} \mathrm{N}-60^{\circ} \mathrm{N}\right],\left[60^{\circ} \mathrm{N}-\right.$ $\left.30^{\circ} \mathrm{N}\right]$. and $\left[60^{\circ} \mathrm{S}-90^{\circ} \mathrm{S}\right]$ and in the period from 1 June 2002 to 26 March 2004. A fine vertical pressure grid, equidis- tant in logarithmic pressure, was selected and both POAM and MIPAS results were interpolated onto this common grid. POAM pressure is derived from UKMO (United Kingdom MetOffice) pressure. The fine vertical pressure grid ensures that fine vertical structures in the profiles from both instruments are preserved for the comparison and smoothing by interpolation can be avoided.

POAM III error analysis has been carried out in Lumpe et al. (2002). The random error is below 5\% throughout the stratosphere with a minimum value of $1 \%$ at $20 \mathrm{~km}$. In the troposphere the random error is rapidly increasing to values of more than $10 \%$. According to Lumpe et al. (2002), POAM III ozone profiles are neither affected by improper removal of sunspot artefacts nor by aerosol feedback errors in gas retrieval, which means that systematic errors are negligible for ozone.

\subsubsection{Results and discussion}

The global average of the relative differences of MIPAS $\mathrm{O}_{3}$ profiles with respect to collocated POAM III measurements is less than $\pm 5 \%$ between approximately $60 \mathrm{hPa}$ and $0.2 \mathrm{hPa}$ (see Fig. 22). No evidence of unexplained biases is found within the whole range from the upper troposphere $(\sim 300 \mathrm{hPa})$ up to the lower mesosphere $(\sim 0.12 \mathrm{hPa})$, with the only exception of a localised peak around $100 \mathrm{hPa}$ where the MRD exceeds the combined systematic error. The available data set of MIPAS/ POAM coincident ozone measurements provides only a partial coverage for calculation of zonal means over different latitude bands, with no matching pairs satisfying the baseline criteria of $300 \mathrm{~km}$ and $3 \mathrm{~h}$ at mid latitude in the Southern Hemisphere (i.e. in the range $30^{\circ} \mathrm{SS}$ to $60^{\circ} \mathrm{SS}$ ). Results of the comparison carried out over the other latitude bands are shown in Fig. 23, where we can notice that the peak of the MRD mainly originates from the high latitude data of both hemispheres. No correlation was found, however, with any seasonal cycle (e.g. PSC climatology), as displayed in Fig. 24, showing an MRD profile that exceeds the combined systematic error around $100 \mathrm{hPa}$ in most of the seasons with peak values ranging between $10 \%$ and $20 \%$.

\subsection{Comparison with ODIN-SMR O 3 profiles}

\subsubsection{SMR data}

The Sub-Millimetre Radiometer (SMR) was launched aboard the ODIN satellite on 20 February 2001 for a combined astronomy and aeronomy mission. SMR is a limb sounding instrument that employs four tunable heterodyne receivers in the range $486-581 \mathrm{GHz}$ and one mm-wave receiver at $119 \mathrm{GHz}$, to observe atmospheric thermal emission spectra for the determination of the vertical distribution of trace species relevant to stratospheric and mesospheric chemistry and dynamics (Murtagh et al., 2002; Frisk et al., 2003). 

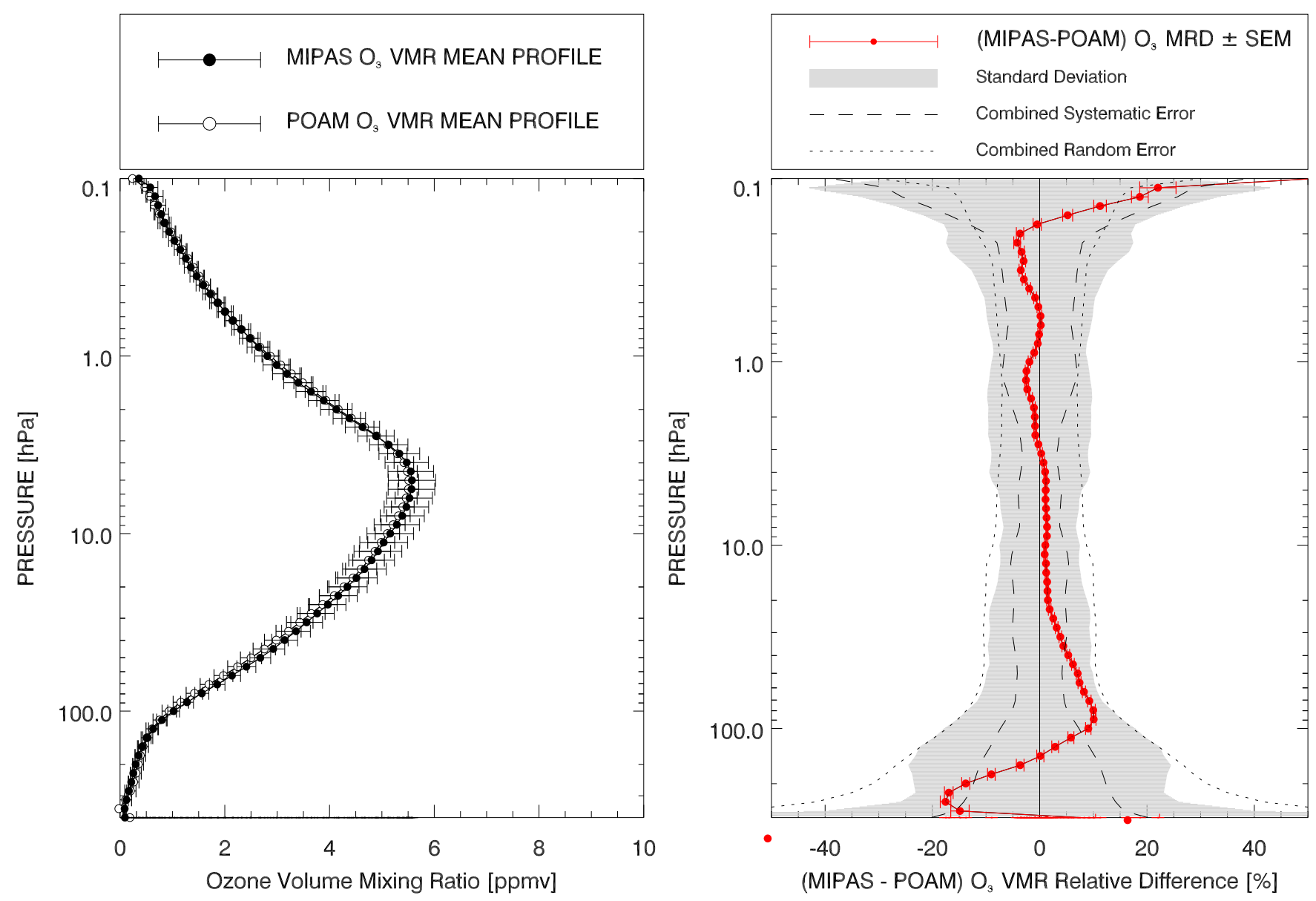

Fig. 22. Comparison between MIPAS and POAM III: statistics over all the collocated $\mathrm{O}_{3}$ profiles. Global mean profiles of $\mathrm{O}_{3}$ VMR measured by MIPAS and by POAM III, with error bars indicating the corresponding total uncertainties (left panel). Mean relative difference between MIPAS and POAM III ozone data and combined error budget (right panel).

In the current work, we compared ODIN-SMR version 1.2 data in the period from 20 July 2002 to 26 March 2004 with collocated MIPAS Ozone profiles v4.61. By applying the standard coincidence criteria of $\Delta s<300 \mathrm{~km}$ and $\Delta t<3 \mathrm{~h}$, we selected a total number of 1270 matching profiles. ODIN-SMR data used for this comparison (available at http://www.rss.chalmers.se/gem/) were obtained from the stratospheric mode band at $501.8 \mathrm{GHz}$. The $\mathrm{O}_{3}$ line is at $501.5 \mathrm{GHz}$, allowing the retrieval of $\mathrm{O}_{3}$ profile between 21 and $45 \mathrm{~km}$ with a vertical resolution of $3.5-4 \mathrm{~km}$. The retrieval algorithm is based on the Optimal Estimation Method. The version 1.2 puts more weight on the a priori information with respect to previous versions and this leads to smoother and less noisy profiles with the drawback of a slightly reduced resolution and altitude range. The ODIN-SMR level 2 analysis uses temperature data from the ECMWF in the stratosphere as well as data from model climatology in the mesosphere (Hedin, 1991). The ozone retrieval in this band is dominated by the spectroscopic error. The expected total systematic error is lower than 0.4 ppmv above $25 \mathrm{~km}$ and in- creases to $\sim 0.75 \mathrm{ppmv}$ at $20 \mathrm{~km}$. In terms of relative units, the error is of the order of $5 \%$ above $30 \mathrm{~km}$ and increases below up to $35 \%$ at $20 \mathrm{~km}$.

The comparison has been done including all the matching pairs of measurements available in the test period. Only good quality ODIN-SMR profiles have been selected and a measurement response (defined by Urban et al., 2005 as the sum of the averaging kernel at a given altitude and providing an estimate of the relative contribution to the information coming from the measurements and from the a priori) larger than $\sim 0.75$ has been used to assure that the information comes from the measurements and not from the a priori. For MIPAS, only profiles associated with a successful pressure/temperature and $\mathrm{O}_{3}$ retrievals have been considered.

The ODIN-SMR systematic error results from the individual instrumental errors (i.e. calibration error, pointing uncertainty, antenna and sideband response knowledge, spectrometer resolution), model error (i.e. temperature knowledge) and spectroscopic error. The ODIN-SMR random error for single profile retrieval is due to the intrinsic receiver noise. 

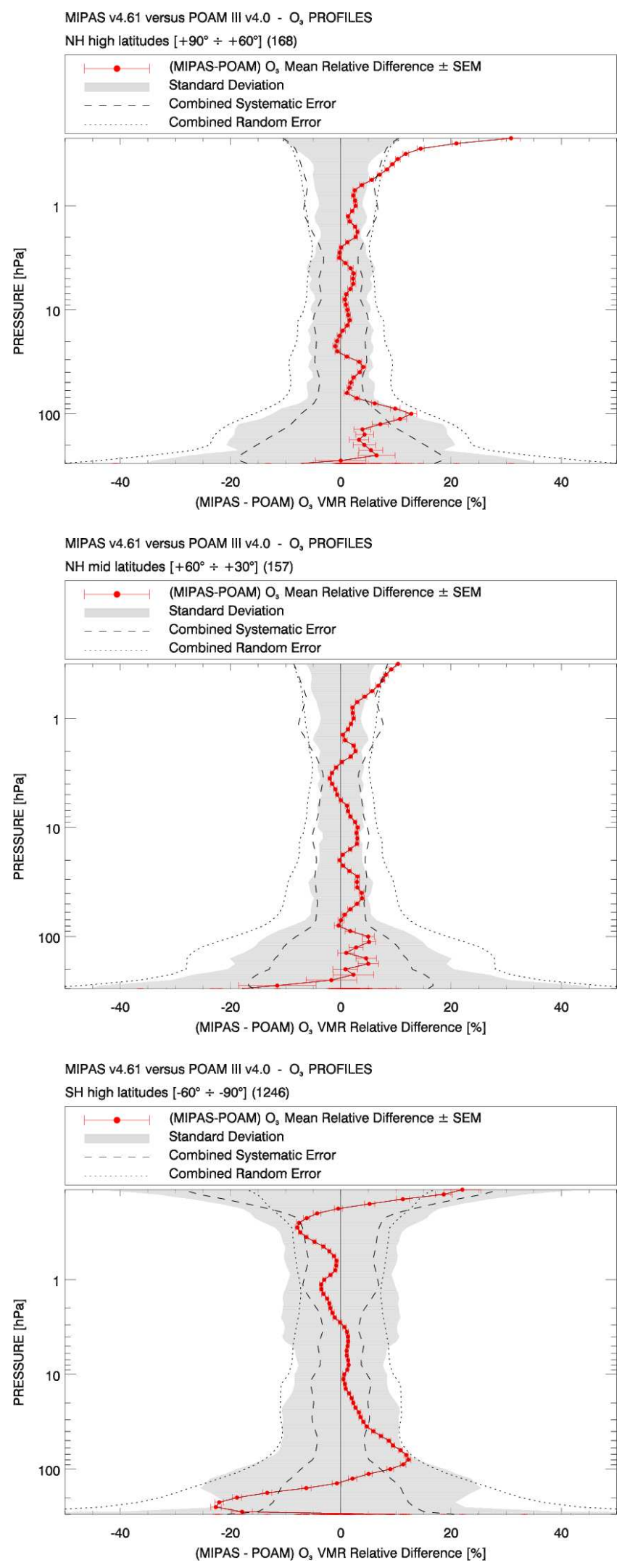

Fig. 23. Comparison between MIPAS and POAM III $\mathrm{O}_{3}$ profiles: zonal averages.
On average, a typical systematic error profile has been considered for both MIPAS (from Univ. Oxford error estimate) and ODIN-SMR measurements. These systematic error profiles are then multiplied by the respective mean $\mathrm{O}_{3}$ profiles of the matching pairs of measurements. The combined systematic error is given by the root sum square of the two instruments systematic errors. The combined random error is given by the root sum square of the averaged random error profiles of the two instruments.

\subsubsection{Results and discussion}

The global average of the percentage difference between MIPAS and ODIN-SMR ozone values, calculated over the full set of collocated measurements is presented in Fig. 25, where the mean profile of the relative difference between MIPAS and ODIN-SMR with respect to the latter is plotted along with error bars representing the standard error on the mean $(1 \sigma)$. The MRD values are within $\pm 5 \%$ from approximately 40 to $1 \mathrm{hPa}$, with MIPAS mostly overestimating the $\mathrm{O}_{3}$ content. The resulting bias is anyhow constantly lower than the combined systematic error in the full range [60-1 hPa]. Outside this interval, both in the upper stratospheric layers and in the UTLS, the average $\mathrm{O}_{3}$ VMR values retrieved by ODINSMR become increasingly higher than those measured by MIPAS. This discrepancy could be due to a lack of statistics. There are not so many points as can be seen from the standard deviation at altitudes below $60 \mathrm{hPa}$. Moreover the theoretical retrieval altitude grid for ODIN-SMR O 3 at $501.5 \mathrm{GHz}$ is between 21 and $45 \mathrm{~km}(60-1 \mathrm{hPa})$, therefore altitudes below $60 \mathrm{hPa}$ might include mainly the a priori information.

No significant variations in the seasonal and latitudinal mean differences are present between MIPAS and ODIN$\mathrm{SMR} \mathrm{O} \mathrm{O}_{3}$; the global average of the differences is representative of the overall comparison between the two different instruments capabilities.

\subsection{Comparison with ACE-FTS $\mathrm{O}_{3}$ profiles}

\subsubsection{ACE-FTS data}

The ACE-FTS (Atmospheric Chemistry Experiment) instrument is a high resolution $\left(\Delta s=0.02 \mathrm{~cm}^{-1}\right)$ Fourier transform spectrometer operating from 2 to $13 \mu \mathrm{m}$ ( $\sigma=750-$ $4100 \mathrm{~cm}^{-1}$ ). It performs solar occultation measurements of the vertical distribution of trace gases and temperature from the cloud top up to about $100 \mathrm{~km}$. The ACE-FTS measurements are recorded every $2 \mathrm{~s}$. This corresponds to a measurement spacing of $2-6 \mathrm{~km}$, which decreases at lower altitudes due to refraction. The latitude coverage is from $85^{\circ} \mathrm{N}$ to $85^{\circ} \mathrm{S}$. The instrument was launched on 12 August 2003, as part of the ACE mission (Bernath et al., 2005), on-board the Canadian satellite SCISAT-1. A modified global fit approach Boone et al. (2005) is adopted for the retrieval of pressure, temperature and volume mixing ratio profiles. Results of 

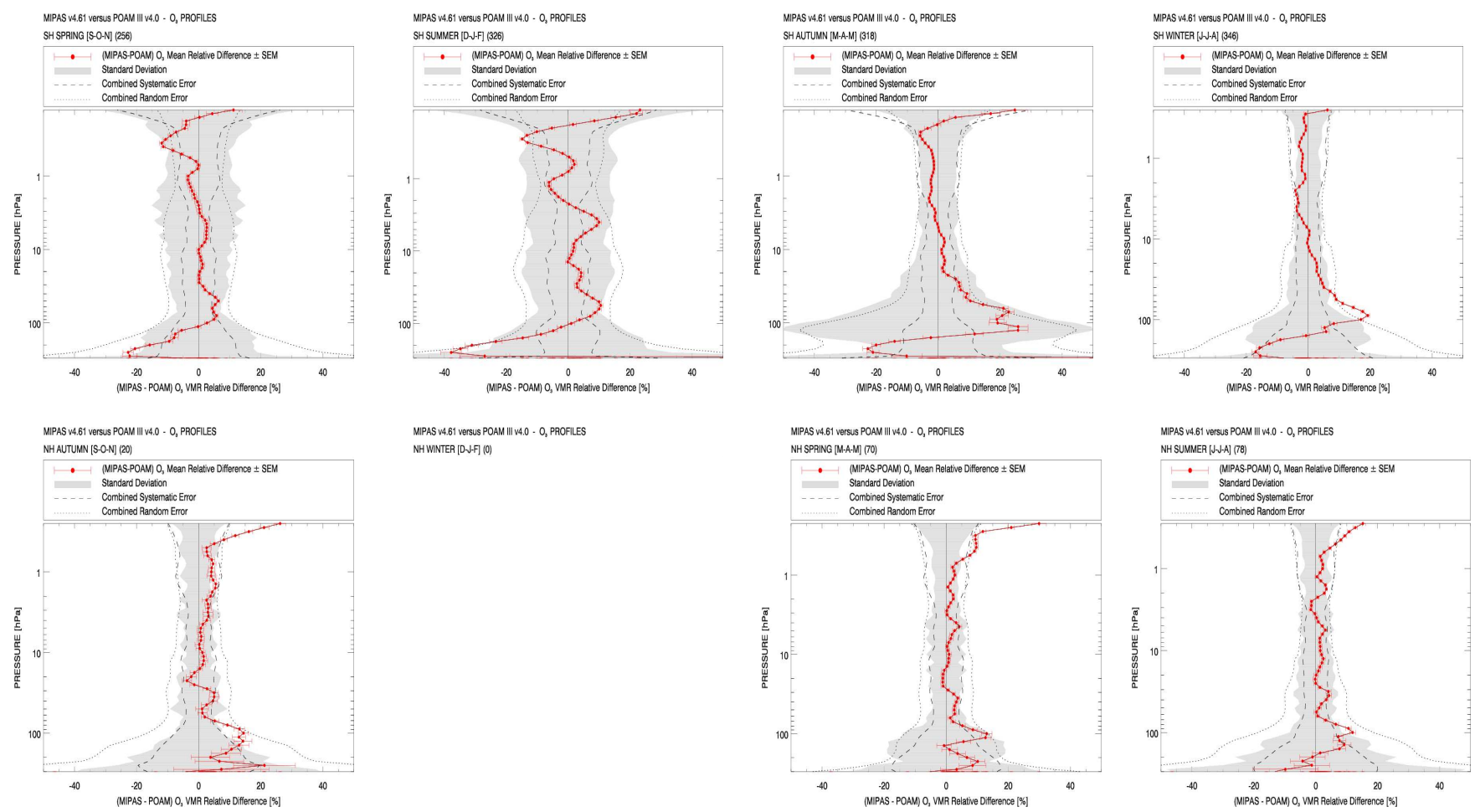

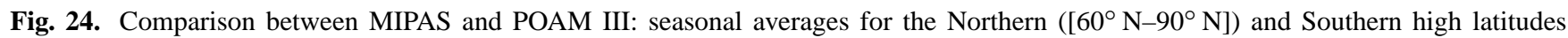
$\left(\left[60^{\circ} \mathrm{S}-90^{\circ} \mathrm{S}\right]\right)$.

ACE-FTS ozone measurements have been validated against ozone sondes and other satellite measurements (Petelina et al., 2005; Fussen et al., 2005; Walker et al., 2005; McHugh et al., 2005).

Here, MIPAS ozone data v4.62 are compared with ACEFTS version 2.2 data in the period from 4 February 2004 to 26 March 2004. During the first five months of the mission, only sunsets were measured because of problems with spacecraft pointing at sunrise. Therefore the latitude coverage for this comparison is limited to $20^{\circ} \mathrm{N}-85^{\circ} \mathrm{N}$. The selected coincidence criteria were $300 \mathrm{~km}, 6 \mathrm{~h}$. A slightly relaxed temporal mismatch, compared to the generally adopted $3 \mathrm{~h}$, has been chosen in order to increase the statistics of the comparison since the ozone does not vary significantly relaxing the time scale from 3 to $6 \mathrm{~h}$. A total of 152 matching pairs of profiles is available for the comparison of MIPAS and ACE $\mathrm{O}_{3}$ data. The ACE operational retrieval employs a weighted non-linear least squares fit. A priori profiles are used only as a first guess and to constraint the shape of the profiles above the highest analyzed measurement.

The comparison has been done including all the matching pairs of measurements available in the test period. Only retrieved ACE points of the $\mathrm{O}_{3}$ profiles have been used in the comparison according to the quality flags specified by ACE team. The ACE profile above the highest analysed measurement is given as a scaled initial guess profile and it is not taken into account in the comparison. For MI-
PAS, only ozone profiles associated with a successful pressure/temperature and $\mathrm{O}_{3}$ retrievals have been considered.

The estimated systematic error profile for ACE-FTS data version 2.2 is based on the validation comparisons of ACE-FTS with different satellite instruments (POAM III, SAGE III and HALOE) and balloon-borne ozone sonde (Walker et al., 2005; McHugh et al., 2005). This estimated systematic error is up to $10 \%$ below $35 \mathrm{~km}$ and up to $35 \%$ above.

\subsubsection{Results and discussion}

The results of the comparison between coincident $\mathrm{O}_{3}$ measurements of MIPAS and ACE-FTS can be summarised by the plot shown in Fig. 26, where the mean relative difference of MIPAS ozone VMR with respect to ACE values is displayed. A pronounced peak of the MRD, corresponding to a low bias of MIPAS, emerges above approximately 1.0 $\mathrm{hPa}$, but appears fully justified by our estimate of the combined systematic errors of the two instruments (larger than $\pm 40 \%$ above $\sim 2 \mathrm{hPa}$ ). This is also the case, throughout the whole profile from $0.1 \mathrm{hPa}$ down to $250 \mathrm{hPa}$, if we exclude a thin layer around $10 \mathrm{hPa}$, where a percentage mean relative difference of about $15-20 \%$ cannot be explained by the estimated systematic uncertainties. 

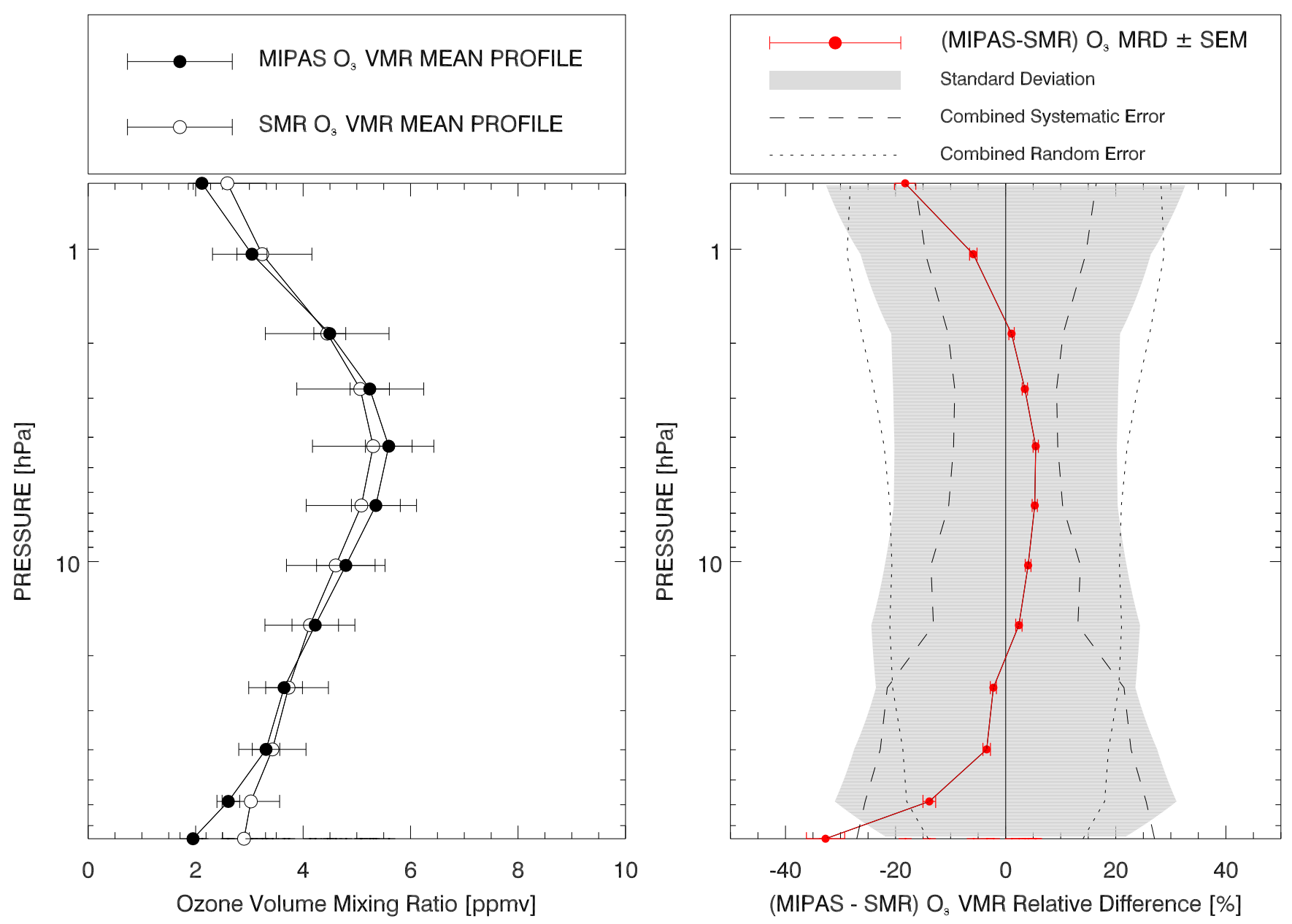

Fig. 25. Comparison between MIPAS and ODIN-SMR: statistics over all the collocated $\mathrm{O}_{3}$ profiles.

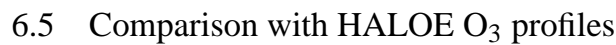

\subsubsection{HALOE data}

The HALOE (HALogen Occultation Experiment) instrument, that operated from September 1991 to November 2005 on-board the Upper Atmospheric Research Satellite (UARS), is a solar occultation infrared radiometer that obtains concentration profiles of pressure, temperature, aerosol and several trace gases. It uses broadband and gas filter radiometry to measure solar energy absorption over the $2.45 \mu \mathrm{m}$ to $10.04 \mu \mathrm{m}$ spectral range (Russell et al., 1993). A single ozone profile is retrieved from $9.6 \mu \mathrm{m}$ channel radiances during each of the daily 15 sunset and 15 sunrise events with an effective $2.5 \mathrm{~km}$ vertical resolution although data are oversampled at $300 \mathrm{~m}$ intervals. The UARS is in a circular orbit inclined at $57^{\circ}$ at altitude of $600 \mathrm{~km}$ from which vertical ozone profiles from 12 to $90 \mathrm{~km}$ are obtained near globally between $30^{\circ} \mathrm{S}$ to $70^{\circ} \mathrm{N}$ and $70^{\circ} \mathrm{S}$ to $30^{\circ} \mathrm{N}$ following a yaw manoeuvre every 36 days. The HALOE retrieval algorithm incorporates a modified onion peeling approach with no a priori assumption and simulates the gas and broadband measurements using specific line by line forward models obtaining $\mathrm{O}_{3}$ and interfering gas spectroscopic information from the HITRAN 1991-1992 database (SPARC, 1998). HALOE ozone measurements have been extensively validated, as described by Bruhl et al. (1996) for the results obtained with version 17 of the retrieval software. The authors present total error estimates associated with the HALOE $\mathrm{O}_{3}$ channel and values range from $95 \%$ at $0.01 \mathrm{hPa}$ and $11 \%$ at $0.1 \mathrm{hPa}$ and gradually increase to $30 \%$ at $100 \mathrm{hPa}$. Significant systematic errors below $50 \mathrm{~km}$ are uncertainties in the retrieval algorithm's forward model in particular, spectral line parameters and approximations, and the instrument's altitude registration. Pointing errors increase rapidly in the lower stratosphere and below where cloud and aerosol interference start to dominate. In general, HALOE version 17 data were to found to agree well within the errors associated with comparative sources, with a tendency to be low by $5 \%$ between $30 \mathrm{hPa}$ and $1 \mathrm{hPa}$.

Off-line MIPAS versions 4.61 and 4.62 level 2 ozone are compared to the HALOE version 19 ozone profiles. The 

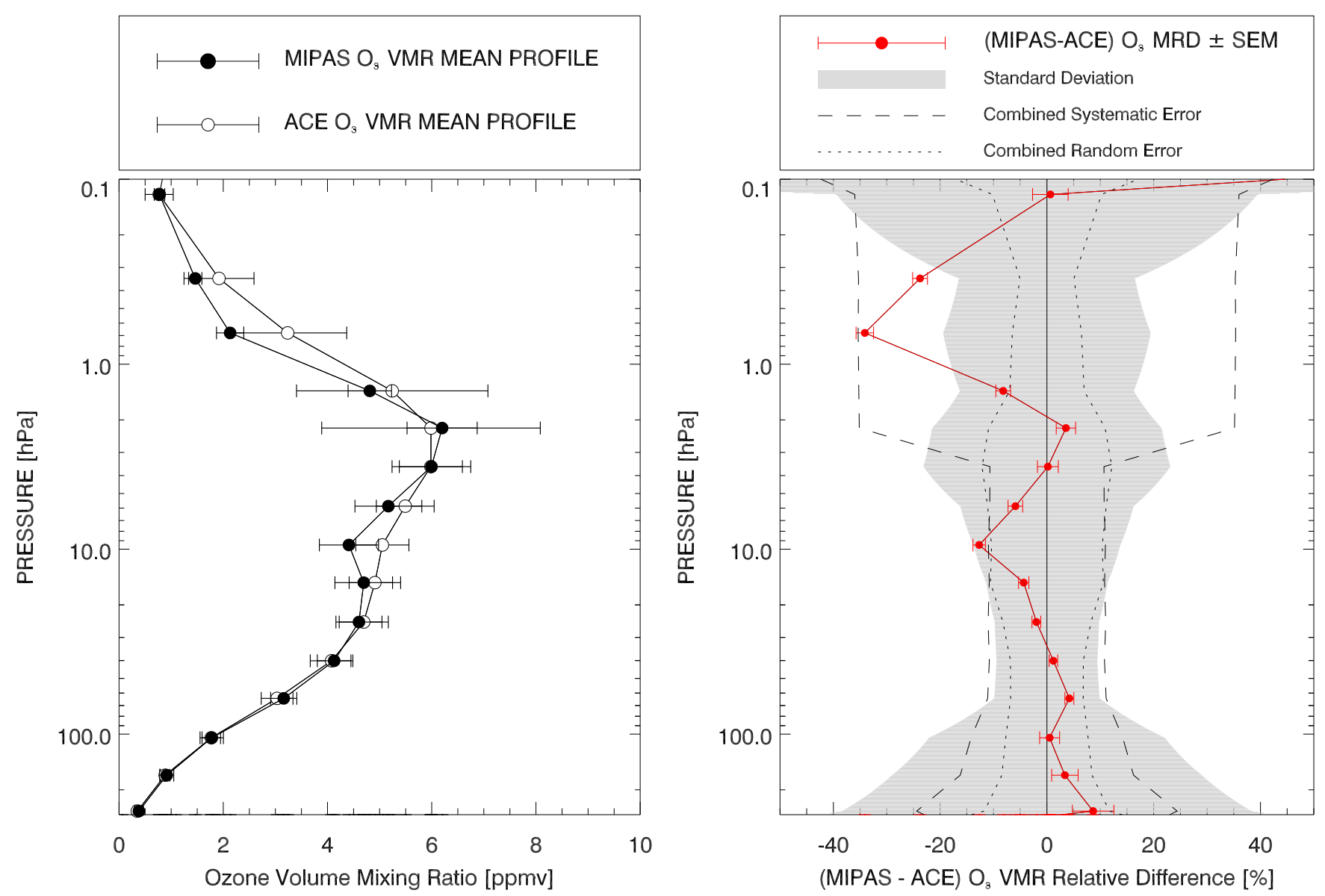

Fig. 26. Comparison between MIPAS and ACE-FTS: statistics over all the collocated $\mathrm{O}_{3}$ profiles.

coincidence criteria used for the validation is a distance and time difference of $300 \mathrm{~km}$ and $3 \mathrm{~h}$ and is applied to MIPAS data from July 2002 to March 2004. Conditions fulfilled for the comparison are (a) only profiles corresponding to successful retrieval flags were selected (b) the profile should exceed $45 \mathrm{~km}$ and reach $12 \mathrm{~km}$ and below and (c) no additional cloud flagging has been applied, i.e. $\mathrm{CI} \leq 1.8$ is assumed from the $v 4.61$ and $v 4.62$ processing. The total number of matches for the above coincidence criteria are 156 with 141 (98 v4.61 and $43 \mathrm{v} 4.62$ ) profiles fulfilling the conditions applied. The estimate of HALOE error budget is based partly on information contained in the data files, which provide along with the ozone profile - the random error component (consisting of noise and aerosol) error, and Table 1 of Bruhl et al. (1996) is consulted for the remaining random and systematic error components. All HALOE version 19 data have been screened for cloud and aerosol effects in accordance with Hervig and McHugh (1999).

\subsubsection{Results}

Results of comparison between MIPAS and HALOE ozone measurements are shown in Fig. 27, in terms of mean rela- tive difference obtained by averaging the deviation of MIPAS $\mathrm{O}_{3}$ values relative to coincident HALOE profiles. From the global average, MIPAS data are found to show constantly higher $\mathrm{O}_{3}$ concentrations from 0.1 to $100 \mathrm{hPa}$ relative to HALOE, with MRD values less than $10 \%$ in the $0.2-50 \mathrm{hPa}$ interval and increasing to $25 \%$ at $100 \mathrm{hPa}$. At pressures less than $100 \mathrm{hPa}$, where estimates of HALOE random and systematic uncertainties are available, the combined systematic error fully accounts for the observed positive bias of MIPAS. Combined random errors are fairly consistent with the root mean square of the relative differences from 0.1 down to $50 \mathrm{hPa}$. Zonal and seasonal averages of the relative difference (MIPAS-HALOE) are plotted in Fig. 28 and Fig. 29, respectively. No evidence for MRD higher than the expected systematic uncertainties emerges, when limiting the calculation of the average to the selected latitude bands or seasons. Table 8 summarises the results of the comparison between MIPAS and HALOE.

In the MIPAS operational processor (Raspollini et al., 2006), both v4.61 and v4.62 algorithms have included a cloud detection algorithm to identify clouds in MIPAS spectra so that such spectra are not included in the retrieval of 

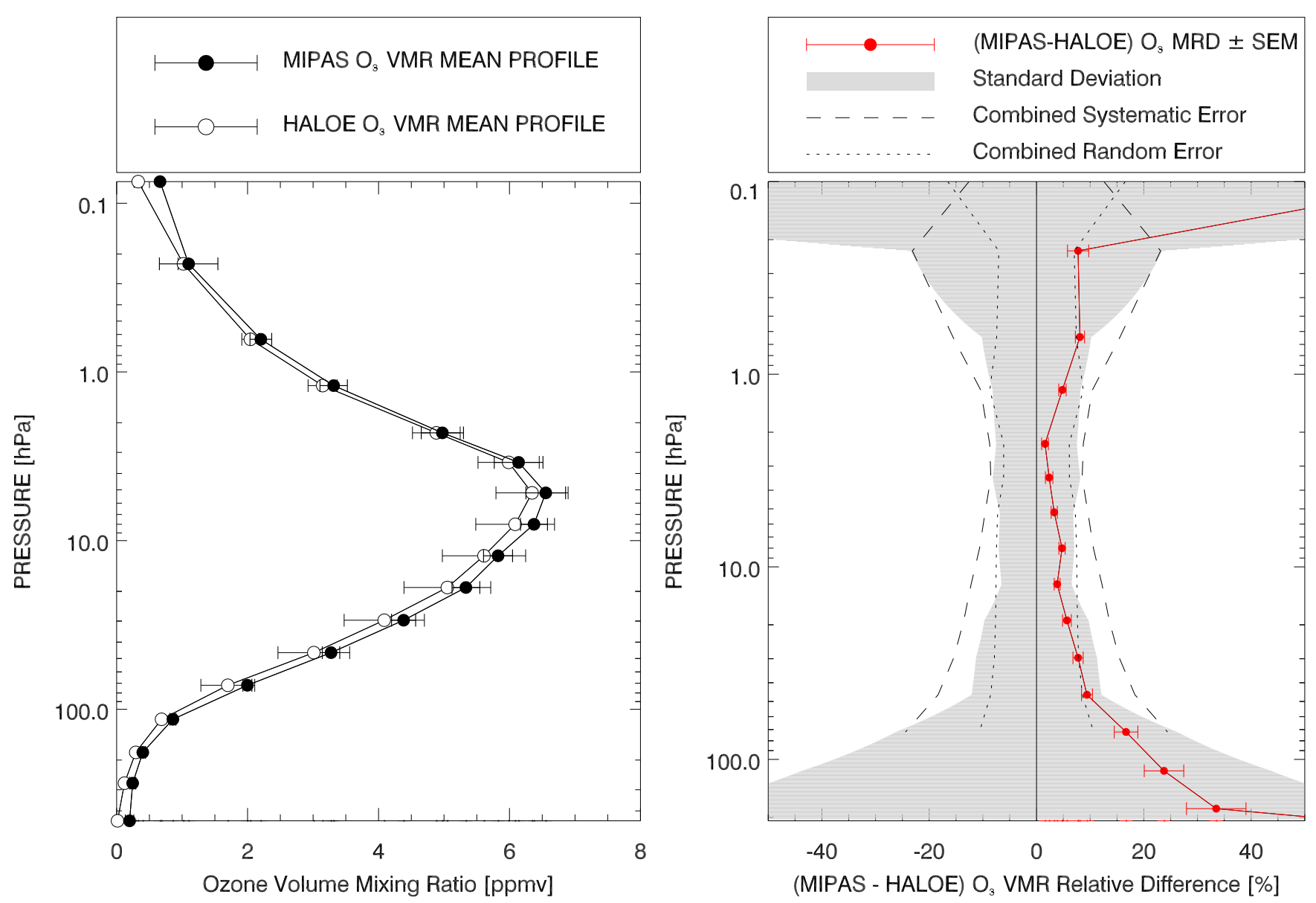

Fig. 27. Comparison between MIPAS and HALOE: statistics over all the collocated $\mathrm{O}_{3}$ profiles.

pressure/temperature and trace gases. For both versions, the cloud index for band A (the most commonly used cloud flag), CI-A, is set with $\mathrm{CI}-\mathrm{A} \leq 1.8$ as flagging cloud (Spang et al., 2004); the CI-A arises from the ratio of the integrated signal from $788-796 \mathrm{~cm}^{-1}$ with the integrated signal from $832-$ $834 \mathrm{~cm}^{-1}$.

A number of tests were performed to investigate whether the increased MIPAS - HALOE MRD below $50 \mathrm{hPa}$ may be due to inefficiencies in the cloud detection algorithm. Two possible scenarios are:

- the cloud detection algorithm does not effectively identify and remove cloudy level $1 \mathrm{~b}$ spectra allowing contaminated spectra to enter level 2 processing and resulting in anomalous ozone concentrations;

- the current CI-A threshold is not rigorous enough meaning that optically thinner clouds in the MIPAS FOV have a significant effect on lower altitude ozone concentrations and that this threshold should be raised.

To test the above hypotheses each MIPAS ozone profile used in the MIPAS vs. HALOE comparisons was isolated and compared to its corresponding CI value. For the MIPAS data that are used in this MIPAS-HALOE analysis, ozone data corresponding to $\mathrm{CI} \leq 1.8$ have been successfully removed in both versions of MIPAS data. In general it has been found that v4.61 processor has not always removed data corresponding to cloudy level $1 \mathrm{~b}$ spectra. A sub-section of MIPAS data was then cloud-screened using a range of CI thresholds, including CI-A $\leq 2.2$ (Sembhi et al., 2006) and up to CI$\mathrm{A} \leq 3.0$, and the analysis repeated. No significant change was found in the MRD between 50 and $100 \mathrm{hPa}$. Thus we can verify that for these cases, which are mid-latitude/polar tropospheric clouds, the current CI can sufficiently remove cloudcorrupted ozone data and increasing the threeshold does not improve the MRD. No coincidences were found in PSC dominated seasons/latitudes or in the tropics. It should be noted that anomalous ozone concentration observed in MIPAS data in the tropical upper troposphere and lower stratosphere (UTLS), where more frequent and higher tropical cirrus persist, are successfully removed when using a higher CI threshold (Sembhi et al., 2006). From the tests described above, it is concluded that MIPAS-HALOE ozone comparisons observed between 50 and $100 \mathrm{hPa}$ are not affected by 

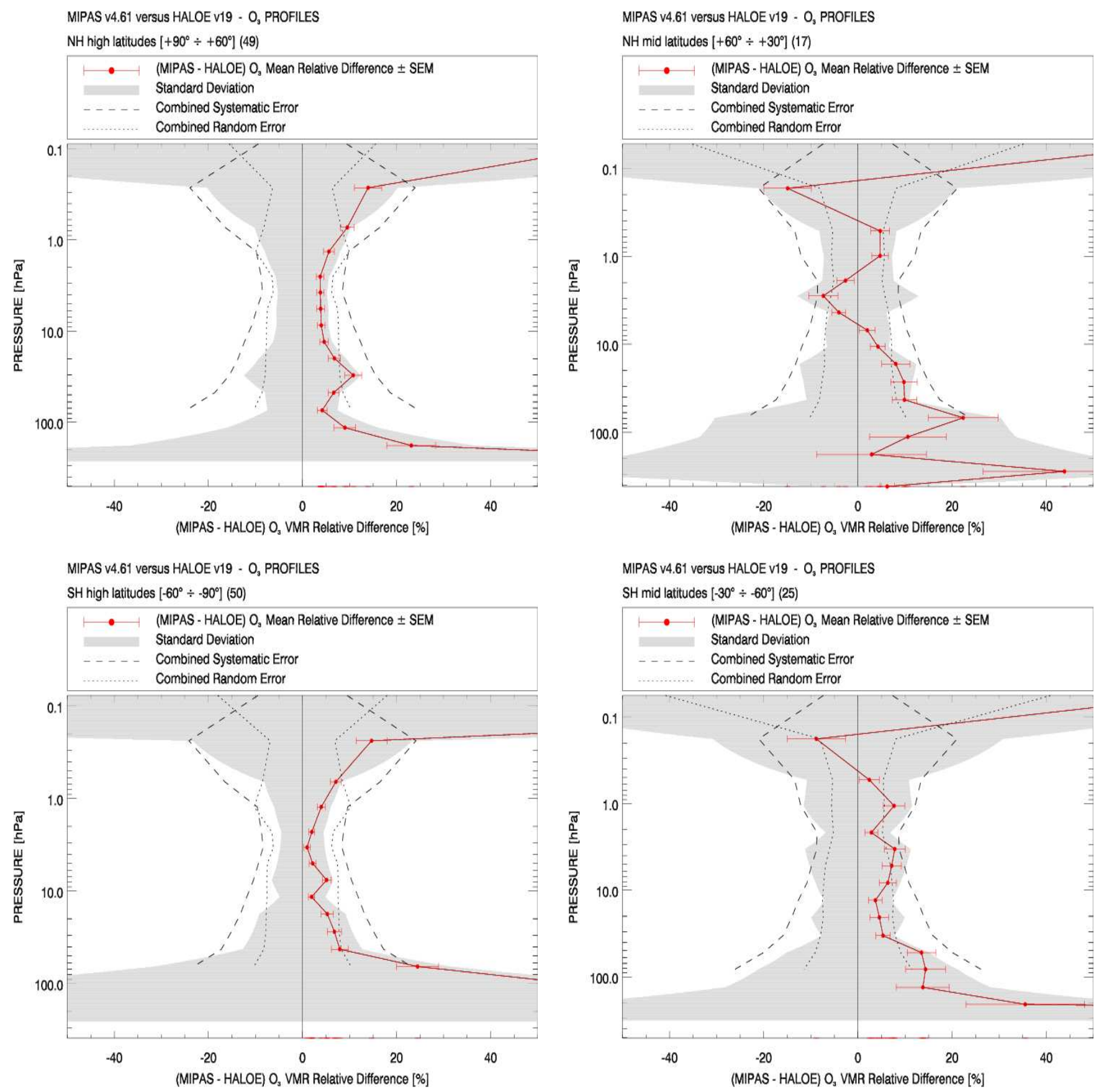

Fig. 28. Comparison between MIPAS and $\mathrm{HALOE}_{3}$ profiles: zonal averages.

cloud contamination and that the cloud detection algorithm is efficiently removing corrupt v4.61 and v4.62 MIPAS data in these cases.

Comparisons of updated HALOE ozone data (versions 18 and 19) with correlative satellite instruments show that generally, HALOE possesses a $5-10 \%$ negative bias at all altitudes below the ozone peak $(\mathrm{p} \sim 10 \mathrm{hPa})$ particularly in comparison to SAGE II - versions 5.93 and 6.0 (Morris et al., 2002), POAM III (Randall et al., 2003) and ACE-FTS
(McHugh et al., 2005). The largest differences of greater than $30 \%$ usually occur at $15 \mathrm{~km}$ and below but also differences of up to $20 \%$ occur near $22 \mathrm{~km}$ in some regions (mostly tropics and subtropics) with HALOE $<$ SAGE II. These comparisons and also the results of Borchi and Pommereau (2007) show that HALOE has a tendency to be low near altitudes of 15 to $20 \mathrm{~km}$ and below and differences are largely due to the band model used to simulate ozone in the HALOE forward model and aerosol/cirrus effects that become dominant when 

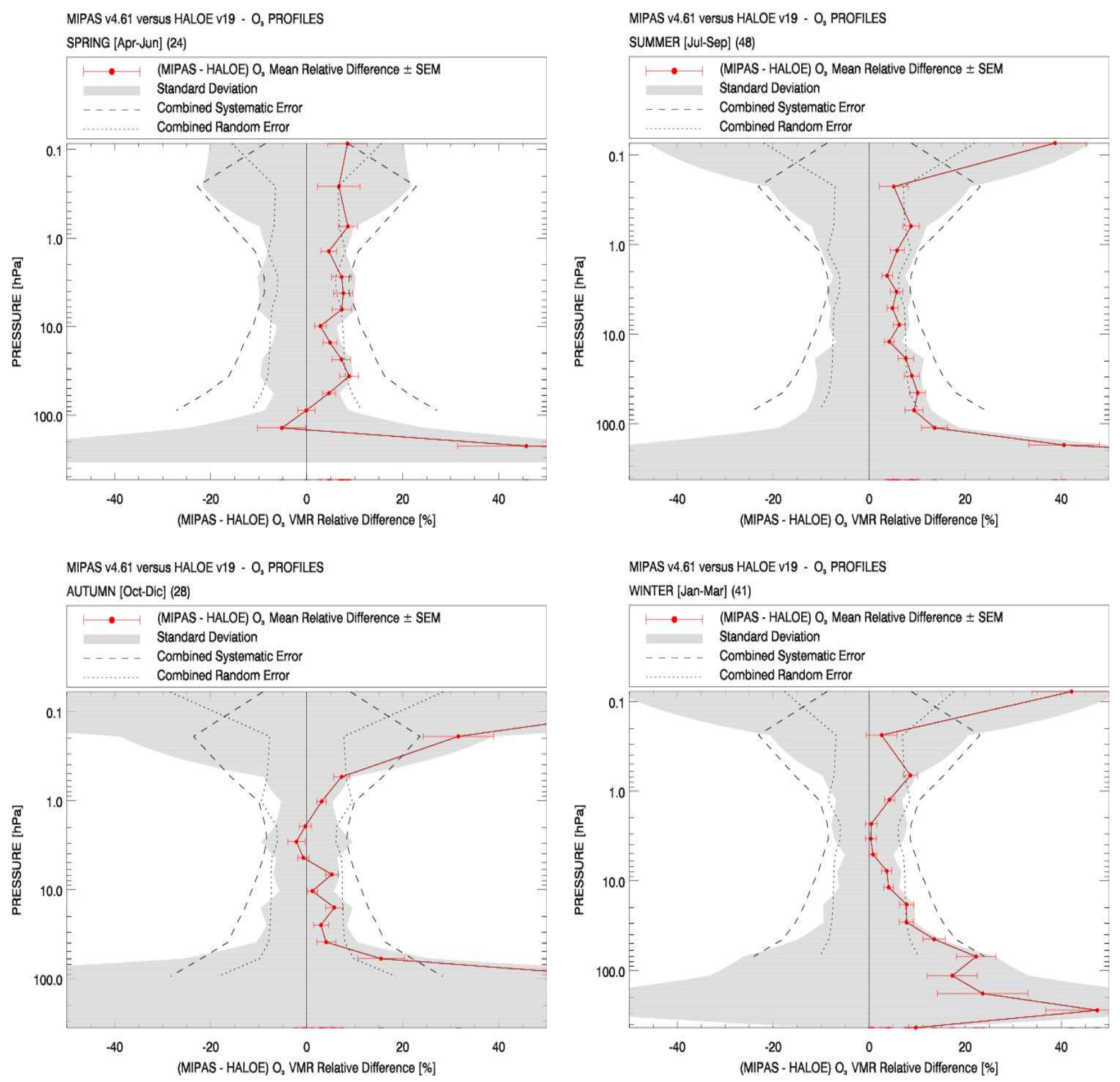

Fig. 29. Comparison between MIPAS and HALOE $\mathrm{O}_{3}$ profiles: seasonal averages.

the ozone signal reduces. It is possible that systematic discrepancies in addition to inaccuracies in HALOE pointing at lower altitudes are likely to contribute to the increased MRD below $50 \mathrm{hPa}$. Forward model errors are to be improved in HALOE version 20 set for release in late 2006 (E. Thompson, personal communication). The remaining MRD is likely to be biased toward MIPAS forward model and instrumental factors such as assumptions of horizontal homogenous atmosphere and uncertainties in the apodised instrument line shape (ILS) that are most significant between 12 and $20 \mathrm{~km}$.

\subsection{Comparison with $\mathrm{GOME} \mathrm{O}_{3}$ profiles}

\subsubsection{GOME data and comparison methodology}

The Global Ozone Monitoring Experiment (GOME) is a nadir viewing backscatter UV-visible spectrometer measuring contiguously between $237-790 \mathrm{~nm}$ with a spectral resolution of $0.2-0.4 \mathrm{~nm}$. It has been operating on the second European Remote-Sensing (ERS-2) satellite since 1995, with global coverage available up to May 2003. At the Rutherford 

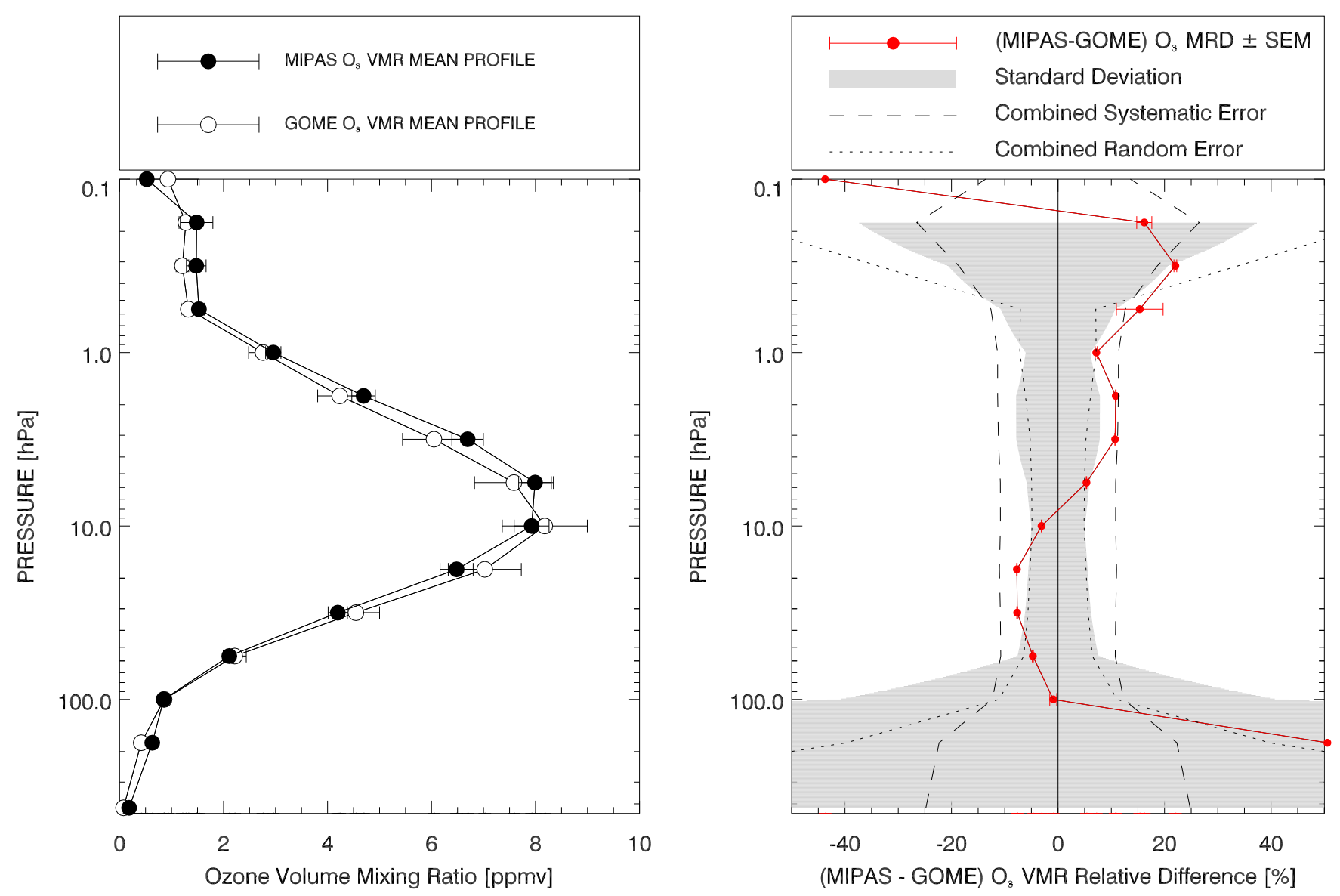

Fig. 30. Comparison between MIPAS and GOME ozone profiles. MIPAS and GOME $\mathrm{O}_{3}$ VMR mean profiles calculated on all the collocations available from $90^{\circ} \mathrm{S}$ to $60^{\circ} \mathrm{N}$ (left panel). Corresponding statistics for the relative differences between MIPAS and GOME and associated comparison error budget (right panel).

Appleton Laboratory (RAL), a retrieval scheme has been developed to retrieve ozone profiles spanning the troposphere and stratosphere (Munro et al., 1998), with vertical resolution of approximately $6 \mathrm{~km}$ in the stratosphere. The data produced by this retrieval scheme and used in our comparison have been validated against ozone sondes and has been found to agree within $10 \%$ in the altitude range between 12 and $40 \mathrm{~km}$. Larger biases have been identified in the Tropical UTLS below $50 \mathrm{hPa}$ with the GOME $\mathrm{O}_{3}$ values up to $50 \%$ higher compared to ozone sondes.

In this work, MIPAS version 4.61 ozone data have been validated against the GOME profiles for the time period between November 2002, and May 2003. Matching MIPAS and GOME profiles were found using the specified coincidence criteria of $3 \mathrm{~h}$ and $300 \mathrm{~km}$, with the best matched GOME profile used if there was more than one match to a given MIPAS profile.

The GOME ozone data were available on a fixed pressure grid between 1000 and $0.01 \mathrm{hPa}$. However, the comparison was restricted to altitudes below $1 \mathrm{hPa}$, as the GOME values are not reliable at high altitudes. Additionally any points where the GOME a priori was found to contribute significantly to the profile (using a cut-off where the reduction in error in the retrieved GOME data is less than $50 \%$ of the a priori error), have been removed.

In order to compare the MIPAS data to GOME, the MIPAS profiles were first interpolated (linearly in log pressure) to the GOME pressure grid. Since GOME has a lower resolution than MIPAS, the GOME averaging kernels were applied to the MIPAS data to degrade its resolution to match that of GOME. As the GOME averaging kernels were only quoted in units of number density the retrieved MIPAS temperature profile was used to convert to units of VMR. In order to apply the averaging kernels the MIPAS profile was extended to cover the complete range of the GOME pressure grid (1000$0.01 \mathrm{hPa}$ ) using ECMWF data below the lowest MIPAS level, and the GOME a priori profile at high altitudes. However, only values in the range of the original MIPAS data were used in the comparison, and a stringent check was applied to remove any points with a significant contribution from altitudes outside the MIPAS range. 

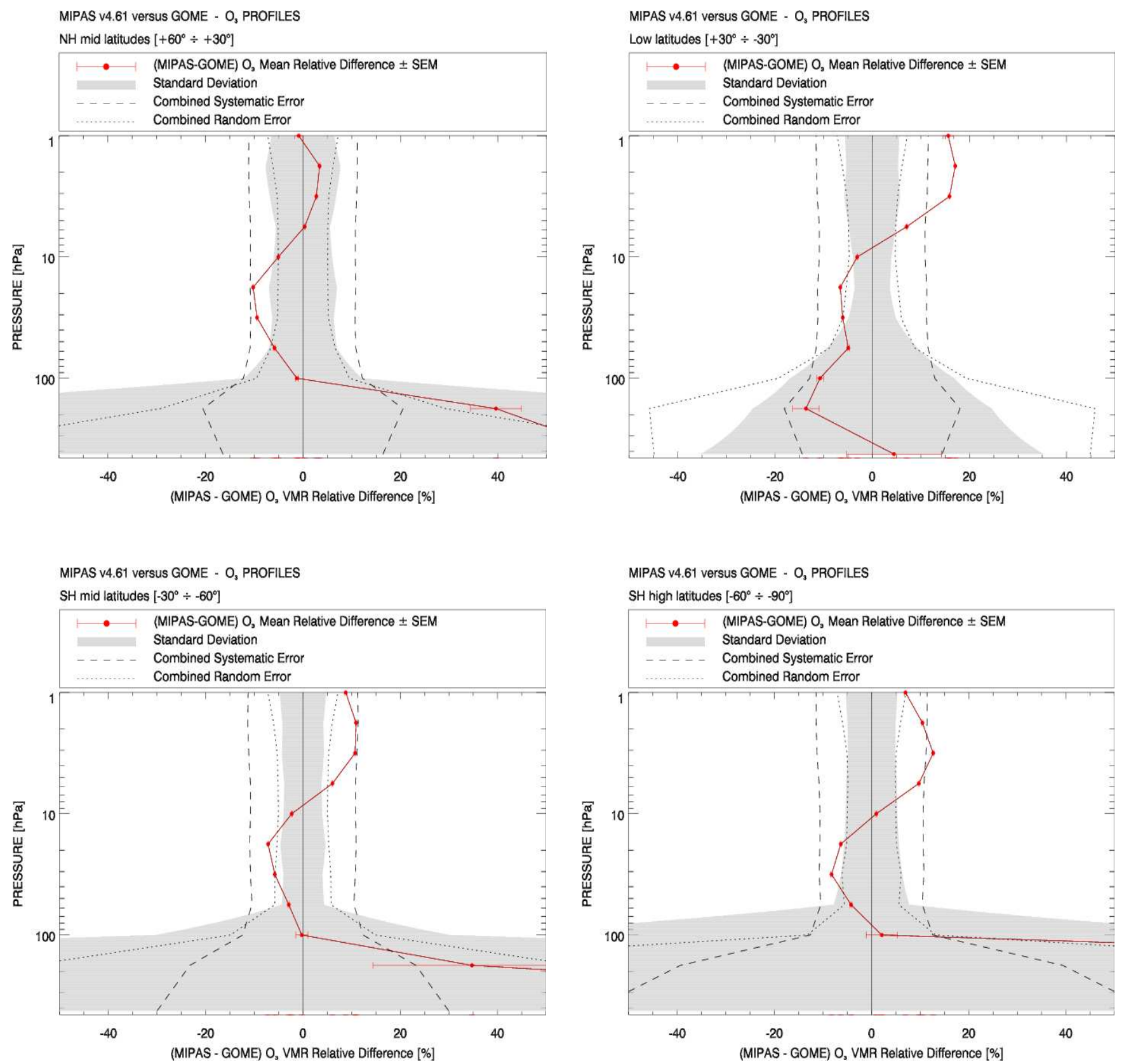

Fig. 31. Comparison between MIPAS and GOME $\mathrm{O}_{3}$ profiles: zonal averages.

The relative differences between the smoothed MIPAS profiles and the collocated GOME profiles were then determined by computing the mean absolute difference and dividing it by the mean GOME profile to obtain global, zonal and seasonal MRD profiles.

For the estimate of GOME total error budget, random errors were obtained from the data file, whilst the systematic error was taken to be $10 \%$. This data set has been validated to have a bias better than $10 \%$ in the range from $12-40 \mathrm{~km}$, although the errors may be greater than this at lower and higher altitudes. In the tropics below approximately $50 \mathrm{hPa}$, larger differences (up to 50\%) are observed. Below $100 \mathrm{hPa}$, the random errors in the GOME data can become large. The MIPAS errors were interpolated to the GOME pressure grid, and also had the GOME averaging kernels applied to give the appropriate errors for the smoothed MIPAS profile. In order to apply the averaging kernels the random error profiles were extended with errors of $100 \%$ above and below the MIPAS amplitudes. The averaging kernels were applied to the random error using Eq. (18):

$S_{A_{\mathrm{rnd}}}=A S_{\mathrm{rnd}} A^{T}$ 

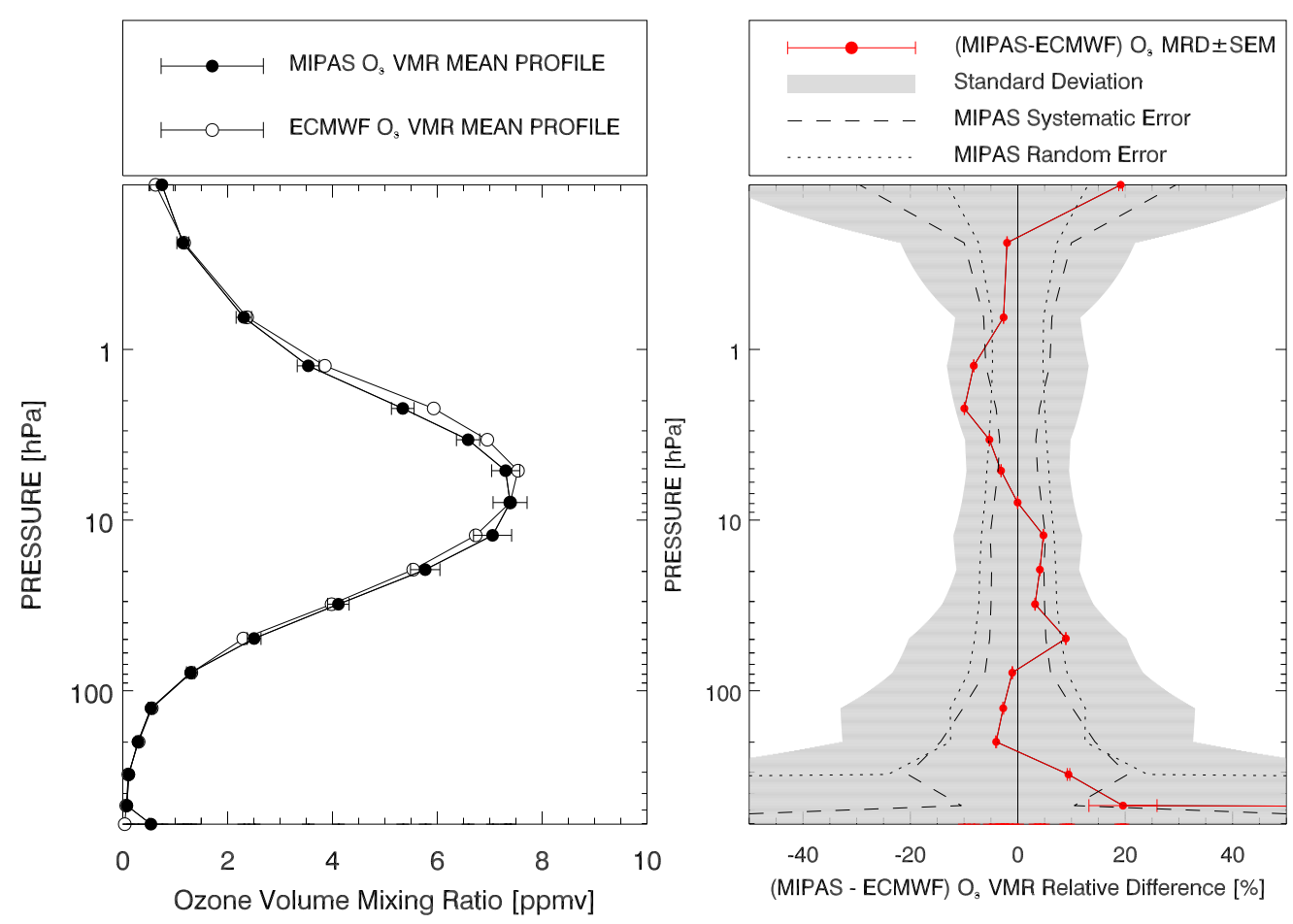

Fig. 32. MIPAS v4.61 and ECMWF $\mathrm{O}_{3}$ VMR mean profiles: global averages (on the left) and corresponding mean relative difference, standard deviation and MIPAS errors (on the right).

where $S_{\text {rnd }}$ is the MIPAS random covariance matrix (only the diagonal elements), whilst the systematic errors were derived from Eq. (19):

$S_{A_{\mathrm{sys}}}=A S_{\mathrm{sys}}$

where $S_{\text {sys }}$ is the systematic error profile.

\subsubsection{Results}

Results of the comparison between MIPAS and GOME $\mathrm{O}_{3}$ measurements, averaged over the whole set of collocated profiles, are shown in Fig. 30. Global means of the GOME ozone retrieved values and of the MIPAS smoothed profiles are displayed on the left panel. On the right, the statistics of the relative differences and of the comparison error budget is presented. Only points at latitudes south of $60^{\circ} \mathrm{N}$ have been included in the global zonal mean, as there was found to be a problem with a number of the GOME retrievals in the Northern Hemisphere high latitudes in April and early May 2003. The mean relative difference between MIPAS and GOME ozone mixing ratio is within the combined systematic error in the pressure range between about $1.0 \mathrm{hPa}$ and $200 \mathrm{hPa}$.

Moreover, as GOME only measures in sunlight, and the period of overlap between GOME and MIPAS was restricted, our comparison could achieve only a limited seasonal and latitudinal coverage. We calculated seasonal mean relative differences for the periods December 2002-February 2003 and March-May 2003 and found that the resulting profiles (not shown here) do not exhibit any relevant features with respect to the global average. Zonal MRD profiles were obtained by averaging over the latitude bands $\left[30^{\circ} \mathrm{N}-60^{\circ} \mathrm{N}\right]$, $\left[30^{\circ} \mathrm{S}-30^{\circ} \mathrm{N}\right],\left[60^{\circ} \mathrm{S}-30^{\circ} \mathrm{S}\right]$ and. $\left[90^{\circ} \mathrm{S}-60^{\circ} \mathrm{S}\right]$, as shown in Fig. 31. A peculiar behaviour is found, at the higher pressure levels, for the low latitudes compared to mid and high latitudes: MRD values within $\pm 5 \%$ are obtained in the belt from $30^{\circ} \mathrm{S}$ to $30^{\circ} \mathrm{N}$, with MIPAS mostly underestimating the ozone content with respect to GOME around $\sim 200 \mathrm{hPa}$; in the other bands, large positive values of the MRD are generally found below $\sim 100 \mathrm{hPa}$. The latter can be explained by a few anomalously high values in MIPAS profiles at these heights, possibly due to the presence of undetected clouds. In the tropics, most of the points at the lowest pressure levels are removed, either because the a priori contribution to the GOME retrieved value is more than $50 \%$ or because a significant area of the GOME averaging kernels lies below the bottom of the MIPAS profile (generally $15 \mathrm{~km}$ at low latitude). If we take into account that the GOME retrieved profiles generally overestimate the ozone content in the Tropical UTLS, the negative bias observed for MIPAS data in comparison with GOME appears to be reasonably justified. 

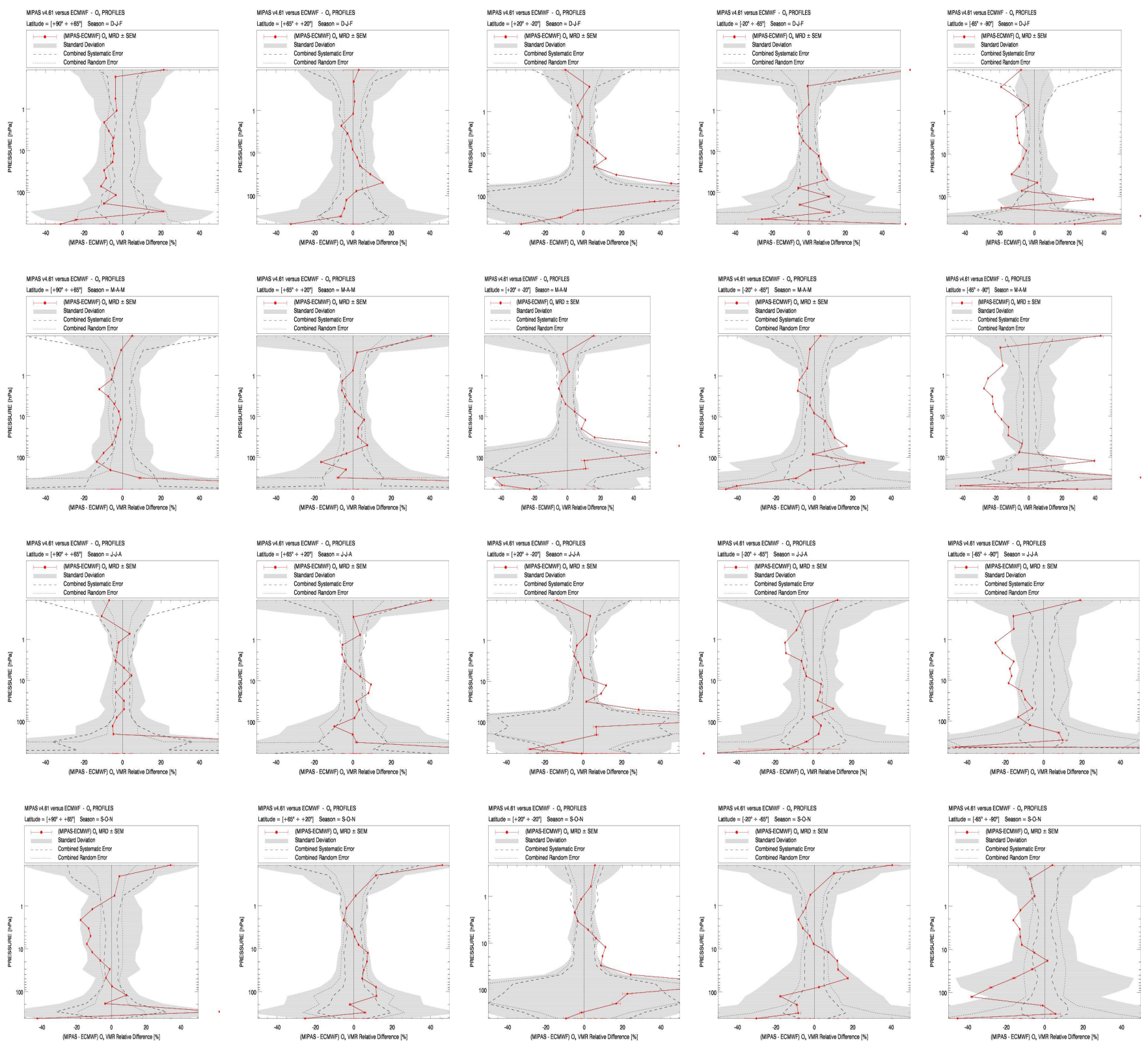

Fig. 33. Comparison between MIPAS v4.61 and ECMWF $\mathrm{O}_{3}$ VMR mean profiles: zonal and seasonal averages.

\section{Comparison with ECMWF assimilated fields}

\subsection{ECMWF data and comparison methodology}

As part of the coordinated effort for the validation of MIPAS full spectral resolution measurements, we have compared MIPAS $\mathrm{O}_{3}$ profiles v4.61 with assimilated ozone fields obtained from the ECMWF operational analysis data archived at the British Atmospheric Data Center (BADC). The ozone mass mixing ratio was provided every $6 \mathrm{~h}$ on an N80 reduced gaussian grid, and vertically on 60 model levels up to $0.1 \mathrm{hPa}$. This was converted to volume mixing ratio, and spatially (in latitude and longitude) and temporally interpolated to the av- erage geo-location and time of each MIPAS scan. The profiles were then interpolated vertically and had MIPAS averaging kernels applied. Prior to October 2003 the operational ECMWF system assimilated only data from SBUV/2 and GOME, which are limited in vertical resolution and restricted to day-time only measurements. SBUV/2 data have been assimilated since April 2002 as 6 layers, with the lowest layer covering the altitude range between $16 \mathrm{hPa}$ and the surface, and has been restricted to observations with solar zenith angles less than 84 degrees. Total column ozone data from GOME were assimilated between April 2002 and June 2003, at latitudes between $40^{\circ} \mathrm{N}$ and $50^{\circ} \mathrm{S}$, and for solar zenith 
angles less than 80 degrees. Between 7 October 2003 and 25 March 2004 MIPAS (version 4.59) data were also assimilated. We have therefore limited our comparison to the period from July 2002 to September 2003, during which ECMWF data represent an independent source for the validation of MIPAS-ENVISAT $\mathrm{O}_{3}$ products.

Quantitative errors were not available for the ECMWF ozone data, and no errors have been included for ECMWF in the plots shown in this paper. In the analysis of the ERA-40 ozone data quality (similar to that of the operational ECMWF data used here prior to the assimilation of MIPAS) conducted by Dethof and Hélm (2004) the ozone profiles were generally found to compare well with independent observations, except for the case of high latitude winter and spring profiles in both hemispheres, where large discrepancies in the ECMWF data were observed. In addition, a low bias was observed for the peak ozone values in the tropics. The "Assimilation of Envisat data" project (ASSET) compared ozone analyses including ECMWF, for the period between July to November 2003 (Geer et al., 2006). In general it was found that ECMWF data agreed to within $\pm 10 \%$ compared to sonde data throughout much of the stratosphere. However larger biases were seen in the UTLS, the troposphere, the mesosphere and for profiles in the Antarctic region. Above $5 \mathrm{hPa}$ there was observed to be a positive bias compared to HALOE, whilst in the mesosphere the model does not include diurnal variability. A low bias was observed in the ECMWF data at the tropical tropopause, whilst in the lower stratosphere ECMWF data were generally biased high compared to the sondes.

The procedure we adopted for comparing ECMWF and MIPAS ozone data is based on the same scheme described in Sect. 6.1 for the comparison with concurrent satellite measurements, although data were averaged over pressure bins, rather than interpolated to a fixed pressure grid. We selected all the MIPAS ozone profiles within the comparison period, except those for which any of the quality flags were set as bad or that contained ozone VMR values greater than $100 \mathrm{ppmv}$, or equal to $10^{-10} \mathrm{ppmv}$, or where the associated variances were negative. For each MIPAS profile, collocated values were obtained, as previously mentioned, by interpolation of the ECMWF ozone VMR fields, both horizontally and temporally. MIPAS averaging kernels were applied vertically to the ECMWF profiles using a modified version of the routine generally adopted in all other cases. In this procedure, the nominal MIPAS averaging kernels were adjusted to match the true pressure levels of each individual MIPAS measurement, whilst the correlative ECMWF data were interpolated to the fine pressure grid on which the averaging kernels were supplied. These averaging kernels were then applied to the adjusted ECMWF data, providing correlative data on the same pressure grid as each of the individual profiles.

The absolute differences between MIPAS $\mathrm{O}_{3}$ VMR and ECMWF values were computed for each of the individual
MIPAS profiles. These were then binned into fixed pressure bins, defined by the midpoints between the nominal retrieval levels for the pressure profile from the mid-latitude reference atmosphere. The mean relative difference (defined by the ratio between the mean absolute difference and the mean ECMWF profile in percent) in each pressure bin was then determined, along with the corresponding mean pressure in each bin.

Global mean profiles of the relative differences have been calculated, along with zonal and seasonal averages over five latitude bands $\left(90^{\circ} \mathrm{N}-65^{\circ} \mathrm{N}, 65^{\circ} \mathrm{N}-20^{\circ} \mathrm{N}, 20^{\circ} \mathrm{N}-20^{\circ} \mathrm{S}\right.$, $20^{\circ} \mathrm{S}-65^{\circ} \mathrm{S}, 65^{\circ} \mathrm{S}-90^{\circ} \mathrm{S}$ ) and four seasons (JJA, including data for July-August 2002 and June-August 2003; SON, including data for September-November 2002 and September 2003; DJF, including data for December 2002 and JanuaryFebruary 2003; MAM, including data for March-May 2003). Random and systematic error estimates were allocated to each mean profile of the relative differences, taking into account only the contribution from MIPAS uncertainties.

\subsection{Results of the comparison}

Mean $\mathrm{O}_{3}$ VMR profiles from global averages of MIPAS v4.61 and ECMWF data are shown in Fig. 32, along with their mean relative difference and combined error estimates. MRD mostly falls within the MIPAS systematic error and appears to be associated with a slight altitude shift between the MIPAS and the ECMWF profiles, that is reflected in significant biases (i.e. $|\mathrm{MRD}|>$ MIPAS systematic error) around $2 \mathrm{hPa}$ and $50 \mathrm{hPa}$. A closer insight can be gained by examining the latitudinal and seasonal dependency of the relative difference between MIPAS and ECMWF ozone profiles. This is shown in Fig. 33, where zonal and seasonal averages, calculated over the 2002-2003 data, are displayed. A substantially good agreement is evident, throughout all seasons, at mid-latitude, both in the Northern and in the Southern Hemisphere, whilst major differences are clearly highlighted in the tropics and at high latitude, particularly in the Antarctic region. In the latitude band between $20^{\circ} \mathrm{N}$ and $20^{\circ} \mathrm{S}$, we observe that MIPAS constantly overestimates the $\mathrm{O}_{3}$ mixing ratio relative to ECMWF by up to $100 \%$ at pressures higher than $\sim 50-60 \mathrm{hPa}$ (approximately $20-25 \mathrm{~km}$ ). On the other hand, a negative bias in the range of $\sim 10$ to $\sim 25 \%$ characterizes the MRD at levels above $\sim 5 \mathrm{hPa}$ in the Southern high latitudes, especially during Summer and Spring (and, slightly reduced, during Winter. This confirms the bias already observed by the ASSET results in the ECMWF data). In the same latitude band large positive and negative differences are found in different seasons around $\sim 100 \mathrm{hPa}$ (up to $+40 \%$ in Winter and Autumn and $\sim 40 \%$ in Summer) possibly connected to the presence of Polar Stratospheric Clouds. Similarly, we assume that the discrepancy observed between MIPAS and ECMWF ozone values at the tropical tropopause might be caused by the presence of high altitude cirrus clouds in the latitude range $\left[20^{\circ} \mathrm{N}-20^{\circ} \mathrm{S}\right]$. 


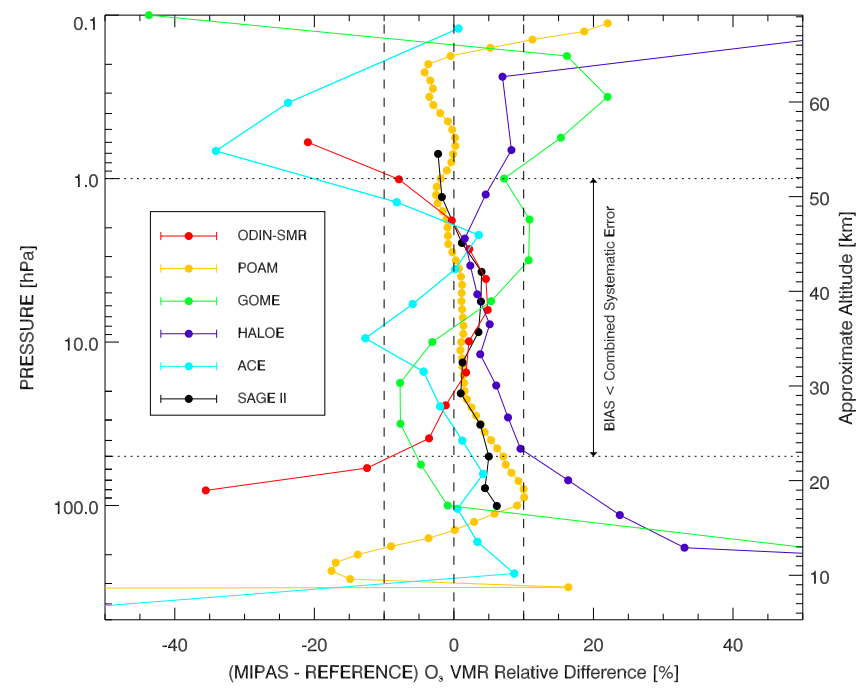

Fig. 34. Summary plot of global mean relative differences between MIPAS $\mathrm{O}_{3}$ VMR profiles and coincidence measurements by concurrent satellite sensors.

In summary, we can conclude that a good agreement is found between MIPAS v4.61 and ECMWF ozone data, with the only notable exception of the discrepancies observed in the SH high latitude at about $100 \mathrm{hPa}$ and in the tropical tropopause, that might be attributed respectively to the presence of Polar Stratospheric Clouds and of high altitude cirrus (see Sect. 8). All the other relevant differences that we could identify in the seasonal and zonal averages can be explained by known effects due to the quality of ECMWF data.

\section{Summary and discussion of the results}

In this section we will go over the main points of the comparison with the different categories of correlative data selected for the validation of MIPAS $\mathrm{O}_{3}$ operational products and we will make an attempt to merge the key results obtained from each group of reference measurements into an overall assessment of MIPAS ozone data quality. We start our summary by focusing on the outcome of the comparisons with other satellite sensors, that - in view of the better spatial and temporal coverage - are capable of providing, by their own right, a general indication on the validity of MIPAS $\mathrm{O}_{3}$ profiles. In Fig. 34, we report the global average of the relative difference between MIPAS and collocated ozone profiles obtained by concurrent space-borne instruments.

An excellent agreement is found in most of the comparisons at pressures ranging from approximately $50 \mathrm{hPa}$ up to $1.0 \mathrm{hPa}$, with MRD values constantly within $\pm 10 \%$ (with the only small exception of the value $\sim 10 \mathrm{hPa}$ for the comparison with ACE-FTS). The results of individual comparisons consistently show that, within this pressure range (roughly corresponding to the altitude interval between $50 \mathrm{~km}$ and 20
$25 \mathrm{~km}$ ), the observed bias is always lower than the combined systematic error. The slightly larger bias observed in the comparison with ACE-FTS measurements, marginally exceeding the combined systematic error around $10 \mathrm{hPa}$, can be possibly explained by the limited number of coincident profiles available for the validation of MIPAS measurements and by the coarse characterisation of ACE-FTS systematic error available for our comparison. Below $20-25 \mathrm{~km}$ and above $50 \mathrm{~km}$, an increase in the absolute values of the global MRD of ozone VMR profiles is generally observed. At the higher pressure levels, particularly around $100 \mathrm{hPa}$, MIPAS $\mathrm{O}_{3}$ values are $5 \%$ to $25 \%$ larger compared to the majority of the validating satellite sensors. Only in the case of the comparison with POAM III data, however, this positive bias is larger than the combined systematic errors of the comparison. No coherent indications can be derived from the large differences observed at the lowermost levels, where the occurrence of stronger atmospheric gradients results in a significant enhancement of different components of the comparison error (primarily those due to time-space mismatch and to differences in vertical and horizontal smoothing). The effect of the larger natural variability on the spatial and temporal scale of the selected coincidence criteria can also be highlighted by looking at the standard deviation of the mean relative differences between MIPAS and other space-borne sensors in comparison with the combined random error. In general, SD and random uncertainty exhibit a very good matching in the stratosphere down to approximately $20 \mathrm{~km}$ or $\sim 60$ $80 \mathrm{hPa}(25 \mathrm{~km}$ or $\sim 30-40 \mathrm{hPa}$ in the case of SAGEII and ODIN-SMR), whilst the standard deviations become increasingly larger than the estimated random error in the lowermost stratosphere and in the upper troposphere. Much greater SD values are found throughout the full altitude range only in the case of the comparison with ACE (Fig. 26). The remarkably good quality of MIPAS v4.61 and v4.62 ozone profiles in the pressure range $1-50 \mathrm{hPa}$, emerging from the results of satellite comparison, is amply confirmed by the extensive analysis we conducted using a variety of ground-based correlative data. Ground-based validation and satellite measurements, on the other hand, also reflect a similar degradation in the outcome of the comparison for the UT and LS regions with respect to the middle stratosphere. In particular, the pole-topole validation, based on ozone sondes, lidar and MWR data from the NDACC network clearly indicates a variability of the results for different synoptic regions below $25 \mathrm{~km}$, with a prevalence of positive biases between 5\% and 20\%. Only in a few cases, a significant bias is found between 25 and $40 \mathrm{~km}$ and the mean difference is always lower than $10 \%$. Evidence of a low bias in MIPAS ozone measurements are also occasionally found, as in the case of the comparison with FTIR $\mathrm{O}_{3}$ partial columns described in Sect. 4.3. Here, significant mean differences are obtained at two stations (Lauder and Arrival Heights), that could be possibly caused by the use of different micro-windows for the retrieval of the $\mathrm{O}_{3}$ profile. 
In order to better investigate the source of the larger discrepancies we found in the altitude range between $25 \mathrm{~km}$ and MIPAS lowest tangent heights, a valuable tool is offered by the comparison with coincident measurements acquired on-board high altitude platforms. The possibility of planning validation flights in optimal coincidence with the satellite overpass and according to the most favourable meteorological conditions, makes it feasible (especially for aircraft payloads) to acquire correlative measurements with minimum spatial and temporal mismatch (often much lower than the required $300 \mathrm{~km}$ and $3 \mathrm{~h}$ ) and in completely clear sky. Most of the balloon and aircraft data presented in this paper satisfy, in fact, the above mentioned requirements, as in the case of MIPAS-B balloon data that were generally obtained from almost perfect time and space coincidence with MIPAS-ENVISAT or in the case of the M-55 Geophysica validation flights that were mostly executed in cloud free conditions. In these cases, we obtain a substantial agreement between MIPAS $\mathrm{O}_{3}$ data and collocated reference profiles also at lower stratospheric and upper tropospheric altitudes, where significant biases and lower precision had been generally found by ground-based and satellite validation experiments. Our results from balloon-borne validation measurements (MIPAS-B, FIRS-2 and SPIRALE) typically provide a mean difference of $\mathrm{O}_{3}$ mixing ratio within $\pm 0.5 \mathrm{ppmv}$ for the full vertical range of the comparison $(\sim 10-35 \mathrm{~km})$. The only exception is offered by the results of the comparison with $\mathrm{O}_{3}$ profiles recorded during the trans-Mediterranean flight of the IBEX spectrometer. In this case, a low bias of MIPAS $\mathrm{O}_{3}$ VMR was observed using trajectory analysis with mean relative differences as high as $30 \%$ between 15 and $20 \mathrm{~km}$. The airborne data set from the validation campaigns with the M-55 Geophysica provides a further clue of the fair quality of MIPAS-ENVISAT ozone measurements in the range from 10 to $20 \mathrm{~km}$; showing that a good match is normally found between the satellite and the aircraft profiles and that discrepancies exceeding our estimate of the total error budget can often be explained in terms of different air masses measured by the satellite or by aircraft sensors. Even though, due to the sparse character of their geographical and temporal coverage, balloon and aircraft measurements can be used to derive information of limited statistical value, still these results suggest that the large discrepancies observed below $20-25 \mathrm{~km}$ must be partly ascribed to the influence of natural variability on the outcome of the comparison.

Additional sources of the discrepancies observed in $\mathrm{O}_{3}$ VMR values at lower altitudes, can be identified on the basis of complementary hypotheses that emerge from specific subsets of individual results. A critical issue is certainly represented by the current choice of the thresholds for the Cloud Index value (Raspollini et al., 2006), that may not be sufficiently stringent to enable the removal of all significant cloud contamination effects from MIPAS ozone retrievals at all latitudes (Glatthor et al., 2006; Sembhi et al., 2006). This might explain, for instance, the high MIPAS $\mathrm{O}_{3}$ values responsi- ble for the large differences observed in the comparison with GOME collocated profiles for $\mathrm{p}>100 \mathrm{hPa}$ in the extratropics (cp. Sect. 6.6); and this is reasonably the cause of the positive bias (MRD $>30 \%$ below $18 \mathrm{~km}$ ) between MIPAS measurements and lidar profiles in the tropics (cp. Sect. 4.2) and in the ECMWF results (cp. Sect. 7.2) and of the worst agreement that is found in the same region with respect to the ASUR data (cp. Sect. 5.5). However, no definite proof of cloud contamination has been established in this study.

Moreover, when evaluating the outcome of our validation exercise, we should take properly into account some of the limitations associated to our estimate of the systematic and random component of the comparison error budget. First of all the choice of considering the different a priori systematic errors as contributing either to the bias (purely systematic errors) or to its standard deviation (systematic errors with a random variability) should in principle be made according to the kind of spatial and temporal average of the individual comparison. On the contrary, the application of uniform criteria to a variety of time and space scales might result in under or over-estimation of both MIPAS systematic and random uncertainty. In addition to this, we must remember that the a priori error values we used for our estimates rely on a linear approximation of the University of Oxford reference forward model and tend to underestimate the actual contributions of systematic uncertainties to the total error budget especially at the lower altitudes.

\section{Conclusions}

In this paper, we have presented the results of an extensive analysis aimed at the validation of MIPAS-ENVISAT $\mathrm{O}_{3}$ vertical profiles obtained during the instrument full spectral resolution mission (6 July 2002-26 March 2004) and retrieved using versions 4.61 and 4.62 of the ESA operational processor.

The validation strategy was based on the synergistic use of a variety of correlative data sets from independent sources, with complementary features in terms of the trade-offs between accuracy and spatial and temporal coverage.

We compared MIPAS ozone partial columns and vertical profiles with collocated measurements from instruments at more than 50 NDACC ground-based stations (ozone sondes, lidar, FTIR and microwave radiometers), from remotesensing and in situ sensors aboard stratospheric aircraft (MIPAS-STR, SAFIRE-A, FOZAN, ASUR) and balloon (FIRS-2, IBEX, MIPAS-B2, SPIRALE) and from 6 concurrent satellite sensors (SAGE II, POAM III, ACE-FTS, ODINSMR, HALOE, GOME), as well as with assimilated fields from ECMWF.

Special attention was paid to rigorous selection of reference data, based on homogeneous criteria that were only slightly adapted, from case to case, to match the specific 
features of each validation data set and of the selected comparison methodologies.

The overall picture that can be derived from the output of the comparisons with the individual groups of collocated ozone measurements provides a sound basis for the required assessment on the validity of MIPAS ozone profiles over a wide range of altitudes, latitudes and seasons.

The very good agreement, that was found between $50 \mathrm{hPa}$ and $1 \mathrm{hPa}$ with the majority of correlative data sets, demonstrates the inherent high quality of MIPAS ozone measurements through most of the stratosphere. The mean relative differences with correlative data are within $\pm 10 \%$ and no apparent bias was observed, in this pressure range, that could not be explained by known systematic effects already included in the comparison error budget. Similarly, the variability of the global mean differences between MIPAS and coincident $\mathrm{O}_{3}$ profiles appears to be fully consistent with the expected random error from $1 \mathrm{hPa}$ down to at least 30$40 \mathrm{hPa}$.

We can conclude therefore that in the altitude interval between approximately $20-25 \mathrm{~km}$ and $50-55 \mathrm{~km}$, the existing estimate of MIPAS $\mathrm{O}_{3}$ systematic error sources provided by University of Oxford are substantially correct; and that MIPAS $\mathrm{O}_{3}$ precision error, as computed from level-2 data and from Univ. of Oxford a priori estimate for $\mathrm{pT}$ error propagation, is equally appropriate. We recall here that, according to the pre-launch calculations of the Oxford team, the systematic and the random components of the a priori error budget (evaluated for a single ozone profile at mid-latitude and in daytime conditions) have an average value of $\sim 6 \%$ and $\sim 5 \%$ respectively in the altitude interval between $20 \mathrm{~km}$ and $52 \mathrm{~km}$. At lower and higher altitudes, a roughly linear increase of both the random and systematic uncertainties is expected up to $\sim 15-20 \%$ at $10 \mathrm{~km}$ and up to up to $\sim 30-35 \%$ at $68 \mathrm{~km}$.

Below $20 \mathrm{~km}$, we generally observe a degradation of the agreement between MIPAS and most of the coincident data, with the appearance of statistically significant biases from $5 \%$ to approximately $25 \%$ at $100 \mathrm{hPa}$ and standard deviation substantially larger than the combined random errors by a factor of 1.5 to 3.0 in the range $\sim 50-100 \mathrm{hPa}$. Part of the discrepancies at pressure levels greater than $\sim 100 \mathrm{hPa}$ can reasonably be traced to the higher variability of the air masses in the lowermost stratosphere and upper troposphere (as clearly shown in Sect. 4.1 by the detailed analysis based on NDACC data, demonstrating that atmospheric inhomogeneities, and particularly horizontal gradients, represent a major component of the comparison error budget).

Further sources of uncertainty, affecting the results of our comparisons, have been identified, that can be more directly translated into specific recommendations for possible improvements of MIPAS ozone data quality and error estimate.

Positive biases, associated with unrealistically large ozone values at the bottom end of MIPAS profiles and observed with respect to various sets of correlative data (cp. the re- sults of the comparison with ground-based ozone sondes and lidar measurements, ASUR or GOME data for typical examples), can be reasonably ascribed to residual cloud contamination. This interpretation would suggest a more conservative choice, in terms of cloud filtering capabilities, for the threshold value of the Cloud Index is needed.

The evidence for an underestimate of MIPAS random error in the lower stratosphere and upper troposphere is also consistent with the linear approximation of the forward model adopted by University of Oxford for the a priori evaluation of systematic errors with random variability. As clearly demonstrated by the results of the comparison in the middle and upper stratosphere, this approximation properly describes the a priori uncertainties down to $20-25 \mathrm{~km}$, but might become inadequate at lower altitudes.

In general, we cannot avoid the intrinsic limit of the linear approach to the calculation of the a priori contributions to MIPAS random error, but some margin of improvement can still be identified in our estimate of specific components. A typical example is provided by the $\mathrm{pT}$ error propagation, that we entered in our calculation of the overall random uncertainty of the comparison. This is an approximate value, both as a consequence of the linearisation introduced to calculate the pT propagation matrices, as well as of the assumptions made for the choice of the pressure and temperature error value to propagate. Since the latter values are mostly underestimated at lower altitudes, this leads to an underestimation also for the contribution of the $\mathrm{pT}$ error propagation to the overall random error budget.

A more realistic estimate could be obtained by considering the actual values for the pressure and temperature retrieval error and propagating it by means of pre-computed matrices included in ESA level-2 data products. A problem due to the incorrect implementation of the $\mathrm{pT}$ error propagation algorithm in MIPAS operational data v4.61 and v4.62 prevented us from using this procedure in our comparison, but will be corrected in future versions, thus making it possible to slightly improve the estimate of MIPAS random uncertainty.

At pressures lower than $1 \mathrm{hPa}$ and particularly for the uppermost retrieval levels of MIPAS ozone profiles, a tendency to observe larger differences is generally shown by our analysis. However, fewer coincidences, mostly from correlative measurements provided by other satellite sensors, are available at these altitude and the output of the comparison cannot achieve the same statistical value as for the rest of the profile. Moreover the larger uncertainties of the reference data in this range and the relatively poor characterisation of their random and systematic errors do not allow us to consider them, in a strict sense, as a useful data set for validation purposes. As a consequence, we cannot derive any quantitative assessment for the quality of MIPAS ozone profiles for $\mathrm{p}<1 \mathrm{hPa}$.

Taking into account the summary of our results and the recommendations and caveats we expressed in our conclusions, we can assess that MIPAS ozone operational data v4.61 and v4.62 are validated in the vertical range from 
$\mathrm{p} \sim 1 \mathrm{hPa}$ down to the lower stratosphere and can be used, therefore, in quantitative scientific studies.

Acknowledgements. The correlative data from ground-based lidar, microwave radiometer and balloon-based ozone sonde used in this publication were obtained as part of WMO's Global Atmospheric Watch (GAW) programme, including the Network for the Detection of Atmospheric Composition Change (NDACC), and are publicly available via the NDACC and World Ozone and Ultraviolet Data Center (WOUDC) archives (see http://www.ndacc.org and http://www.woudc.org). We thank warmly several members of the NDACC community for fruitful discussions. NASA's Southern Hemisphere Additional Ozonesonde programme (SHADOZ) provided useful ozonesonde data in the tropics. The BASCOE team at BIRA-IASB (http://bascoe.oma.be) is acknowledged for generating and providing assimilated MIPAS ozone fields used for the assessment of ground-based comparison errors. The reported work was supported partly by ESA-funded projects EQUAL and TASTE, and by the ProDEx project CINAMON. The EQUAL project relies on the contribution of lidar data which are nationally funded and supported. We are grateful for the contributions from the following institutes, and thank their co-workers who contributed to generating these data, NILU (ALOMAR,Andoya station, PI is G. H. Hansen), MSC (Eureka station, PI is K. Strawbridge), DWD (Hohenpeissenberg station, PI is H. Claude), RIVM and NIWA (Lauder station, PI is D. P. J. Swart), NASA/JPL (Mauna Loa Observatory and Table Mountain Facility, PI is I. S. McDermid), AWI (Ny-Ålesund station, PI is P. von der Gathen), CNRS and CNES (Observatoire Haute Provence, PI is S. Godin-Beekmann), and NIES (Tsukuba station, PI is H. Nakane). The FTIR teams acknowledge their national authorities for supporting the observations and the many people who have participated to them. In addition, they wish to thank the Stiftungsrat of the Jungfraujoch for supporting the facilities allowing to perform long term and regular observations at that site and Antarctica New Zealand for supporting the Antarctic measurements. Funding for FTIR measurements at Arrival Heights were provided by the New Zealand Foundation for Research Science and Technology and by ESA as part of the TASTE project. The validation work by IUP-IFE Bremen was funded in part by BMBF (FKZ01 SF994) and ESA/ESRIN under the SciLoV project. The validation work by the team of the Institute of Atmospheric Physics of Chinese Academy of Science was funded by 2 Key Program Projects of National Natural Science Foundation of China: 40633015 and 40333034, which support a great deal to launch Ozone sounding from Beijing for the past 4 years. The Vanscoy data came from the MANTRA 2002 campaign, which was supported by the Canadian Space Agency, Environment Canada (T. McElroy and J. Davis who provided the $\mathrm{O}_{3}$ sonde measurements) and NSERC. Additional sources of funding for validation activities from ground-based stations, as well as from balloon and aircraft campaigns were guaranteed by ESA (contracts 10249/01/NL/SF and 16039/02/NL/SF), by the European Union (APE-INFRA: EVRI-CT-200140020) and the German Federal Ministry of education and Research (FKZ 01SF9953/08 and 50EE0203). The Italian Space Agency funded the 2002 trans-Mediterranean flight of the IBEX instrument and the M-55 Geophysica ENVISAT validation campaigns, by supporting the Italian teams involved in the aircraft activity and part of aircraft operation (APE-ENVISAT project, CNR/ASI contracts n.I/R/27/00, n.I/R/073/01 and n.I/R/186/02). SPIRALE technical team is acknowledged for making the flight possible and successful. The campaign were funded by the European Space Agency and by the French Space Agency (CNES). The MIPAS-B2 and SPIRALE balloon teams thank the CNES launching team and the Swedish Space Corporation team at Esrange for the success of the validation campaign. We thank the Centre National d'Etudes Spatiales (CNES) balloon launching team and the Swedish Space Corporation (SSC) Esrange people for the excellent balloon operation and the Free University of Berlin for meteorological support. The IUP/ASUR team (H. Bremer, A. Kleinboehl, G. Naeveke, J. Notholt and K. Kunzi) is acknowledged for the support offered to the utilisation of the ASUR measurement for MIPAS validation purposes. We are thankful to the HALOE and the SAGE II teams at NASA LaRC for providing us with data from these instruments and information about data and instruments. GOME ozone profiles were produced by the Rutherford Appleton Laboratory, under funding from NERC (via DARC). The authors acknowledge ECMWF for providing data which were used in this validation, and the British Atmospheric Data Centre (BADC) through which these data were obtained. Leicester studies were supported by a grant from the UK Natural Environment Research Council.

Edited by: P. Hartogh

\section{References}

Bernath, P. F., McElroy, C. T., Abrams, M. C., Boone, C. D., Butler, M., Camy-Peyret, C., Carleer, M., Clerbaux, C., Coheur, P.-F., Colin, R., DeCola, P., De Mazière, M., Drummond, J. R., Dufour, D., Evans, W. F. J., Fast, H., Fussen, D., Gilbert, K., Jennings, D. E., Llewellyn, E. J., Lowe, R. P., Mahieu, E., McConnell, J. C., McHugh, M., McLeod, S. D., Michaud, R., Midwinter, C., Nassar, R., Nichitiu, F., Nowlan, C., Rinsland, C. P., Rochon, Y. J., Rowlands, N., Semeniuk, K., Simon, P., Skelton, R., Sloan, J. J., Soucy, M. A., Strong, K., Tremblay, P., Turnbull, D., Walker, K. A., Walkty, I., Wardle, D. A., Wehrle, V., Zander, R., and Zou, J.: Atmospheric Chemistry Experiment (ACE): Mission overview, Geophys. Res. Lett., 32, L15S01, doi:10.1029/2005GL022386, 2005.

Bianchini, G., Cortesi, U., Palchetti, L., and Pascale, E.: SAFIREA (Spectroscopy of the Atmosphere by Far-Infrared Emission - Airborne): Optimized Instrument Configuration and New Assessment of Improved Performance, Appl. Optics, 43(14), 29622977, 2004.

Bianchini, G., Boscaleri, A., Carli, B., Mencaraglia, F., Palchetti, L., and Pascale, E.: Infrared Balloon Experiment: improved instrumental configuration and assessment of instrument performance, Appl. Optics, 45, 1041-1051, 2006.

Blumenstock, T., Mikuteit, S., Hase, H., Boyd, I., Calisesi, Y., DeClercq, C., Lambert, J.-C., Koopman, R., McDermid, S., Oltmans, S., Swart, D., Raffalski, U., Schets, H., De Muer, D., Steinbrecht, W., Stubi, R., and Wood, S.: Comparison of MI$\mathrm{PAS}_{3}$ profiles with ground-based measurements, ESA SP-562, Proceedings Second Atmospheric Chemistry Validation of ENVISAT Workshop (ACVE-2), ESRIN, Frascati, Italy, pp. 157163,2004

Boyd, I. S., Bodeker, G. E., Connor, B. J., Swart, D. P. J., and Brinksma, E. J.: An assessment of ECC ozonesondes oper- 
ated using $1 \%$ and $0.5 \%$ KI kathode solutions at Lauder, New Zealand, Geophys. Res. Lett., 5, 2409-2412, 1998.

Boone, C. D., Nassar, R., Walker, K. A., Rochon, Y., McLood, S. D., Rinsland, C. P., and Bernath, P. F.: Retrievals for the atmospheric chemistry experiment Fourier-transform spectrometer, Appl. Optics, 44(33), 7218-7231, 2005.

Borchi, F. and Pommereau, J.-P.: Evaluation of ozonesondes, HALOE, SAGE II and III, ODIN-OSIRIS and SMR, and ENVISAT-GOMOS, -SCIAMACHY and -MIPAS ozone profiles in the tropics from SAOZ long duration balloon measurements in 2003 and 2004, Atmos. Chem. Phys., 7, 2671-2690, 2007, http://www.atmos-chem-phys.net/7/2671/2007/.

Bruhl, C., Drayson, R. S., Russel III, J. M., Crutzen, P. J., McInerney, J. M., Purcell, P. N., Claude, H., Gernandt, H., McGee, T. J., McDermid, I. S., and Gunson, M. R.: Halogen Occultation Experiment ozone channel validation, J. Geophys. Res., 101(D6), 10217-10 240, 1996.

Calisesi, Y., Soebijanta, V. T., and van Oss, R.: Regridding of remote soundings: Formulation and application to ozone profile comparison, J. Geophys. Res., 110, D23306, doi:10.1029/2005JD006122, 2005.

Chu, W. P., McCormick, M. P., Lenoble, J., Brogniez, C., and Pruvost, P.: SAGE II Inversion Algorithm, J. Geophys. Res., 94(D6), 8339-8352, 1989.

Connor, B. J., Parrish, A., Tsou, J.-J., and McCormick, M. P.: Error analysis for the ground-based microwave ozone measurements during STOIC, J. Geophys. Res., 100, 9283-9291, 1995.

Cortesi, U., Blom, C. E., Camy-Peyret, C., Chance, K., Davies, J., Goutail, F., Kuttippurath, J., McElroy, C. T., Mencaraglia, F., Oelhaf, H., Petritoli, A., Pirre, M., Pommereau, J. P., Ravegnani, F., Renard, J. B., and Strong, K.: MIPAS ozone validation by stratospheric balloon and aircraft measurements, ESA SP-562, Proceedings Second Atmospheric Chemistry Validation of ENVISAT Workshop (ACVE-2), ESRIN, Frascati, Italy, 2004.

Crutzen, P. J., Grooß, J.-U., Brühl, C., Müller, R., and Russell III, J. M.: A Reevaluation of the Ozone Budget with HALOE UARS Data: No Evidence for the Ozone Deficit, Science, 268, 705708, 1995.

Cunnold, D. M., Chu, W. P., Barnes, R. A., McCormick, M. P., and Veiga, R. E.: Validation of SAGE II Ozone Measurements, J. Geophys. Res., 94, 8447-8460, 1989

Danilin, M. Y., Ko, M. K. W., Froidevaux, L., Santee, M. L., Lyjak, L. V., Bevilacqua, R. M., Zawodny, J. M., Sasano, Y., Irie, H., Kondo, Y., Russell III, J. M., Scott, C. J., and Read, W. G.: Trajectory hunting as an effective technique to validate multiplatform measurements: Analysis of the MLS, HALOE, SAGEII, ILAS, and POAM-II data in OctoberNovember 1996, J. Geophys. Res., 107, 4420, doi:10.1029/2001JD002012, 2002.

De Clercq, C. and Lambert, J.-C.: A forward model of limb infrared emission spectra in a two-dimensional atmosphere, in Proc. Atmospheric Science Conference, Frascati, Italy, 8-12 May 2006, ESA SP-628, 2006.

Dethof, A. and Hélm, E. V.: Ozone assimilation in the ERA-40 reanalysis project, Q. J. Roy. Meteor. Soc., 130(603), 2851-2872, 2004.

Dragani, R., Redaelli, G., Mariotti, A., Rudakov, V. V., MacKenzie, A. R., Stefanutti, L., and Visconti, G.: High resolution stratospheric tracer fields reconstructed with Lagrangian techniques: a comparative analysis of predictive skill, J. Atmos. Sci., 59, 1943-
1958, 2002

Dudhia, A., Jay, V. L., and Rodgers, C. D.: Microwindow Selection for High-Spectral-Resolution Sounders, Appl. Optics, 41, 36653673, 2002.

Hedin, A.: Extension of the MSIS thermosphere model into the middle and lower atmosphere, J. Geophys. Res., 96, 1159-1172, 1991.

Errera, Q. and Fonteyn, D.: Four-dimensional variational chemical assimilation of CRISTA stratospheric measurements, J. Geophys. Res., 106(D11), 12 253-12 265, 2001.

Fischer, H. and Oelhaf, H.: Remote sensing of vertical profiles of atmospheric trace constituents with MIPAS limb-emission spectrometers, Appl. Optics, 35(16), 2787-2796, 1996.

Fischer, H., Blom, C. E., Oelhaf, H., Carli, B., Carlotti, M., Delbouille, L., Ehhalt, D., Flaud, J.-M., Isaksen, I., Lopez-Puertas, M., McElroy, C. T., and Zander, R.: ENVISAT, MIPAS An instrument for Atmospheric Chemistry and Climate Research, edited by: Readings, C. and Harris, R. A., ESA Publications Division, ESTEC, P.O. Box 299, 2200, AG Nordwijk, The Netherlands, SP-1229, 2000.

Fischer, H., Birk, M., Blom, C. E., Carli, B., Carlotti, M., von Clarmann, T., Delbouille, L., Dudhia, A., Ehhalt, D., Endemann, M., Flaud, J.-M., Gessner, R., Kleinert,A., Koopmann, R., Langen, J., Lopez-Puertas, M., Mosner, P., Nett, H., Oelhaf, H., Perron,G., Remedios, J., Ridolfi, M., Stiller, G., and Zander, R.: MIPAS: an instrument for atmospheric and climate research, Atmos. Chem. Phys. Discuss., 7, 8795-8893, 2007,

http://www.atmos-chem-phys-discuss.net/7/8795/2007/.

Fix, A., Ehret, G., Flentje, H., Poberaj, G., Gottwald, M., Finkenzeller, H., Bremer, H., Bruns, M., Burrows, J. P., Kleinböhl, A., Küllmann, H., Kuttippurath, J., Richter, A., Wang, P., Heue, K.P., Platt, U., and Wagner, T.: SCIAMACHY validation by aircraft remote measurements: Design, execution, and first results of the SCIA-VALUE mission, Atmos. Chem. Phys., 5, 12731289, 2005, http://www.atmos-chem-phys.net/5/1273/2005/.

Fonteyn, D., Bonjean, S., Chabrillat, S., Daerden, F., and Errera, Q.: 4D-VAR chemical data assimilation of ENVISAT chemical products (BASCOE): Validation support issues, in: Proc. Envisat Validation Workshop, ESA Scientific Publication SP-531, 2003.

Friedl-Vallon, F., Maucher, G., Seefeldner, M., Trieschmann, O., Kleinert, A., Lengel, A., Keim, C., Oelhaf, H., and Fischer, H.: Design and characterisation of the balloon-borne Michelson Interferometer for Passive Atmospheric Sounding (MIPAS-B2), Appl. Optics, 43(16), 3335-3355, 2004.

Frisk, U., Hagstroem, M., Ala-Laurinaho, J., Andersson, S., Berges, J.-C., Chabaud, J.-P., Dahlgren, M., Emrich, A., Florén, H.-G., Florin, G., Fredrixon, M., Gaier, T., Haas, R., Hirvonen, T., Hjalmarsson, Å., Jakobsson, B., Jukkala, P., Kildal, P. S., Kollberg, E., Lassing, J., Lecacheux, A., Lehikoinen, P., Lehto, A., Mallat, J., Marty, C., Michet, D., Narbonne, J., Nexon, M., Olberg, M., Olofsson, A. O. H., Olofsson, G., Origné, A., Petersson, M., Piironen, P., Pons, R., Pouliquen, D., Ristorcelli, I., Rosolen, C., Rouaix, G., Räisänen, A. V., Serra, G., Sjöberg, F., Stenmark, L., Torchinsky, S., Tuovinen, J., Ullberg, C., Vinterhav, E., Wadefalk, N., Zirath, H., Zimmermann, P., and Zimmermann, R.: The ODIN satellite I. Radiometric design and test, Astronomy and Astrophysics, 402, L27-L34, doi:10.1051/0004-6361:20030335, 2003. 
Fussen, D., Vanhellemont, F., Dodion, J., Bingen, C., Walker, K. A., Boone, C. D., McLeod, S. D., and Bernath, P. F.: Initial intercomparison of ozone and nitrogen dioxide number density profiles retrieved by the ACE-FTS and GOMOS occultation experiments, Geophys. Res. Lett., 32, L16S02, doi:10.1029/2005GL022468, 2005.

Geer, A. J., Lahoz, W. A., Bekki, S., Bormann, N., Errera, Q., Eskes, H. J., Fonteyn, D., Jackson, D. R., Juckes, M. N., Massart, S., Peuch, V. H., Rharmili, S., and Segers, A.: The ASSET intercomparison of ozone analyses: method and first results, Atmos. Chem. Phys., 6, 5445-5474, 2006,

http://www.atmos-chem-phys.net/6/5445/2006/.

Glatthor, N., von Clarmann, T., Fischer, H., Funke, B., Gil-López, S., Grabowski, U., Höpfner, M., Kellmann, M. S., Linden, A., López-Puertas, M., Mengistu Tsidu, G., Milz, M., Steck, T., Stiller, G. P., and Wang, D. Y.: Retrieval of stratospheric ozone profiles from MIPAS/ENVISAT limb emission spectra: a sensitivity study, Atmos. Chem. Phys., 6, 2767-2781, 2006,

http://www.atmos-chem-phys.net/6/2767/2006/.

Godin, S., Carswell, A. I., Donovan, D. P., Claude, H., Steinbrecht, W., McDermid, I. S., McGee, T. J., Gross, M. R., Nakane, H., Swart, D. P. J., Bergwerff, H. B., Uchino, O., von der Gathen, P., and Neuber, R.: Ozone Differential Absorption Lidar Algorithm Intercomparison, Appl. Optics, 38, 6225-6236, 1999.

Hase, F.: Inversion von Spurengasprofilen aus hochaufgelösten bodengebundenen FTIR-Messungen in Absorption, Wissenschaftliche Berichte, FZK Report No. 6512, Forschungszentrum Karlsruhe, Germany, 2000.

Hase, F., Hannigan, J. W., Coffey, M. T., Goldman, A., Höpfner, M., Jones, N. B., Rinsland, C. P., and Wood, S. W.: Intercomparison of retrieval codes used for the analysis of high-resolution, ground-based FTIR measurements, J. Quant. Spectrosc. Rad. Trans., 87, 25-52, 2004.

Hervig, M. and McHugh, M.: Cirrus detection using HALOE measurements, Geophys. Res, Lett., 26(6), 719-722, 1999.

Höpfner, M., Stiller, G. P., Kuntz, M., von Clarmann, T., Echle, G., Funke, B., Glatthor, N., Hase, F., Kemnitzer, H., and Zorn, S.: The Karlsruhe optimized and precise radiative transfer algorithm, Part II: Interface to retrieval applications, SPIE Proceedings, 3501, 186-195, 1998.

Höpfner, M., Blom, C. E., Echle, G., Glatthor, N., Hase, F., and Stiller, G.: Retrieval simulations for MIPAS-STR measurements, edited by: Smith, W. L., IRS 2000: Current Problems in Atmospheric Radiation; Proc. Int. Radiation Symp., St.Petersburg, Russia, 24-29 July 2000, Hampton, Va; DEEPAK Publ., S.11211124, 2001.

Höpfner, M., Oelhaf, H., Wetzel, G., Friedl-Vallon, F., Kleinert, A., Lengel, A., Maucher, G., Nordmeyer, H., Glatthor, N., Stiller, G., von Clarmann, T., Fischer, H., Kröger, C., and Deshler, T.: Evidence of scattering of tropospheric radiation by PSCs in mid-IR limb emission spectra: MIPAS-B observations and KOPRA simulations, Geophys. Res. Lett., 29(8), 1278, doi:10.1029/2001GL014443, 2002.

Johnson, D. G., Jucks, K. W., Traub, W. A., and Chance, K. V.: The Smithsonian stratospheric far-infrared spectrometer and data reduction system, J. Geophys. Res., 100, 3091-3106, 1995.

Keckhut, P., McDermid, S., Swart, D., McGee, T., GodinBeekmann, S., Adriani, A., Barnes, J., Baray, J.-L., Bencherif, H., Claude, H., Di Sarra, A., Fiocco, G., Hansen, G.,
Hauchecorne, A., Leblanc, T., Lee, C. H., Pal, S., Megie, G., Nakane, H., Neuber, R., Steinbrecht, W., and Thayer, J.: Review of ozone and temperature lidar validations performed within the framework of the Network for the Detection of Stratospheric Change., J. Environ. Monit., 6, 721733, 2004.

Keim, C., Blom, C. E., von der Gathen, P., Gulde, T., Höpfner, M., Liu, G. Y., Oulanovski, A., Piesch, C., Ravegnani, F., Sartorius, C., Schlager, H., and Volk, C. M.: Validation of MIPASENVISAT by correlative measurements of MIPAS-STR, Proc. ACVE-2 meeting, 3-7 May 2004, Frascati, Italy, ESA SP-562, 2004.

Kerridge, B. J., Goutail, F., Bazureau, A., Wang, D.-Y., Bracher, A., Weber, M., Bramstedt, H., Siddans, R., Latter, B. G., Reburn, W. J., Jay, V. L., Dethof, A., Payne, V. H., et al.: MIPAS ozone validation by satellite intercomparison, ESA SP-562, Proceedings Second Atmospheric Chemistry Validation of ENVISAT Workshop (ACVE-2), ESRIN, Frascati, Italy, 2004.

Kleinert, A., Aubertin, G., Perron, G., Birk, M., Wagner, G., Hase, F., Nett, H., and Poulin, R.: MIPAS Level 1B algorithms overview: operational processing and characterisation, Atmos. Chem. Phys., 7, 1395-1406, 2007,

http://www.atmos-chem-phys.net/7/1395/2007/.

Komhyr, W. D., Barnes, R. A., Brothers, G. B., Lathrop, J. A., and Opperman, D. P.: Electrochemical concentration cell ozonesonde performance evaluation during STOIC 1989, J. Geophys. Res., 100, 9231-9244, 1995.

Kurylo, M. J. and Zander, R. J.: The NDSC - Its status after ten years of operation, in: Proceedings of the Quadrennial Ozone Symposium 2000, Hokkaido Univ., Sapporo, Japan, edited by: NASDA, 167-168, 2001.

Kuttippurath, J., Bremer, H., Burrows, J., Kleinboehl, A., Kuellmann, H., Kuenzi, K., Notholt, J., Sinnhuber, M., von Savigny, C., Lautié, N., Murtagh, D., Urban, J., Milz, M., Stiller, G., Petelina, S., de La Noë, J., Le Flochmoen, E., and Ricaud, P.: Intercomparison of ozone profile measurements from ASUR, SCIAMACHY, MIPAS, OSIRIS, and SMR, J. Geophys. Res., 112, D09311, doi:10.1029/2006JD007830, 2007.

Lucke, R. L., Korwan, D., Bevilacqua, R. M., Hornstein, J. S., Shettle, E. P., Chen, D. T., Daehler, M., Lumpe, J. D., Fromm, M. D., Debrestian, D., Neff, B., Squire, M., König-Langlo, G., and Davies, J.: The Polar Ozone and Aerosol Measurement (POAM III) Instrument and Early Validation Results, J. Geophys. Res., 104, 18 785-18 799, 1999.

Lumpe, J. D., Bevilacqua, R. M., Hoppel, K. W., and Randall, C. E.: POAM III Retrieval Algorithm and Error Analysis, J. Geophys. Res., 107(D21), 4575-4607, 2002.

Mauldin III, L. E., Zaun, N. H., McCormick, M. P., Guy, J. H., and Vaughn, W. R.: Stratospheric Aerosol and Gas Experiment II instrument: A functional description, Opt. Eng., 24, 307-312, 1985.

McCornick, M. P.: SAGE II: An Overview, Adv. Space Res., 7, 219-226, 1987.

McDermid, I. S., Bergwerff, J. B., Bodeker, G., Boyd, I. S., Brinksma, E. J., Connor, B. J., Farmer, R., Gross, M. R., Kimvilakani, P., Matthews, W. A., McGee, T. J., Ormel, F. T., Parrish, A., Singh, U., Swart, D. P. J., and Tsou, J. J.: OPAL: Network for the Detection of Stratospheric Change Ozone Profiler Assessment at Lauder, New Zealand: II. Intercomparison of revised results, J. Geophys. Res., 103(D22), 28 693-28 699, 1998. 
McHugh, M., Magill, B., Walker, K. A., Boone, C. D., Bernath, P. F., and Russell III, J. M.: Comparison of atmospheric retrievals from ACE and HALOE, Geophys. Res. Lett., 32, L15S10, doi:10.1029/2005GL022403, 2005.

Mees, J., Crewell, S., Nett, H., de Lange, G., van de Stadt, H., Kuipers, J. J., and Panhuyzen, R. A.: ASUR - An Airborne SIS-Receiver for Atmospheric Measurements at 625 to $720 \mathrm{GHz}$, IEEE Trans. Microwave Theory Tech., 43(11), 2543-2548, 1995.

Moreau, G., Robert, C., Catoire, V., Chartier, M., Camy-Peyret, C., Huret, N., Pirre, M., Pomathiod, L., and Chalumeau, G.: SPIRALE: a multispecies in situ balloon-borne instrument with six tunable diode laser spectrometers, Appl. Optics, 44(28), 59725989, 2005.

Morris, G. A., Gleason, J. F., Russel III, J. M., Schoeberl, M. R., McCormick, M. P.: A comparison of HALOE v19 with SAGE II v6.00 ozone observations using trajectory mapping, J. Geophys. Res., 107(D13), 4177-4186, 2002.

Munro, R., Siddans, R., Reburn, W. J., and Kerridge, B. J.: Direct measurements of tropospheric ozone from space, Nature, 392, 168-171, 1998.

Murtagh, D., Frisk, U., Merino, F., Ridal, M., Jonsson, A., Stegman, J., Eriksson, G. W. P., Jiménez, C., Megie, G., de la Noëë, J., Ricaud, P., Baron, P., Pardo, J. R., Hauchcorne, A., Llewellyn, E. J., Degenstein, D. A., Gattinger, R. L., Lloyd, N. D., Evans, W. F. J., McDade, I. C., Haley, C. S., Sioris, C., von Savigny, C., Solheim, B. H., McConnell, J. C., Strong, K., Richardson, E. H., Leppelmeier, G. W., Kyrö, E., Auvinen, H., and Oikarinen, L.: An overview of the Odin atmospheric mission, Can. J. Phys., 80(4), 309-319, 2002.

Oelhaf, H., Friedl-Vallon, F., Kleinert, A., Lengel, A., Maucher, G., Nordmeyer, H., Wetzel, G., Zhang, G., and Fischer, H.: ENVISAT validation with MIPAS-B, in: Proc. ENVISAT Validation Workshop, 9-13 December 2002, ESRIN, Frascati, Italy, CDROM, vol. SP-531, ESA Publications Division, ESTEC, Postbus 299, 2200AG Noordwijk, The Netherlands, 2003.

Petelina, S. V., Llewellyn, E. J., Walker, K. A., Degenstein, D. A., Boone, C. D., Bernath, P. F., Haley, C. S., von Savigny, C., Lloyd, N. D., and Gattinger, R. L.: Validation of ACE-FTS stratospheric ozone profiles against Odin/OSIRIS measurements, Geophys. Res. Lett., 32, L15S06, doi:10.1029/2005GL022377, 2005.

Piesch, C., Gulde, T., Sartorius, C., Friedl-Vallon, F., Seefeldner, M., Wölfel, M., Blom, C. E., and Fischer, H.: Design of a MIPAS instrument for high-altitude aircraft, Proc. of the 2nd Internat. Airborne Remote Sensing Conference and Exhibition, ERIM, Ann Arbor, MI, Vol. II, 199-208, 1996.

Pougatchev, N. S., Connor, B. J., and Rinsland, C. P.: Infrared measurement of the ozone vertical distribution above Kitt Peak, J. Geophys. Res., 100(D8), 16 689-16 698, 1995.

Pyle, J., Shepherd, T., Bodeker, G. E., Canziani, P., Dameris, M., Forster, P. M., Gruzdev, A., Müller, R., Muthama, N., Pitari, G., and Randel, W. J.: Ozone and climate: a review of interconnections, in Special report on safeguarding the ozone layer and global climate system, IPCC/TEAP, Cambridge, 2005.

Randall, C. E., Rusch, D. W., Bevilacqua, R. M., Hoppel, K. W., Lumpe, J. D., Shettle, E., Thompson, E., Deaver, L., Zawodny, J., Kyro, E., Johnson, B., Kelder, H., Dorokhov, V. M., KoenigLanglo, G., and Gil, M.: Validation of POAM III ozone: comparisons with ozonesonde and satellite data, J. Geophys. Res.,
108(D12), 4367, doi:10.1029/2002JD002944, 2003.

Raspollini, P., Belotti, C., Burgess, A., Carli, B., Carlotti, M., Ceccherini, S., Dinelli, B. M., Dudhia, A., Flaud, J.-M., Funke, B., Höpfner, M., López-Puertas, M., Payne, V., Piccolo, C., Remedios, J. J., Ridolfi, M., and Spang, R.: MIPAS level 2 operational analysis, Atmos. Chem. Phys., 6, 5605-5630, 2006, http://www.atmos-chem-phys.net/6/5605/2006/.

Redaelli, G.: Lagrangian techniques for the analysis of stratospheric measurements, PhD thesis, University of L'Aquila, Italy, 1997.

Redaelli, G., Cortesi, U., Bianchini, G., Castelli, E., Dinelli, B. M., Grassi, B., Mencaraglia, F., Taddei, A., and Visconti, G.: Multitechnique comparison of MIPAS $\mathrm{O}_{3}$ measurements with correlative data obtained by FT-FIR measurements during the ENVISAT stratospheric aircraft and balloon campaign, Proceedings Third Atmospheric Chemistry Validation of ENVISAT Workshop (ACVE-3), ESA-ESRIN, Frascati, Italy, 4-7 December 2006, ESA Special Publication SP-642, 2006.

Ridolfi, M., Blum, U., Carli, B., Catoire, V., Ceccherini, S., De Clercq, C., Fricke, K. H., Iarlori, M., Kerridge, B., Keckhut, P., Lambert, J.C., Meijer, Y., Mona, L., Oelhaf, H., Pappalardo, G., Pirre, M., Rizi, V., Robert, C., Swart11, D., von Clarmann, T., Waterfall, A., and Wetzel, G.: Geophysical validation of temperature retrieved by the ESA processor from MIPAS/ENVISAT atmospheric limb-emission measurements, Atmos. Chem. Phys., 7, 4459-4487, 2007,

http://www.atmos-chem-phys.net/7/4459/2007/.

Rinsland, C. P., Connor, B. J., Jones, N. B., Boyd, I., Matthews, W. A., Goldman, A., Murcray, F. J., Murcray, D. G., David, S. J., and Pougatchev, N. S.: Comparison of infrared and Dobson total ozone columns measured from Lauder, New Zealand, Geophys. Res. Lett., 23(9), 1025-1028, 1996.

Rinsland, C. P., Jones, N. B., Connor, B. J., Logan, J. A., Pougatchev, N. S., Goldman, A., Murcray, F. J., Stephen, T. M., Pine, A. S., Zander, R., Mahieu, E., and Demoulin, P.: Northern and southern hemisphere ground-based infrared measurements of tropospheric carbon monoxide and ethane, J. Geophys Res., 103(21), 28 197-28 217, 1998.

Rodgers, C. D.: Characterization and error analysis of profiles retrieved from remote sounding measurements, J. Geophys. Res., 95, 5587-5595, 1990.

Rodgers, C. D.: Inverse methods for atmospheric sounding: Theory and practice, 238 pp., World Scientific, Inc., 2000.

Rodgers, C. D. and Connor, B. J.: Intercomparison of remote sounding instruments, J. Geophys. Res., 108(D3), 4116-4130, 2003.

Rothman, L. S., Jacquemart, D., Barbe, A., Chris Bennerc, D., Birk, M., Brown, L. R., Carleer, M. R., Chackerian Jr., C., Chance, K., Coudert, L. H., Dana, V., Devi, V. M., Flaud, J.-M., Gamache, R. R., Goldman, A., Hartmann, J.-M., Jucks, K. W., Maki, A. G., Mandin, J.-Y. Massie, S. T., Orphal, J., Perrin, A., Rinsland, C. P., Smith, M. A. H., Tennyson, J., Tolchenov, R. N., Toth, R. A., Vander Auwera, J., Varanasi, P., and Wagner, G.: The HITRAN 2004 molecular spectroscopic database, J. Quant. Spect. Rad. Trans., 96, 139-204, 2005.

Russell III, J. M., Gordley, L. L., Park, J. H., Drayson, S. R., Hesketh, W. D., Cicerone, R. J., Tuck, A. F., Frederick, J. E., Harries, J. E., and Crutzen, P. J.: The Halogen Occultation Experiment, J. Geophys. Res., 98, 10777-10 798, 1993.

Sembhi, H., Remedios, J. J., and Raspollini, P.: Validation of cloudfree tropical UTLS MIPAS ozone and water vapour, Proceedings 
of ASC 2006, ESA/ESRIN, Frascati, Italy, 8-12 May 2006.

Smit, H. G. J. and Sträter, W.: Jülich ozone sonde intercomparison experiment 2000 (JOSIE-2000), World Meteorological Organization Global Atmospheric Watch (WMO-GAW), TD N. 1225, 2004.

Solomon, S.: Stratospheric Ozone depletion: a review of concept and history, Rev. Geophys., 37, 275-316, 1999.

Spang R., Remedios, J. J., and Barkley, M. P.: Colour indices for the detection and differentiation of cloud types in infra-red limb emission spectra, Adv. Space Res., 33(7), 1041-1047, 2004.

Taddei, A., Redaelli, G., Grassi, B., and Visconti, G.: Selfconsistency analysis of MIPAS data using the Trajectory Hunting Technique (THT), Proceedings of the Atmospheric Science Conference, 8-12 May 2006, ESA-ESRIN, Frascati, Italy, 2006.

Tsou, J. J., Connor, B. J., Parrish, A., McDermid, I. S., and Chu, W. P.: Ground-based microwave monitoring of middle atmosphere ozone: Comparison to lidar and Stratospheric and Gas Experiment II satellite observations, J. Geophys. Res., 100, 3005-3016, 1995.

Tsou, J. J., Connor, B. J., Parrish, A, Pierce, R. B., Boyd, I. S., Bodeker, G. E., Chu, W. P., Russell, J. M., Swart, D. P. J., and McGee, T. J.: NDSC millimeter wave ozone observations at Lauder, New Zealand, 1992-1998: Improved methodology, validation, and variation study, J. Geophys. Res., 105(D19), $24263-$ $24281,2000$.

Urban, J., Lautié, N., Le Flochemoen, E., Jiménez, C., Eriksson, P., de la Noëë, J., Dupuy, E., Ekström, M., El Amraoui, L., Frisk, U., Murtagh, D., Olberg, M., and Ricaud, P.: Odin/SMR limb observations of stratospheric trace gases: Level 2 processing of $\mathrm{ClO}, \mathrm{N}_{2} \mathrm{O}, \mathrm{HNO}_{3}$, and $\mathrm{O}_{3}$, J. Geophys. Res., 110, D14307, doi:10.1029/2004JD005741, 2005.

Vigouroux, C., De Mazière, M., Errera, Q., Chabrillat, S., Mahieu, E., Duchatelet, P., Wood, S., Smale, D., Mikuteit, S., Blumenstock, T., Hase, F., and Jones, N.: Comparisons between groundbased FTIR and MIPAS N2O and HNO3 profiles before and after assimilation in BASCOE, Atmos. Chem. Phys., 7, 377-396, 2007, http://www.atmos-chem-phys.net/7/377/2007/. von Clarmann, T.: Validation of remotely sensed profiles of atmospheric state variables: strategies and terminology, Atmos. Chem. Phys., 6, 12, 4311-4320, 2006.

von der Gathen, P., Rex, M., Harris, N. R. P., Lucic, D., Knudsen, B. M., Braathen, G. O., De Backer, H., Fabian, R., Fast, H., Gil, M., Kyro, E., Mikkelsen, I. S., Rummekainen, M., Stahelin, J., and Varotsos, C.: Observational evidence for chemical ozone depletion over the Arctic in winter 1991-92, Nature, 375(6527), 131-134, 1995.

Yushkov, V., Oulanovsky, A., Lechenuk, N., Roudakov, I., Arshinov, K., Tikhonov, F., Stefanutti, L., Ravegnani, F., Bonafe, U., and Georgiadis, T.: A chemiluminescent analyzer for stratospheric measurements of the ozone concentration (FOZAN), J. Atmos. Ocean. Tech., 16(10), 1345-1350, 1999.

Walker, K. A., Randall, C. E., Trepte, C. R., Boone, C. D., and Bernath, P. F.: Initial validation comparisons for the Atmospheric Chemistry Experiment (ACE-FTS), Geophys. Res. Lett., 32, L16S04, doi:10.1029/2005GL022388, 2005.

Wang, H. J., Cunnold, D. M., Thomason, L. W., Zawodny, J. M., and Bodeker, G. E.: Assessment of SAGE version 6.1 ozone data quality, J. Geophys. Res., 107(D23), 4691-4709, 2002.

Wetzel, G., Oelhaf, H., Friedl-Vallon, F., Kleinert, A., Lengel, A., Maucher, G., Nordmeyer, H., Ruhnke, R., Nakajima, H., Sasano, Y., Sugita, T., and Yokota, T.: Intercomparison and validation of ILAS-II version 1.4 target parameters with MIPAS-B measurements, J. Geophys. Res., 111, D11S06, doi:10.1029/2005JD006287, 2006. 